Aus dem Institut für Neuropathologie (Prof. Dr. med. W. Brück)

der Medizinischen Fakultät der Universität Göttingen

\title{
Charakterisierung von Veränderungen in der normal erscheinenden weißen Substanz bei entzündlich-demyelinisierenden Erkrankungen
}

\author{
INAUGURAL - DISSERTATION \\ zur Erlangung des Doktorgrades \\ für Zahnheilkunde \\ der Medizinischen Fakultät der \\ Georg-August-Universität zu Göttingen
}

vorgelegt von

Agnes Joanna Geiger (geb. Swiniarski)

aus

Lodsch (Łódź), Polen 
Dekan:

Referentin:

Ko-Referentin:
Prof. Dr. rer. nat. H. K. Kroemer

PD Dr. Dr. med. C. Theodossiou-Wegner Prof. Dr. med. K. Hein

Datum der mündlichen Prüfung: 23.04.2018 


\section{Inhaltsverzeichnis}

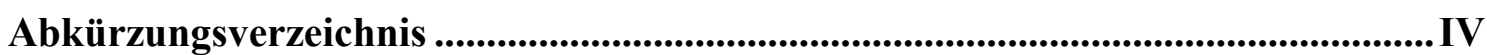

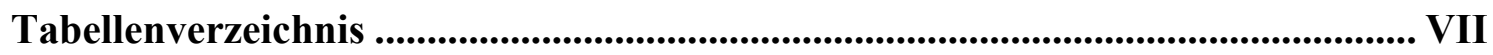

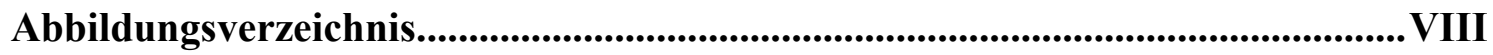

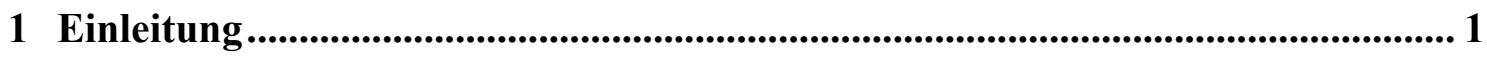

1.1 Entzündlich-demyelinisierende Erkrankungen....................................................................1

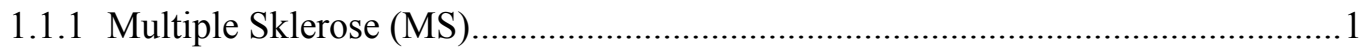

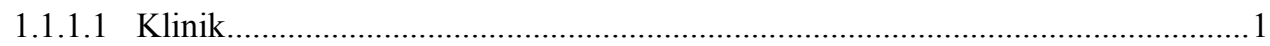

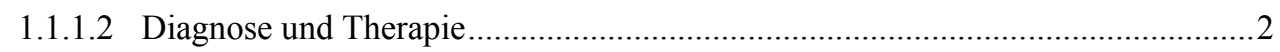

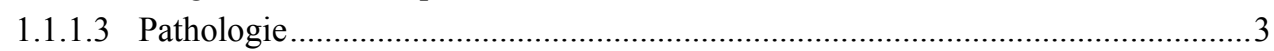

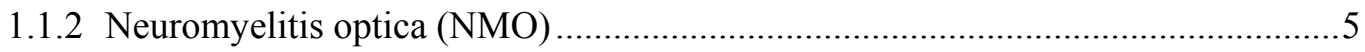

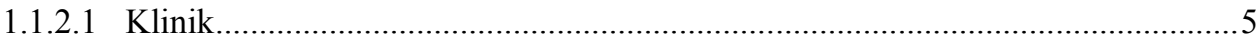

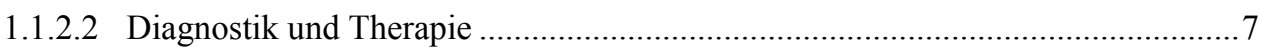

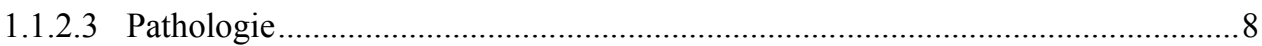

1.1.3 Experimentell autoimmune Enzephalomyelitis (EAE) .......................................10

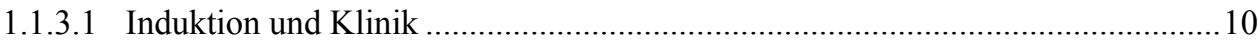

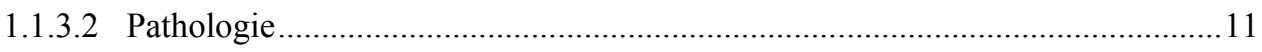

1.2 Normal erscheinende weiße Substanz (NAWM) ...................................................12

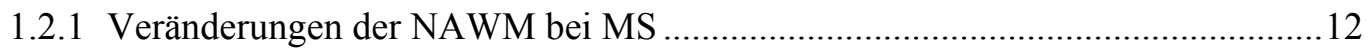

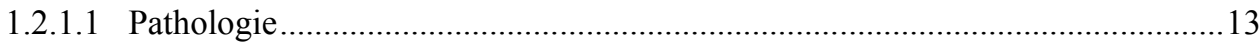

1.3 Veränderungen in der weißen Substanz bei gesunden Probanden.............................14

1.4 Veränderungen in der NAWM bei NMO und EAE.................................................15

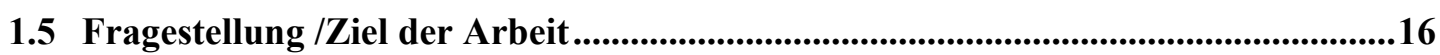

2 Material und Methoden .................................................................................... 17

2.1 Histologisches Material......................................................................................................17

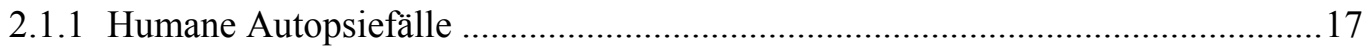

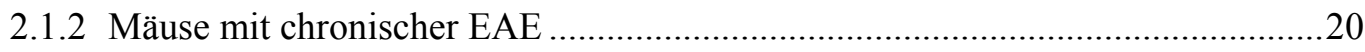

2.2 Histopathologische Methoden ….....................................................................................22

2.2.1 Anfertigen der histologischen Präparate ………...............................................22

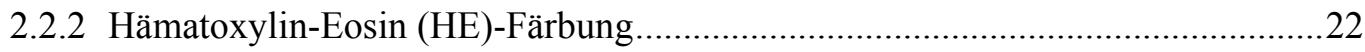

2.2.3 LFB/PAS-Färbung (Luxol-Fast-Blue/Periodic acid Schiff reaction)....................23

2.2.4 Modifizierte Bielschowsky-Silberimprägnation ................................................24

2.2.5 Immunhistochemie (Avidin-Biotin-Methode) ……............................................25 


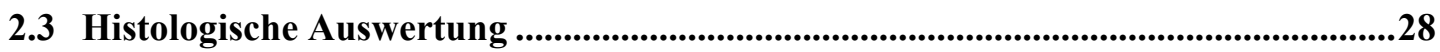

2.3.1 Auswertung von Veränderungen in der NAWM bei humanen Autopsiefällen ....29

2.3.1.1 Auswahl der NAWM anhand histologischer Färbungen ...................................29

2.3.1.2 CD3 ${ }^{+}$-T-Lymphozyten als Entzündungsparameter.............................................29

2.3.1.3 Mikrogliaktivierung (KiM1P ${ }^{+}$-Zellen) als Entzündungsparameter .....................30

2.3.1.4 $\mathrm{APP}^{+}$-Axone als Zeichen der akuten axonalen Schädigung ..................................32

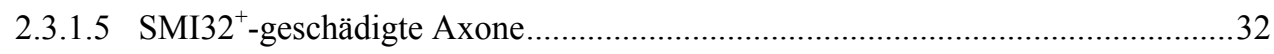

2.3.1.6 Bielschowsky-Färbung zur Beurteilung der axonalen Dichte ............................33

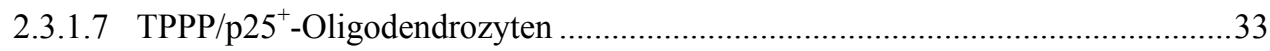

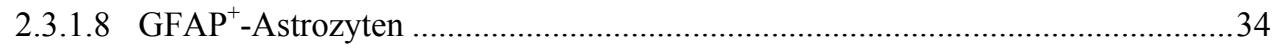

2.3.2 Auswertung von Veränderungen in der NAWM bei gesunden Tieren und Mäusen mit chronischer EAE .................................................... 34

2.3.2.1 Auswahl der NAWM anhand LFB/PAS-Färbungen und der Läsionslast ...........34

2.3.2.2 Vorgehen bei der histologischen Auswertung von Mausgewebe .........................35

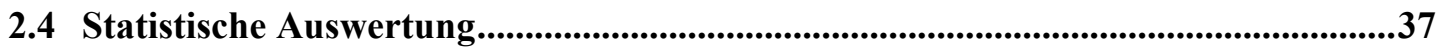

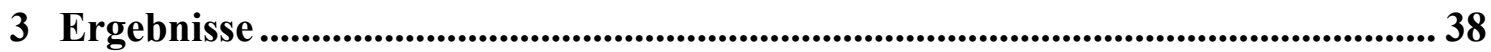

3.1 Veränderungen in der NAWM bei MS, NMO und gesunden Kontrollen humaner Autopsiefälle.

3.1.1 Erhöhte T-Lymphozytendichte in der NAWM bei MS und NMO im Vergleich zu Kontrollfällen

3.1.2 Vermehrte spinale Mikrogliaaktivierung in der NAWM bei MS und NMO im Vergleich zu Kontrollfällen ................................................................44

3.1.3 Axonaler Verlust in der NAWM bei MS im Vergleich zu Kontrollfällen...........48

3.1.4 Vermehrte spinale akute axonale Schädigung bei MS im Vergleich zu NMO- und Kontrollfällen....

3.1.5 Mehr desphosphorylierte Axone in der NAWM bei MS im Vergleich zu NMO- und Kontrollfällen....................................................52

3.1.6 Erhöhte Dichte von TPPP/p25 $25^{+}$-Oligodendrozyten in der NAWM bei MS.........54

3.1.7 Spinal vermehrte Astrogliose in der NAWM bei MS im Vergleich zu

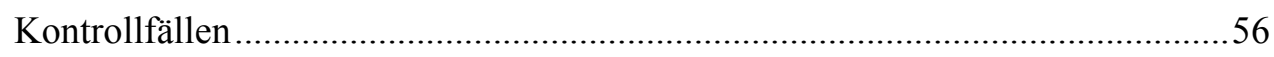

3.2 Spinale Veränderungen in der NAWM bei Mäusen mit chronischer EAE .58

3.2.1 Erhöhte T-Lymphozytendichte in der NAWM bei Mäusen mit EAE in Abhängigkeit von der Läsionslast.

3.2.2 Vermehrte Mikrogliaaktivierung in der NAWM bei Mäusen mit EAE... 62

3.2.3 Reduktion der axonalen Dichte in der NAWM bei Mäusen mit EAE in Abhängigkeit von der Läsionslast.

3.2.4 Vermehrte akute axonale Schädigung in der NAWM bei kranken Tieren mit hoher Läsionslast.

3.2.5 Erhöhte Dichte von TPPP/p25 -Oligodendrozyten in der NAWM in Abhängigkeit von der Läsionslast. 


\subsubsection{Vermehrte Astrogliose in der NAWM insbesondere bei Tieren mit hoher Läsionslast.}

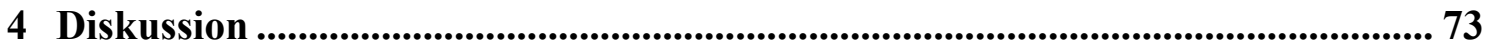

4.1 Vermehrte T-Lymphozytendichte und Mikrogliaaktivierung in der NAWM ........73

4.2 Vermehrte akute axonale Schädigung sowie axonaler Verlust in der NAWM .......75

4.3 Veränderte astrozytäre und gliale Parameter in der NAWM..................................78

4.4 Unterschiede zwischen MS, NMO und EAE................................................81

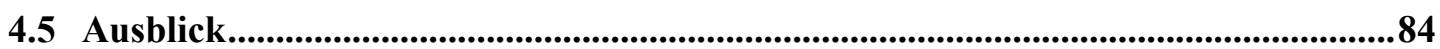

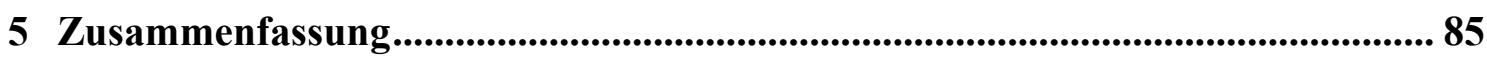

6 Literaturverzeichnis.......................................................................................... 87

Anhang $\ldots . . \ldots \ldots \ldots \ldots \ldots \ldots \ldots \ldots \ldots \ldots \ldots \ldots \ldots \ldots \ldots \ldots \ldots \ldots \ldots \ldots \ldots \ldots \ldots \ldots \ldots \ldots \ldots \ldots \ldots \ldots \ldots \ldots \ldots \ldots \ldots \ldots \ldots \ldots \ldots \ldots \ldots \ldots \ldots \ldots \ldots . . \ldots \ldots$ A1

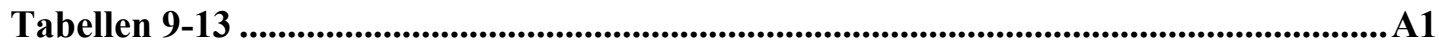




\section{Abkürzungsverzeichnis}

$\mathrm{AgNO}_{3} \quad$ Silbernitrat

APAAP Alkalische-Phosphatase-Anti-Alkalische-Phosphatase-Komplex

APP amyloid precursor protein, Amyloid-Vorläufer-Protein

AQP4 Aquaporin 4

Aqua bidest. lat.: aqua bidestillata, zweifach destilliertes Wasser

Aqua dest. lat.: aqua destillata, destilliertes Wasser

CFA complete freund's adjuvant, komplettes Freundsches Adjuvans

CNP 2'3'-cyclic nucleotide 3'phosphodiesterase, zyklische NukleotidPhosphodiesterase (Marker für myelinisierende Oligodendrozyten)

DAB 3-3'-Diamino-Benzidintetrahydrochlorid

EAE experimentelle autoimmune Enzephalomyelitis

EDTA Ethylendiamintetraessigsäure

FCS fetal calf serum, fetales Kälberserum

GFAP glial fibrillary acidic protein, saures gliales Faserprotein

h Stunde(n)

$\mathbf{H}_{2} \mathbf{O}_{2} \quad$ Wasserstoffperoxid

HCl Salzsäure

HE Hämatoxylin-Eosin

IFA incomplete freund's adjuvant, inkomplettes Freundsches Adjuvans

IgG Immunglobulin G

IHC Immunhistochemie

iNOS induzierbare Stickstoffmonoxid-Synthase

LAB labelled avidin biotin technique, indirekte Avidin-Biotin-Methode

longitudinally extensive transverse myelitis, longitudinal extensive transverse Myelitis 
LFB Luxol-fast-blue

MBP Myelin-basisches Protein

MGK Mikrogliaknötchen

MOG 35-55 Myelin-Oligodendrozyten-Glykoprotein: Aminosäuren 35-55

MRT Magnetresonanztomographie

MS Multiple Sklerose

MW Mittelwert

n

Anzahl ausgewerteter Fälle

n. S.

nicht signifikant

$\mathrm{NaOH}$

Natronlauge/Natriumhydroxid

NAWM normal appearing white matter, normal erscheinende weiße Substanz

NMO Neuromyelitis optica

NMOsd neuromyelitis optica spectrum disorder,

Neuromyelitis optica -Spektrum-Erkrankungen

OKB oligoklonale Banden

ON Optikusneuritis

OPC oligodendrocyte precursor cell, Oligodendrozyten-Vorläuferzelle

p. i. lat.: post injectionem, nach Injektion

PAS periodic acid Schiff reaction, Perjodsäure-Schiff'sches Reagenz

PBS phosphate-buffered saline, Phosphat-gepufferte Salzlösung

PFA Paraformaldehyd

PLP Proteolipid-Protein

PPMS primary progressive multiple sclerosis, Primär progrediente Multiple Sklerose

PPWM periplaque white matter, die Läsion-umgebende weiße Substanz

PTx Pertussis-Toxin

RRMS relapsing remitting multiple sclerosis, schubförmig remittierende Multiple Sklerose 
SPMS secondary progressive multiple sclerosis, Sekundär progrediente Multiple Sklerose

TPPP/p25 tubulin polymerization promoting protein $/ 25 \mathrm{kDa}$ brain specific protein, Tubulin-Polymerisation-förderndes-Protein/25 kDa großes hirnspezifisches Protein

VRR Virchow-Robin-Raum

WM white matter, weiße Substanz

WML WM-Läsionsfläche

ZNS zentrales Nervensystem 


\section{Tabellenverzeichnis}

Tabelle 1: Charakteristika der Multiplen Sklerose und der Neuromyelitis optica im Vergleich (Modifiziert nach Wingerchuk et al. 2007).

Tabelle 2: $\quad$ Übersicht über das verwendete humane histologische Material ........................... 18

Tabelle 3: Übersicht zu klinischen Daten/Angaben der untersuchten NAWM-Regionen der humanen Autopsie-Fälle .................................................. 18

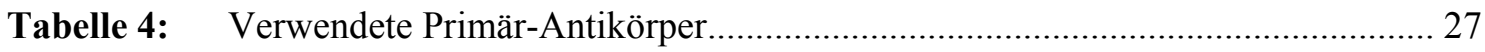

Tabelle 5: Verwendete biotinylierte Sekundär-Antikörper................................................. 28

Tabelle 6: Semi-quantitativer Score zur T-Lymphozyteninfiltration des Virchow-Robin-Raumes der NAWM/WM ..................................................... 30

Tabelle 7: Semi-quantitativer Score zur Bestimmung der Dichte aktivierter Mikroglia in der NAWM/WM

Tabelle 8: Abschließender Score zum Vorhandensein oder Fehlen von

Mikrogliaknötchen in der NAWM/WM 31

\section{im Anhang:}

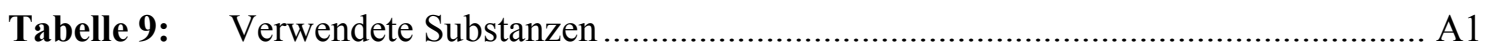

Tabelle 10: Verwendete Lösungen und Reagenzien ........................................................ A2

Tabelle 11: Geräte und relevante Verbrauchsmaterialien ..................................................... A3

Tabelle 12, Teil 1: Klinische Daten humaner Autopsiefälle

- altersentsprechende gesunde Kontrollen.

Teil 2: Klinische Daten humaner Autopsiefälle

- Patienten mit Multipler Sklerose (MS)

Teil 3: Klinische Daten humaner Autopsiefälle

- Patienten mit Neuromyelitis optica (NMO)

Tabelle 13, Teil 1: Alle Ergebnisse in der Übersicht

- Auswertung: Hirn humaner Autopsiefälle

Teil 2: Alle Ergebnisse in der Übersicht

- Auswertung: Rückenmark humaner Autopsiefälle .

Teil 3: Alle Ergebnisse in der Übersicht

- Auswertung: Rückenmark der Mäuse. 


\section{Abbildungsverzeichnis}

Abbildung 1: Schematischer Ablauf der indirekten immunhistochemischen

Avidin-Biotin-Methode (LAB).

Abbildung 2: $\quad$ Zerebrale NAWM humaner Autopsiefälle................................................ 39

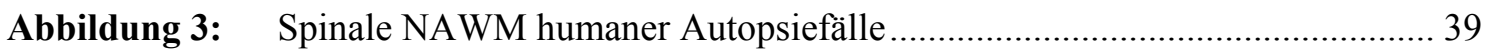

Abbildung 4: $\quad$ Erhöhte T-Lymphozytendichte in der NAWM bei MS und NMO im Vergleich zu Kontrollfällen

Abbildung 5: Kein signifikanter Unterschied der T-Lymphozyteninfiltration im VRR der NAWM humaner Autopsiefälle

Abbildung 6: Vermehrte spinale Mikrogliaaktivierung in der NAWM bei MS und NMO im Vergleich zu Kontrollfällen

Abbildung 7: $\quad$ Vermehrt vorhandene Mikrogliaknötchen in der NAWM bei MS ................ 47

Abbildung 8: $\quad$ Reduzierte relative axonale Dichte in der NAWM von MS und NMO ......... 49

Abbildung 9: Akuter axonaler Schaden in der spinalen NAWM bei MS ........................ 51

Abbildung 10: Mehr desphosphorylierte Axone in der NAWM bei MS im Vergleich zu NMO- und Kontrollfällen .............................................. 53

Abbildung 11: Erhöhte Oligodendrozytendichte in der zerebralen NAWM bei MS............. 55

Abbildung 12: Spinal vermehrt reaktive Astrozyten in der NAWM bei MS im Vergleich zu Kontrollfällen

Abbildung 13: Anteil demyelinisierter weißer Substanz im Rückenmark von gesunden Tieren und Mäusen mit chronischer EAE.

Abbildung 14: Erhöhte T-Lymphozytendichte in der spinalen NAWM bei Mäusen mit EAE in Abhängigkeit von der Läsionslast

Abbildung 15: Vermehrte Mikrogliaaktivierung in der spinalen NAWM von Mäusen mit chronischer EAE

Abbildung 16: Vermehrt vorhandene Mikrogliaknötchen in der spinalen NAWM von Mäusen mit chronischer EAE im Vergleich zu gesunden Tieren.

Abbildung 17: Reduzierte relative axonale Dichte in der spinalen NAWM von Mäusen mit chronischer EAE in Abhängigkeit von der Läsionslast

Abbildung 18: Vermehrte akute axonale Schädigung in der spinalen NAWM von Mäusen mit chronischer EAE und hoher Läsionslast 68

Abbildung 19: Erhöhte Oligodendrozytendichte in der spinalen NAWM von Mäusen mit chronischer EAE in Abhängigkeit von der Läsionslast

Abbildung 20: Vermehrt reaktive Astrozyten in der spinalen NAWM insbesondere bei Mäusen mit chronischer EAE .... 


\section{Einleitung}

\subsection{Entzündlich-demyelinisierende Erkrankungen}

\subsubsection{Multiple Sklerose (MS)}

\subsubsection{Klinik}

Die Multiple Sklerose (MS) ist eine chronische, entzündlich-demyelinisierende Erkrankung des zentralen Nervensystems (ZNS). In Deutschland geht man von einer Prävalenz um die 149 pro 100.000 Einwohner aus (Hein und Hopfenmuller 2000). Frauen sind heute im Schnitt etwas mehr als doppelt so häufig betroffen wie Männer (Alonso und Hernan 2008). Die Ätiologie ist trotz intensiver Forschung noch nicht abschließend geklärt. Es wird gegenwärtig von einem multifaktoriellen Geschehen ausgegangen, dem ein autoimmun vermittelter Prozess im ZNS zugrunde liegt. Ferner werden verschiedene Umweltfaktoren diskutiert, welche die Erkrankung begünstigen können. Eine familiäre Häufung (Carton et al. 1997) und umfangreiche genetische Studien (Beecham et al. 2013) deuten auf eine genetische Prädisposition hin, wobei primär genetische immunologische Faktoren identifiziert wurden. Die Erstmanifestation der Multiplen Sklerose findet meist in der zweiten bis vierten Lebensdekade statt, kann aber selten auch im Kindes- und Jugendalter oder im höheren Alter auftreten (Banwell et al. 2007).

Typische pathologische Charakteristika sind multiple, örtlich und zeitlich disseminierte entzündlich-demyelinisierende fokale Läsionen in der weißen und grauen Substanz in Gehirn und Rückenmark. Nach aktuellen Forschungsergebnissen treten zusätzlich zu den Läsionen auch Veränderungen in der normal erscheinenden grauen Substanz (grey matter, GM) und der normal erscheinenden weißen Substanz (normal appearing white matter, NAWM) auf, welche vermutlich zur klinischen Symptomatik beitragen (siehe hierzu auch Kapitel 1.2). Die klinische Symptomatik hängt von der Lage der Läsionen im ZNS ab. Erste Symptome sind häufig Sensibilitätsausfälle, Sehstörungen (Optikusneuritis) und Koordinationsprobleme. Als Zeichen einer Kleinhirnschädigung können zudem Nystagmus, Intentionstremor und eine skandierte Sprache (CharcotTrias) auftreten. Im weiteren Verlauf kann eine große Bandbreite von Symptomen wie vegetative Störungen u. a. der Blasen- und Mastdarmregulation, verschiedenste Schmerzsymptome bis hin zur Trigeminusneuralgie (Cruccu et al. 2009; Bischof und 
Sprenger 2014), Abgeschlagenheit (Fatigue) (Andreasen et al. 2010), kognitive Beeinträchtigungen (Smestad et al. 2010) und psychopathologische Auffälligkeiten (Jose 2008) vorliegen. Zudem treten motorische Beeinträchtigungen und spastische Paresen auf. Im fortgeschrittenen Stadium steht bis heute nicht selten eine Gehbehinderung im Vordergrund. Ein schwerer Verlauf ist jedoch nicht zwingend (Noseworthy et al. 2000).

Auch der Krankheitsverlauf ist nicht einheitlich. Die gebräuchlichste Einteilung der Verlaufsformen ist bis heute die nach Lublin und Reingold (1996). Am Anfang der Erkrankung steht häufig eine schubförmig remittierende (relapsing remitting $M S$, RRMS) Verlaufsform (Lublin und Reingold 1996), welche bei 80\% aller MS-Fälle zu finden ist (Noseworthy et al. 2000). Bei dieser Verlaufsform bildet sich die schubartig aufgetretene Symptomatik typischerweise innerhalb von Wochen partiell oder vollständig wieder zurück (Lublin und Reingold 1996; Noseworthy et al. 2000). Der Großteil dieser Fälle geht über die Jahre in eine sekundär chronisch progrediente Verlaufsform über (secondary progressive MS, SPMS) (Lublin und Reingold 1996; Noseworthy et al. 2000). Die Symptome nehmen dann schleichend zu und weisen keine Rückbildungstendenz mehr auf, Schübe können zusätzlich auftreten (Lublin und Reingold 1996). Etwa 20\% aller Erkrankungen (Noseworthy et al. 2000) äußern sich als primär progrediente MS (primary progressive MS, PPMS), wobei sich die Symptomatik von Beginn an schleichend verschlechtert (Lublin und Reingold 1996; Noseworthy et al. 2000).

\subsubsection{Diagnose und Therapie}

Die Diagnostik beruht auf einer ausführlichen Anamnese, einer klinischen Untersuchung inklusive neurologischer Befunderhebung und der Bildgebung (siehe zur Bildgebung auch Kapitel 1.2.1) von Hirn und Rückenmark. Hinzu kommen die Ableitung evozierter Potentiale und die Liquordiagnostik mit Nachweis oligoklonaler Banden (OKB). Ferner müssen Differentialdiagnosen ausgeschlossen werden.

Derzeit gelten die Diagnosekriterien nach McDonald, welche zuletzt 2010 von Polman et al. aktualisiert wurden (McDonald et al. 2001; Polman et al. 2005; Polman et al. 2011). Hierbei steht der Nachweis einer räumlichen und zeitlichen Dissemination der entzündlich-demyelinisierenden Läsionen mit Hilfe der Magnetresonanztomographie (MRT, auch Kernspintomographie) im Vordergrund. 
Eine kausale Therapie der Multiplen Sklerose ist bis heute nicht möglich. Da der MS ein immun-vermittelter Prozess zugrunde liegt, besteht das Therapiekonzept hauptsächlich aus der Darreichung immunmodulierender und immunsuppressiver Substanzen, die abhängig vom Krankheitsverlauf zum Einsatz kommen. Prinzipiell wird zwischen der Schubtherapie und der verlaufsmodifizierenden Langzeittherapie unterschieden. Des Weiteren wird parallel eine symptomatische Therapie durchgeführt.

Akute Schübe werden primär mit hochdosierten Glukokortikoiden (Prednisolon i.v.) behandelt. Schlagen diese nicht zufriedenstellend an, dann kann bei schweren Schüben auf die Plasmapherese zurückgegriffen werden. Zur Langzeittherapie und Schubprophylaxe werden hauptsächlich immunmodulatorische Medikamente eingesetzt, wie $\beta$-Interferone und Glatirameracetat. Stellt sich deren Wirkung als nicht zufriedenstellend heraus, kann eine Therapieeskalation mit Fingolimod oder dem monoklonalen Antikörper Natalizumab erfolgten. Für aggressivere Krankheitsverläufe können auch andere monoklonale Antikörper wie Rituximab oder Alemtuzumab zum Einsatz kommen. Des Weiteren ist die Verwendung immunsupressiver Medikamente wie Azathioprin, Cyclophosphamid und Mitoxantron in bestimmten Fällen möglich. Die verschiedenen Verlaufsformen der MS sprechen unterschiedlich gut auf die einzelnen Therapeutika an. Letztlich muss jeder Patient individuell in Einzelfallentscheidungen auf die für ihn optimale Therapie eingestellt werden.

\subsubsection{Pathologie}

Pathologische Charakteristika der Multiplen Sklerose sind multifokale, entzündlichdemyelinisierende Läsionen. Die klassischen Prädilektionsstellen der MS-Läsionen sind die Nervi optici, die periventrikuläre und subkortikale weiße Substanz (white matter, WM) inklusive des Corpus callosum, der Hirnstamm, das Cerebellum und die spinale WM (Stadelmann et al. 2011). Aktuellen Studien zufolge treten bei den meisten Patienten auch Läsionen in der GM auf (Bo et al. 2003), wobei der Anteil der demyelinisierten GM oft den Anteil der entmarkten WM in vielen ZNS-Regionen übersteigt (Gilmore et al. 2009). Die WM-Läsionen sind häufig rund bis ovoid, können im Krankheitsverlauf aber auch konfluieren und unregelmäßig begrenzte Läsionen bilden, die weite Teile der WM betreffen können (Fazekas et al. 1999). Neben den fokalen Läsionen zeigt sich auch eine Hirnatrophie, die nach langjährigen Krankheitsverläufen ausgeprägt sein kann (Kutzelnigg und Lassmann 2005). 
Histopathologisch sind die Läsionen durch ein entzündliches Infiltrat, den Verlust von Myelin, einen relativen Erhalt von Axonen und eine Astrogliose gekennzeichnet (Noseworthy et al. 2000; Brück 2005). Typischerweise sind auch axonale Schäden $\left(\mathrm{APP}^{+}\right.$- und SMI32 ${ }^{+}$-Axone, siehe 2.3.1.4 und 2.3.1.5) nachweisbar (Trapp et al. 1998). Je nach Läsionsstadium treten zudem mehr oder weniger dichte entzündliche parenchymatöse und perivaskuläre Infiltrate aus Makrophagen, T- aber auch wenigen B-Lymphozyten auf. Die genauere histologische Zusammensetzung einer Läsion ist abhängig von ihrem Alter bzw. dem Stadium der demyelinisierenden Aktivität innerhalb der Läsion.

In früh aktiven Läsionen ist das Entzündungsinfiltrat sehr ausgeprägt, wodurch die Läsion hyperzellulär erscheint. Die meisten infiltrierenden Zellen sind aktivierte, phagozytierende Makrophagen, welche massiv Myelinbestandteile beinhalten. Weitere Zellen des Infiltrates sind T-Lymphozyten. Diese Läsionen erscheinen aufgrund des aktiven Myelinabbaus häufig etwas unschärfer begrenzt. Mit der Zeit nimmt die Dichte der entzündlichen Zellen in den Läsionen ab. Chronisch aktive Läsionen weisen einen inaktiven hypozellulären Kern und einen umgebenden aktiven hyperzellulären Randsaum auf. In diesem Saum schreitet die Demyelinisierung weiterhin fort. Chronische inaktive Läsionen sind schließlich weitgehend demyelinisiert und hypozellulär. Sie weisen nur wenige Entzündungszellen ohne aktive Demyelinisierung auf. Dafür findet sich eine ausgeprägte fibrilläre Astrogliose.

Mit dem Läsionsalter geht typischerweise auch eine Reduktion der Oligodendrozytendichte einher - bis hin zu einem fast vollständigen Verlust in chronischen Läsionen (Ozawa et al. 1994). Auch das Ausmaß des akuten axonalen Schadens variiert je nach Alter der Läsion, abhängig von der bestehenden Entzündungsreaktion, dabei ist sie in aktiven Läsionen besonders ausgeprägt (Ferguson et al. 1997; Trapp et al. 1998; Kornek et al. 2000; Kuhlmann et al. 2002).

Darüber hinaus kann in etwa 40\% der chronischen Läsionen eine Regeneration der Myelinscheiden (Remyelinisierung) in unterschiedlichem Ausmaß beobachtet werden (Barkhof et al. 2003). Solche partiell bis komplett remyelinisierten Läsionen werden auch shadow plaques genannt. Die neu gebildeten Myelinscheiden sind vergleichsweise dünner als das vorbestehende Myelin, wodurch die Myelinfärbung relativ gesehen in den remyelinisierten Arealen schwächer ausfällt. 


\subsubsection{Neuromyelitis optica (NMO)}

\subsubsection{Klinik}

Die Neuromyelitis optica (NMO, auch Devic-Syndrom) ist eine seltene, chronisch entzündlich-demyelinisierende Erkrankung des ZNS. Klassische klinische Charakteristika sind eine schwere transversale Myelitis, welche sich über mindestens drei Rückenmarksegmente erstreckt, und eine uni- oder bilaterale Optikusneuritis. Kürzliche Untersuchungen haben zudem ergeben, dass im Gegensatz zu bisherigen Annahmen bei 60-70\% der Patienten auch Hirnläsionen auftreten (Pittock et al. 2006a; Kim et al. 2012).

Die Datenlage zur Prävalenz und Inzidenz ist spärlich. Die Prävalenz wird für die westlichen Länder auf etwa 1 bis 4.4/100.000 Menschen geschätzt (Trebst et al. 2014). Das durchschnittliche Erkrankungsalter liegt bei NMO etwa um das 40. Lebensjahr, also etwa zehn Jahre später als bei MS. Die Erstmanifestation kann jedoch auch bei jüngeren oder älteren Personen auftreten (Wingerchuk et al. 2007). Zudem sind Frauen nicht nur doppelt so häufig betroffen wie bei MS, sondern etwa neun Mal so oft wie Männer (Wingerchuk et al. 2007). Im Gegensatz zur MS ist bei der NMO seit kurzem die die immunologische Zielstruktur bekannt.

Lange Zeit wurde die NMO als eine Variante der Multiplen Sklerose angesehen. Doch seit der Entdeckung eines NMO-spezifischen Antikörpers, welcher als „NMO-IgG“ bezeichnet wird, wird die NMO als eigenständige, autoimmun vermittelte Erkrankung eingeordnet. Dieses NMO-IgG ist mit den derzeit verfügbaren Nachweisverfahren bei 60-90\% der NMO-Patienten im Serum nachweisbar, nicht jedoch bei Patienten mit MS oder gesunden Testpersonen (Lennon et al. 2005; Jarius et al. 2008). Es richtet sich direkt gegen Aquaporin 4 (AQP4), den häufigsten Wasserkanal im ZNS (AmiryMoghaddam und Ottersen 2003; Lennon et al. 2005). Die höchste Konzentration an AQP4 ist in den peripialen und perivaskulären astrozytären Endfüßchen zu finden, tritt aber auch in der Ependymzellmembranen gehäuft auf (Roemer et al. 2007). Das NMOIgG ist für die NMO hoch spezifisch (91-100\%) (Lennon et al. 2004; Jarius und Wildemann 2010). Die Antikörper können jedoch neben der klassischen NMO teilweise auch bei den sogenannten „NMO-Spektrum-Erkrankungen“ (neuromyelitis optica spectrum disorder, NMOsd) nachgewiesen werden (Aktas und Hartung 2009). Zu diesen gehören unter anderem die isolierte longitudinale extensive transverse Myelitis (LETM) und die monophasische oder rezidivierende isolierte Optikusneuritis (ON) 
(Wingerchuk et al. 2007; Freitas und Guimarães 2015). Lennon et al. wiesen bereits 2004 bei rund 52\% der Patienten mit LETM und bei immerhin 25\% mit ON das NMOIgG nach. Bei der klassischen NMO-Fällen waren 73\% positiv (Lennon et al. 2004). Mit dem Nachweis des NMO-IgG-Antikörpers im Serum von Patienten mit LETM oder ON, erhöht sich das Risiko eines Rezidivs bis hin zur Ausbildung einer klassischen NMO (Weinshenker et al. 2006; Jarius et al. 2010).

Die NMO verläuft in $80-90 \%$ der Fälle schubförmig und nur viel seltener (10-20\%) monophasisch (Wingerchuk et al. 2007). Leitsymptome sind die longitudinale extensive transverse Myelitis ( $\geq 3$ Wirbelkörpersegmente) und schwerwiegende, rezidivierende, zum Teil auch beidseitige Optikusneuritiden mit oftmals persistierender Visusminderung bis hin zur Erblindung. Spontane Remissionen sind selten und meist unvollständig. Die klinische Manifestation der Myelitis verläuft meist akut bis subakut und kann von einer milden Ausprägung bis hin zum kompletten Querschnittsyndrom mit Para- oder Tetraparese reichen. Daneben sind unter anderem Sensibilitätsstörungen unterhalb der Läsion, und Blasenstörungen charakteristisch (Wingerchuk et al. 1999). Zudem können eine Schwäche der Extremitäten, wiederkehrende schmerzhafte tonische Spasmen und radikuläre Rückenschmerzen auftreten (Wingerchuk et al. 1999). Bei Beteiligung des Hirnstamms können Nausea, Vomitus und ein andauernder Singultus auftreten (Misu et al. 2005; Takahashi et al. 2008; Riphagen et al. 2010; Kim et al. 2012). Ferner ist auch das Eintreten einer respiratorischen Ateminsuffizienz mit Todesfolge möglich (Wingerchuk et al. 1999). Wingerchuck et al. berichten zudem von weiteren Non-optic-spinal-Symptomen, wie z.B. Vertigo, Nystagmus, Ptosis, Ataxie, Gesichtstaubheit, Hörverlust und Trigeminusneuralgie (Wingerchuk et al. 2006; Kim et al. 2012). Viele dieser Symptome konnten mit zerebralen, zerebellären oder HirnstammVeränderungen in der MRT in Zusammenhang gebracht werden (Wingerchuk et al. 2006; Pittock et al. 2006a). Die Leitsymptome treten selten gleichzeitig, meist aber zeitlich versetzt auf. Zwischen dem Auftreten beider Leitsymptome können Jahre bis Jahrzehnte verstreichen (O'Riordan et al. 1996; Wingerchuk et al. 1999).

Des Weiteren sind die NMO und die NMOsd häufiger als die MS mit anderen Autoimmunerkrankungen, wie z.B. Lupus erythematodes oder Sjögren-Syndrom, assoziiert (Pittock et al. 2008; Jarius et al. 2011; Freitas und Guimarães 2015). 
Tabelle 1: Charakteristika der Multiplen Sklerose und der Neuromyelitis optica im Vergleich (Modifiziert nach Wingerchuk et al. (2007) „The spectrum of Neuromyelitis optica”)

\begin{tabular}{|c|c|c|}
\hline & Multiple Sklerose & Neuromyelitis optica \\
\hline $\begin{array}{l}\text { Klin. Manifestation } \\
\text { und Verlauf }\end{array}$ & $\begin{array}{l}80 \% \text { schubförmig RRMS } \\
20 \% \text { primär progredient PPMS }{ }^{1)}\end{array}$ & $\begin{array}{l}\text { 80-90\% schubförmig } \\
\text { 10-20\% monophasisch }\end{array}$ \\
\hline $\begin{array}{l}\text { Durchschnittliches } \\
\text { Erkrankungsalter }\end{array}$ & 29 Jahre & 39 Jahre \\
\hline o $: \hat{0}$ & $2: 1$ & $9: 1$ \\
\hline Kraniale MRT & $\begin{array}{l}\text { vor allem periventrikuläre } \\
\text { Läsionen der WM }\end{array}$ & $\begin{array}{l}\text { o. p. B., unspezifische WM-Läsionen, } \\
10 \% \text { mit MS-typischen WM-Läsionen }{ }^{2)} \text { und/oder } \\
\text { NMO-typische Läsionen in Hypothalamus, } \\
\text { Corpus callosum, periventrikulär, Hirnstamm }\end{array}$ \\
\hline Spinale MRT & $\begin{array}{l}\text { kurzstreckige laterale oder } \\
\text { exzentrisch gelegene Läsionen }\end{array}$ & $\begin{array}{l}\text { langstreckige ( } \geq 3 \text { Segmente) zentrale Läsionen, } \\
\text { oft mit Schwellung, teilweise Kavitation }{ }^{4}\end{array}$ \\
\hline Liquordiagnostik & $\begin{array}{l}\text { milde Pleozytose } \\
\text { (Leukozytenzahl <50/ } \mu \text { l) } \\
\text { mononukleare Zellen } \\
\text { OKB in ca. } 85 \%\end{array}$ & $\begin{array}{l}\text { zeitweilig prominente Pleozytose } \\
\text { (Leukozytenzahl häufig > 50/ } \mu \text { l) } \\
\text { Granulozyten und Monozyten } \\
\text { OKB ca. } 10-25 \% \text { ) }\end{array}$ \\
\hline Labor & kein spezifischer Marker & Nachweis von NMO-IgG im Serum \\
\hline
\end{tabular}

$q: \hat{O}=$ Verhältnis Anzahl Frauen zu Männern; o. p. B.: ohne pathologischen Befund; OKB: oligoklonale Banden; ${ }^{1)}$ (Noseworthy et al. 2000); ${ }^{2)}$ (Pittock et al. 2006a); ${ }^{3)}$ (Pittock et al. 2006b; Roemer et al. 2007; Misu et al. 2007); ${ }^{4)}$ (Mandler et al. 1993); ${ }^{5)}$ (Jurynczyk et al. 2015)

\subsubsection{Diagnostik und Therapie}

Die Diagnostik der Neuromyelitis optica umfasst die Anamnese, eine körperliche Untersuchung und die Durchführung einer Basislaboranalyse mit eventueller erweiterter Labordiagnostik. Zudem wird wie auch bei MS eine Liquoruntersuchung durchgeführt. Im Gegensatz zur MS, wo die oligoklonalen Banden bei ca. 85\% der Fälle nachweisbar sind, werden sie bei NMO jedoch in lediglich 10-25\% der Fälle - teils auch nur vorübergehend im akuten Schub - nachweisbar (Jurynczyk et al. 2015). Ein weiterer Grundpfeiler der Diagnostik ist die Anwendung bildgebender Verfahren mit einer spinalen und zerebralen MRT-Untersuchung. Hinzu kommt bei Verdacht auf NMO die Bestimmung des NMO-IgGs im Serum. Ein fehlender Antikörpernachweis schließt eine NMO jedoch nicht aus.

Zur sicheren Diagnose der NMO müssen nach Wingerchuk et al. mehrere Kriterien erfüllt sein (Wingerchuk et al. 2006). Obligat ist das Auftreten beider Leitsymptome, also der uni- oder bilateralen Optikusneuritis und der Myelitis. Zusätzlich müssen zwei der drei folgenden Nebenkriterien erfüllt sein: erstens eine zusammenhängende, longitudinale extensive spinale MRT-Läsion ( $\geq 3$ Wirbelkörpersegmente), zweitens eine 
kraniale MRT ohne Nachweis der MS-typischer Läsionen und drittens der Befund von NMO-IgG-Antikörpern im Serum.

Wie die Multiple Sklerose ist auch die Neuromyelitis optica nicht heilbar. Die aktuellen Therapieempfehlungen beruhen derzeit noch auf kleinen Fallserien und der klinischen Erfahrung spezialisierter Zentren. Zur Behandlung der Schübe sind hochdosierte Glukokortikoide (Prednisolon i. v.) Mittel der Wahl. Führt diese Behandlung nicht zu einer raschen Besserung der neurologischen Symptomatik, dann wird entweder eine Plasmapherese durchgeführt oder eine erneute Glukokortikoidgabe erwogen (Trebst et al. 2014). Ist die NMO sicher diagnostiziert, so ist das Ziel der weiteren Behandlung die langfristige, immunmodulatorische bzw. immunsuppressive Therapie. Als Mittel der ersten Wahl wird Azathioprin angesehen. Es wird bis zu seinem Wirkungseintritt (nach bis zu 3-6 Monaten) zunächst in Kombination mit Prednisolon verabreicht (Trebst et al. 2014). Alternativ kann Rituximab als Medikament der ersten Wahl zur Depletion der BZellen eingesetzt werden. Neben Azathioprin und Rituximab stehen noch weitere Immunsuppressiva zur Verfügung (Trebst et al. 2014). Neben der Langzeittherapie erfolgt zudem eine symptomatische Behandlung.

\subsubsection{Pathologie}

Typische histopathologische Charakteristika sind entzündliche-demyelinisierende Läsionen, verbunden mit axonaler Schädigung und einem - zumindest zeitweisen kompletten Verlust von AQP4 (Misu et al. 2007; Roemer et al. 2007). Die Prädilektionsstellen sind die Nervi optici und das Rückenmark. Im Rückenmark ist meist sowohl die weiße, als auch die graue Substanz involviert (Mandler et al. 1993). Darüber hinaus können zerebrale Läsionen auftreten, die in der Bildgebung bei etwa 6070\% der NMO-Patienten nachweisbar sind (Pittock et al. 2006a; Kim et al. 2012). Typische Hirnläsionen sind in Bereichen mit einer hohen AQP4-Konzentration lokalisiert, wie den periventrikulären Arealen und dem Hypothalamus (Pittock et al. 2006b). Die höchste Konzentration von AQP4 findet sich im Hirnstamm, im Rückenmark und den Nervi optici (Misu et al. 2007; Roemer et al. 2007), was mit der typischen Lage der NMO-Läsionen korreliert. Kortikale Läsionen scheinen bei NMO nicht vorzukommen (Popescu et al. 2010).

NMO-Läsionen sind häufig deutlich destruktiver als MS-Läsionen und gehen mit einem extensiven axonalen Schaden einher, zum Teil begleitet von Kavitation des Gewebes (Mandler et al. 1993; Wingerchuk et al. 2007). Die Blutgefäße innerhalb der Läsionen 
erscheinen oft stark verdickt und hyalinisiert (Mandler et al. 1993). Das Ausmaß der entzündlichen Komponente hängt bei NMO-Läsionen ebenfalls vom Alter der Läsion $\mathrm{ab}$.

Frühe Läsionen weisen eine ausgeprägte humorale Immunantwort mit perivaskulärer Ansammlung von Immunglobulinen (IgG, IgM) und aktivierten Komplementkomponenten auf (Lucchinetti et al. 2002). Die Entzündungsinfiltrate in frühen Läsionensstadien bestehen hauptsächlich aus Makrophagen, neutrophilen und eosinophilen Granulozyten und nur wenigen T-Lymphozyten (Lucchinetti et al. 2002). Frühe entzündliche NMO-Läsionen weisen als frühste Veränderungen Komplementablagerungen auf der Astrozytenoberfläche auf, begleitet von einwandernden neutrophilen und eosinophilen Granulozyten, aber auch von astrozytärem Zelltod (Misu et al. 2013). Diese Läsionen weisen typischerweise einen Verlust von perivaskulären Astrozyten auf. Sie konnten zudem apoptotische Oligodendrozyten in diesen frühen Läsionsstadien nachweisen. Myelin und Axone scheinen jedoch in diesem Stadium noch intakt zu sein (Misu et al. 2013). Diese Beobachtung innerhalb früher aktiver Läsionen stimmen mit Daten aus tierexperimentellen NMO-Modellen überein (Bradl et al. 2009; Saadoun et al. 2010; Wrzos et al. 2014).

Fasst man zusammen, so sind aktive NMO-Läsionen durch diffuse Schwellung, infiltrierende Makrophagen, eine ausgeprägte Entzündung (s.o.) mit Komplementaktivierung, astrozytäre Schädigung bis hin zum Zelltod, AQP4-Verlust und apoptotische Oligodendrozyten gekennzeichnet. Darüber hinaus treten je nach Läsionsstadium Demyelinisierung, axonale Sphäroidbildung und Axonverluste bis hin zu zystischen Gewebeveränderungen auf (Lucchinetti et al. 2002). Chronische Läsionen weisen zudem Gliose, zystische Degeneration und Atrophie auf (Lucchinetti et al. 2002). Inaktive Läsionen zeigen weniger Entzündung. Dafür treten nun die bereits erwähnten verdickten Gefäße verstärkt auf. 


\subsubsection{Experimentell autoimmune Enzephalomyelitis (EAE)}

Viele Erkenntnisse über die Multiple Sklerose wurden mit Hilfe von Tiermodellen gewonnen. Die drei wichtigsten Tiermodelle der MS sind die experimentelle autoimmune Enzephalomyelitis (EAE), die Infektion mit dem Theiler-Virus sowie das Cuprizon-Modell (Denic et al. 2011). Die EAE ist das am häufigsten verwendete Tiermodell für die MS. Dabei handelt es sich um eine durch Myelinantigene induzierte, T-Lymphozyten vermittelte entzündlich-demyelinisierende Autoimmunerkrankung des ZNS.

Es gibt viele verschiedene Formen der EAE, die abhängig von der eingesetzten Tierart bzw. dem genetischen Hintergrund des Tierstammes, dem verwendeten Immunogen sowie der Induktionsweise verschiedene spezifische Charakteristika der Erkrankung wiedergeben und unterschiedliche Verlaufsformen der MS nachahmen können. Keines der Tiermodelle spiegelt jedoch die gesamte Heterogenität der Multiplen Sklerose wider.

\subsubsection{Induktion und Klinik}

Die EAE kann auf verschiedene Weisen induziert werden. Einerseits aktiv, durch die Immunisierung mit Antigenen, wie beispielsweise dem Myelin-basischen Protein (MBP), dem Proteolipid-Protein (PLP) oder dem Myelin-OligodendrozytenGlykoprotein (MOG). Andererseits passiv, durch den adoptiven Transfer von autoreaktiven T-Lymhozyten, die gegen Myelinbestandteile gerichtet sind.

In der vorliegenden Arbeit wurde die EAE am Mausstamm C57BL/6J durch die aktive Immunisierung mit dem enzephalitogenen Myelin-Peptid MOG $_{35-55}$ (Aminosäuren 3555) induziert. Dieses löst eine Autoimmunreaktion im Rückenmark aus, so dass sich eine der MS ähnlichen spinalen Läsionen und Symptomen kommt. Bei dieser Tierstamm-Antigen-Kombination kommt es zur spinal demyelinisierten Läsionen, die durch T-Lymphozyten und Makrophagen vermittelt werden (Mendel et al. 1995). Klinisch tritt meist eine aufsteigende, schlaffe Paralyse des Schwanzes und der Hinterläufe auf (Mendel et al. 1995), welche jedoch auch bis hin zu den Vorderläufen reichen kann. 


\subsubsection{Pathologie}

Histopathologisch ist die MOG35-55-induzierte EAE in C57BL/6-Mäusen durch eine perivaskuläre Makrophagen- und T-Lymphozytenreiche Entzündung, Demyelinisierung sowie Axonverlust gekennzeichnet (Mendel et al. 1995; Gold et al. 2006; Jones et al. 2008). Im Unterschied zur MS finden sich die Läsionen nur in der spinalen WM (Jones et al. 2008). Des Weiteren konnten akute und chronische axonale Schäden (APP ${ }^{+}$und SMI32 ${ }^{+}$-Axone, siehe 2.3.1.4 und 2.3.1.5) (Herrero-Herranz et al. 2008), Astrogliose und Oligodendrozytenverluste innerhalb der Läsionen nachgewiesen werden (Bannerman et al. 2007). Jones et al. beobachteten zudem ein unterschiedliches Ausmaß an Mikrogliaaktivierung, abhängig vom Zeitverlauf der EAE (Jones et al. 2008).

Durch die Ähnlichkeit der histopathologischen Charakteristika zur MS können Untersuchungen $\mathrm{zu}$ einem besseren Verständnis der frühen Pathogenese der MS beitragen. 


\subsection{Normal erscheinende weiße Substanz (NAWM)}

\subsubsection{Veränderungen der NAWM bei MS}

Die NAWM wurde laut Filippi und Kollegen zum ersten Mal im Jahre 1979 von Allen und McKeown als makroskopisch normale weiße Substanz bei MS definiert, welche mikroskopisch normal myelinisiert erscheint (Allen und McKeown 1979; Filippi et al. 2012). Für ihre histologischen Untersuchungen verwendeten sie WM, die sie möglichst weit vom Läsionsrand entnahmen (Allen und McKeown 1979). Später wurde die ursprüngliche Definition der NAWM um einen Mindestabstand zum Läsionsrand ergänzt. Die meisten histopathologischen Studien definieren die NAWM als WM, welche mindestens $10 \mathrm{~mm}$ von fokalen demyelinisierenden Läsionsrändern entfernt liegt (Kutzelnigg et al. 2005; Höftberger et al. 2010; Howell et al. 2010; Filippi et al. 2012; Markoullis et al. 2012).

Je nach Studie wurde zudem darauf geachtet, dass keine Nervenfaserbahnen aus WMLäsionsflächen (WML) in die NAWM einstrahlten (Kutzelnigg et al. 2005; Howell et al. 2010) und zudem auch genügend Abstand nicht nur zu Läsionen, sondern auch zur weißen Substanz direkt um die Läsion herum (periplaque white matter, PPWM) eingehalten wurde (Höftberger et al. 2010). Höftberger et al. definierten die PPWM als einen etwa $10 \mathrm{~mm}$ breiten Gewebestreifen um den Läsionsrand herum.

In der Radiologie werden andere Kriterien zur Definition der NAWM hinzugezogen. Zur Diagnostik und Verlaufskontrolle der Multiplen Sklerose hat sich die Magnetresonanztomographie bewährt, da diese Technik einen hohen Weichteilkontrast aufweist und ohne ionisierende Strahlung auskommt. Zudem zeichnet sie sich durch eine sehr hohe Sensitivität aus. Daher wird die NAWM in der Bildgebung im Allgemeinen auch über die konventionelle MRT definiert. Hier wird die NAWM als der Bereich der WM bezeichnet, welcher in der T2-Wichtung normal erscheint (Seewann et al. 2009; Moll et al. 2011). Die sogenannte T2-gewichtete Bildgebung stellt Flüssigkeiten und Entzündungen hyperintens (hell) dar, auch die MS-Läsionen imponieren hell aus dem umliegenden Gewebe hervor. Problematisch ist jedoch die geringe Spezifität, da die Signale von MS-Läsionen in der MRT nicht charakteristisch sind. Viele der in der MRT sichtbaren Veränderungen der WM ähneln Signalen, welche durch andere Erkrankungen (Trip und Miller 2005; Filippi et al. 2012) oder 
physiologische Altersveränderungen verursacht werden können (Trip und Miller 2005). Auch lassen sich von MS-typischen Signalveränderungen in der MRT keine weiteren fundierten Rückschlüsse auf die histopathologischen Veränderungen ziehen.

Des Weiteren kann es teilweise Unterschiede zwischen Volumen und Lage der Läsionen, die sich in der konventionellen MRT darstellen lassen, und den neurologischen Defiziten bei MS-Patienten geben. Dieses Phänomen wird das klinischradiologische Paradoxon (clinicoradiologic dissociation) genannt (Seewann et al. 2009). So weiß man heute, dass es neben den in der konventionellen MRT sichtbaren Läsionen, auch nicht sichtbare Veränderungen in der NAWM gibt, welche u. a. zur klinischen Manifestation beitragen können.

Die NAWM wird radiologisch als der Bereich definiert, der in der konventionellen T2gewichteten MRT als unauffällig/normal erscheint. Histologisch korrelieren diese Bereiche in der Regel mit unauffälligen LFB/PAS-Färbungen und somit mit einer meist weitgehend regelrechten Myelindichte.

\subsubsection{Pathologie}

Obwohl bereits früh histopathologische Veränderungen in der NAWM beschrieben worden sind (Allen und McKeown 1979), dauerte es noch etliche Jahre, bis sie Beachtung fanden.

Bisherige histologische Untersuchungen der makroskopisch normal erscheinenden weißen Substanz bei MS haben gezeigt, dass zwar die Myelindichte normal ist, diese Areale jedoch Veränderungen im Vergleich zu gesunden Kontrollen aufweisen. Die pathologischen Charakteristika sind vielfältig. Es tritt eine diffuse axonalen Pathologie auf, welche durch das Vorliegen nicht-phosphorylierter Axone in der NAWM (SMI32 ${ }^{+}$ Axone, siehe 2.3.1.5) gekennzeichnet ist (Trapp et al. 1998). Des Weiteren sind akute axonale Schäden mit Nachweis axonaler Sphäroide (APP ${ }^{+}$-Axone, siehe 2.3.1.4) typisch (Bitsch et al. 2000; Kornek et al. 2000). Außerdem wird von axonalen Verlusten in der NAWM von Hirn (Evangelou et al. 2000a) und Rückenmark (Ganter et al. 1999; Lovas et al. 2000; DeLuca et al. 2004) berichtet, welche sich je nach untersuchter Region und Methode in ihrer Ausprägung unterscheiden können. Diese diffusen Veränderungen werden zum Teil auf durchtrennte Axone in entfernten fokalen Läsionen zurückgeführt, woraufhin eine Wallersche Degeneration der distalen Axone erfolgt (Lovas et al. 2000; 
Evangelou et al. 2000b; Bjartmar und Trapp 2001; Kutzelnigg et al. 2005; Dziedzic et al. 2010).

Daneben wird eine diffuse Entzündungsreaktion beobachtet. Perivaskulär wurde eine gering ausgeprägte Manschettenbildung mit mononukleären Leukozyten beschrieben (Hauser et al. 1986; Kutzelnigg et al. 2005). Einzelne T-Lymphozyten infiltrieren auch in das Parenchym (Hauser et al. 1986; Kutzelnigg et al. 2005; Androdias et al. 2010). Darüber hinaus tritt eine erhöhte Mikrogliaaktivierung auf (Kutzelnigg et al. 2005; Androdias et al. 2010; Howell et al. 2010).

Eine Studie zeigte zudem eine erhöhte Oligodendrozytendichte in der NAWM verglichen mit gesunden Kontrollen (Höftberger et al. 2010). Auch reaktive Astrozyten (Astrogliose) treten auf (Allen und McKeown 1979; Ludwin 2006).

\subsection{Veränderungen in der weißen Substanz bei gesunden Probanden}

Auch bei Gesunden treten im Rahmen des physiologischen Alterns neuropathologische Veränderungen in der WM bis hin zu läsionsartigen Befunden auf. Diese dürfen nicht mit den Läsionen bei Multipler Sklerose verwechselt werden. Generell wird bei alterspathologischen Veränderungen zwischen den periventrikulären und den subkortikalen/tiefen Veränderungen der WM unterschieden (Schmidt et al. 2011). Die subkortikalen Läsionen erweisen sich histopathologisch meist als erweiterte perivaskuläre Räume mit einem unterschiedlichen Ausmaß an Myelinverlust und Atrophie des Neuropils um fibrohyalinisierte Arterien bis hin zu ischämischen Gewebeschäden mit ausgeprägten perivaskulären Myelin- und Axonverlusten und variabler ausgeprägter Astro- und Mikrogliose auf (Simpson et al. 2007; Schmidt et al. 2011).

Diese Erkenntnisse legen nahe, das altersbedingte kleine Gefäßerkrankungen im Sinne arteriosklerotischer Prozesse zu den diffusen Veränderungen der weißen Substanz im Rahmen des Alterungsprozesses beitragen (Schmidt et al. 2011). In der Folge könnte es dann teilweise auch zur Wallerschen Degeneration kommen. Diese Vorgänge sind bisher jedoch noch nicht vollständig erforscht (Schmidt et al. 2011). 


\subsection{Veränderungen in der NAWM bei NMO und EAE}

Bis heute liegen keine histopathologischen Studien zu Veränderungen in der NAWM bei NMO vor. Es gibt jedoch einige wenige bildgebende Studien, welche Veränderungen der NAWM mit Hilfe quantitativer MRT-Verfahren untersucht haben. Die daraus gewonnenen Erkenntnisse unterscheiden sich allerdings. Ein Teil solcher Studien berichten von Veränderungen innerhalb von Bahnen, die mit dem Rückenmark oder der Nervi Optici in Verbindung stehen, wie der Pyramidenbahn (Tractus corticospinalis) und der Radiatio optica, nicht jedoch außerhalb dieser Bereiche. Aufgrund ihrer Ergebnisse schließen sie auf einen sekundären Schaden durch Wallersche Degeneration und gehen davon aus, dass es im Gegensatz zur MS keine primären, diffusen Veränderungen abseits der Läsionen gibt (Yu et al. 2006; Yu et al. 2008; Jeantroux et al. 2012). Rueda Lopes et al. konnten hingegen zeigen, dass neben der Pyramidenbahn und der Radiatio optica auch u. a. Veränderungen innerhalb des Corpus Callosum auftreten (Rueda Lopes et al. 2012). Zwei andere magnetresonanzspektroskopische Studien haben NAWM bei NMO untersucht und konnten keinen Verlust von N-Acetyl-Aspartat und damit keine axonalen Veränderungen nachweisen, welche hingegen typischerweise in der NAWM von MS-Patienten nachweisbar sind (Bichuetti et al. 2008; Aboul-Enein et al. 2010). Histologische Untersuchungen zu Veränderungen in der NAWM bei NMO stehen bislang noch aus.

Bislang liegen nur zwei Studien zu Veränderungen der NAWM von C57BL/6-Mäusen mit chronischer, MOG-induzierter EAE vor. Eine dieser Studien berichtet von einer signifikanten Reduktion der axonalen Dichte trotz sinkender Entzündungsinfiltration im Krankheitsverlauf, dem Auftreten einzelner akut geschädigter $\mathrm{APP}^{+}$-Axone und einer Erhöhung nicht-phosphorylierter Axone (SMI32 ${ }^{+}$-Axone) in der spinalen NAWM von C57BL/6-Mäusen mit $\mathrm{MOG}_{35-55}$-induzierter chronischer EAE (Herrero-Herranz et al. 2008). Aktivierte Mikroglia ist in diesem EAE-Modell ebenfalls zu finden (HerreroHerranz et al. 2008; Howell et al. 2010). 


\subsection{Fragestellung /Ziel der Arbeit}

Sowohl die Multiple Sklerose (MS) als auch die Neuromyelitis optica (NMO) zeigen entzündlich-demyelinisierende Läsionen im Rückenmark, Hirn und Sehnerv. Im Gegensatz zu einer relativen klinischen Stabilität zwischen den Schüben bei NMO, kommt es bei Patienten mit MS typischerweise zur schleichenden Akkumulation von Behinderungen unabhängig von Schüben während der progressiven Phase der Erkrankung. Es wird angenommen, dass pathologische Veränderungen in der normal erscheinenden weißen Substanz (normal-appearing white matter (NAWM)) zu dieser klinischen Progression bei der MS beitragen.

Das Ziel dieser medizinischen Doktorarbeit ist, entzündliche, gliale und axonale Veränderungen in der NAWM bei MS- und NMO-Fällen zu untersuchen. Dabei soll geprüft werden, ob sich die Veränderungen in der NAWM beider Erkrankungen unterscheiden und entsprechend zum unterschiedlichen Krankheitsverlauf beitragen. Hierzu sollen zerebrale und spinale Areale der NAWM anhand von autoptischen Gewebeproben von Patienten mit progressiver MS und langjähriger NMO untersucht und mit altersentsprechenden Kontrollen ohne neurologische Erkrankungen verglichen werden. Zur Identifizierung der NAWM sollen LFB/PAS-Färbungen und Aquaporin-4 (AQP-4)-Immunfärbungen verwendet werden. Die Quantifizierung von TLymphozyten, Gliazellen und akut geschädigter Axone mit immunpositiver Reaktion auf das Amyloid-Vorläufer-Protein (amyloid precursor protein (APP)) wird mit Hilfe immunhistochemischer Verfahren erfolgen. Die axonale Dichte wird in BielschowskySilber-Färbungen bestimmt.

Des Weiteren sollen auch Veränderungen in der spinalen NAWM an Mäusen mit experimenteller autoimmuner Enzephalomyelitis (EAE), dem am häufigsten verwendeten Mausmodell der MS, untersucht werden.

Mit den hieraus gewonnenen Erkenntnissen soll die bisher dürftige vergleichende Datenlage $\mathrm{zu}$ pathologischen Veränderungen in der NAWM beider humaner entzündlich demyelinisierender Erkrankungen verbessert werden und so möglicherweise $\mathrm{zu}$ einem besseren Verständnis der komplexen Krankheitsbilder beitragen. Zudem kann die Studie Hinweise liefern, ob das Mausmodell auch für Auswertungen zu Veränderungen in der NAWM und mögliche künftige therapeutische Untersuchungen geeignet ist. 


\section{Material und Methoden}

Verwendete Substanzen, Lösungen, Geräte und relevante Verbrauchsmaterialien sind dem Anhang beigefügt (Tabellen 9, 10 und 11).

\subsection{Histologisches Material}

\subsubsection{Humane Autopsiefälle}

In der vorliegenden Arbeit wurde Autopsiegewebe von 24 Patienten mit MS, fünf Patienten mit NMO und 13 gesunden altersentsprechende Kontrollen untersucht. Bei dem Autopsiegewebe handelte es sich um in Paraffin eingebettetes Gewebe, das zuvor in Formalin fixiert worden war. Sämtliche Gewebeproben stammten aus dem Archiv des Instituts für Neuropathologie der Universitätsmedizin Göttingen (UMG). Vor Beginn der Studie lag von der Ethikkommission die positive Beurteilung dieses Forschungsvorhabens vor.

Die Hirngewebeproben stammten aus dem Frontal- und Parietallappen. Dabei handelte es sich um NAWM aus der subkortikalen weißen Substanz. Bei den NMO-Fällen wurden zusätzlich temporale Gewebeproben untersucht. Das spinale histologische Material stammte aus dem zervikalen, thorakalen und lumbalen Rückenmark (siehe Tabelle 3).

Anhand der Befunde wurde eine Vorauswahl geeigneter Fälle getroffen. Anschließend wurden adäquate Gewebeblöcke mit Nachweis von NAWM (siehe Kapitel 2.3.1.1 „Auswahl der NAWM anhand histologischer Färbungen“) für die Untersuchungen auswählt. Von den 13 gesunden, altersentsprechenden Kontrollen wurden insgesamt 18 Blöcke Rückenmark und 22 Blöcke aus dem Frontal- oder Parietallappen untersucht. Von den 24 Fällen mit Multipler Sklerose wurden insgesamt 16 Blöcke Rückenmark und 20 Blöcke aus dem Frontal- oder Parietallappen analysiert. Zudem wurden von fünf Fällen mit einer diagnostizierten Neuromyelitis optica insgesamt sechs Blöcke Rückenmark und sechs Blöcke aus dem Frontal-/Parietal- und Temporallappen untersucht. Die vorliegende Studie beruhte somit auf der Auswertung von 88 humanen Gewebeproben von insgesamt 42 Individuen (vergl. Übersicht Tabelle 2; siehe für eine detaillierte Auflistung auch Tabelle 3). Sämtliche Paraffingewebeblöcke sind nach 
Material und Methoden

einem etablierten Standardprotokoll des Instituts mit einem vollautomatisierten

Einbettautomaten eingebettet worden.

Tabelle 2: Übersicht über das verwendete humane histologische Material

\begin{tabular}{lcccccr}
\hline Diagnose & Fallzahl & Anzahl Blöcke & spinal & $\begin{array}{c}\text { Hirn, subkortikal } \\
\text { (Region) }\end{array}$ & $\begin{array}{c}\text { Alter zum Zeitpunkt } \\
\text { des Todes* }\end{array}$ & $\begin{array}{c}\text { Geschlecht } \\
\left(+, 0^{\lambda}\right)\end{array}$ \\
\hline Kontrollen & 13 & 40 Blöcke & 18 & $22(\mathrm{~F} / \mathrm{P})$ & $62,62 \pm 12,10(42-81)$ & $4+, 9 \bigcirc^{\lambda}$ \\
\hline MS & 24 & 36 Blöcke & 16 & $20(\mathrm{~F} / \mathrm{P})$ & $57,83 \pm 11,33(36-77)$ & $10+, 14 \bigcirc^{\lambda}$ \\
\hline NMO & 5 & 12 Blöcke & 6 & $6(\mathrm{~F} / \mathrm{P} / \mathrm{T})$ & $62,20 \pm 14,72(44-77)$ & $4+, 10^{\lambda}$ \\
\hline \hline Gesamt: & 42 & 88 Blöcke & 40 & 48 & $59,88 \pm 11,90(36-81)$ & $18+, 24 \bigcirc^{\lambda}$ \\
\hline
\end{tabular}

* Mittelwert \pm Standardabweichung (Altersspanne); $\uparrow$ Anzahl der Frauen; $\widehat{\jmath}$ Anzahl der Männer;

$\mathrm{F}=$ Frontallappen; $\mathrm{P}=$ Parietallappen; $\mathrm{T}=$ Temporallappen;

Tabelle 3: Übersicht zu klinischen Daten/Angaben der untersuchten NAWM-Regionen der humanen Autopsie-Fälle

\begin{tabular}{|c|c|c|c|c|c|c|c|}
\hline Diagnose & Fall & Alter* & Geschl. & $\begin{array}{c}\text { KD } \\
\text { (Jahre) }\end{array}$ & Verlauf & Todesursache** & $\begin{array}{l}\text { NAWM in Großhirn } \\
\text { und Rückenmark }\end{array}$ \\
\hline \multirow[t]{13}{*}{ Ktr. } & K1 & 63 & $\mathrm{~m}$ & - & - & k. A. & frontal, zervikal, thorakal, lumbal \\
\hline & K2 & 70 & $\mathrm{~m}$ & - & - & kardiovaskulär & frontal, thorakal \\
\hline & K3 & 80 & w & - & - & kardiovaskulär & parietal, zervikal \\
\hline & K4 & 42 & $\mathrm{~m}$ & - & - & kardiovaskulär & frontal, parietal, zervikal \\
\hline & K5 & 54 & $w$ & - & - & kardiovaskulär & frontal, parietal \\
\hline & K6 & 45 & $\mathrm{~m}$ & - & - & kardiovaskulär & frontal $2 x$, zervikal \\
\hline & K7 & 81 & $\mathrm{~m}$ & - & - & Sepsis & frontal $2 x$, zervikal, thorakal, lumbal \\
\hline & K8 & 64 & w & - & - & kardiovaskulär & frontal, parietal, zervikal \\
\hline & K9 & 67 & $\mathrm{~m}$ & - & - & Sepsis & frontal $2 x$, zervikal, thorakal \\
\hline & K10 & 65 & w & - & - & kardiovaskulär & frontal, parietal, zervikal \\
\hline & K11 & 73 & $\mathrm{~m}$ & - & - & Sepsis & frontal, parietal, zervikal \\
\hline & K12 & 56 & $\mathrm{~m}$ & - & - & kardiovaskulär & frontal, parietal, zervikal \\
\hline & K13 & 54 & $\mathrm{~m}$ & - & - & kardiovaskulär & frontal, zervikal, thorakal \\
\hline \multirow[t]{12}{*}{ MS } & MS1 & 61 & $\mathrm{~m}$ & 6 & k. A. & k. A. & spinal \\
\hline & MS2 & 67 & $\mathrm{~m}$ & k. A. & k. A. & kardiovaskulär & zerebral \\
\hline & MS3 & 56 & $\mathrm{~m}$ & k. A. & PMS & kardiovaskulär & spinal \\
\hline & MS4 & 36 & w & k. A. & PPMS & kardiovaskulär & spinal \\
\hline & MS5 & 56 & $w$ & 9 & PMS & k. A. & zerebral \\
\hline & MS6 & 61 & $\mathrm{~m}$ & k. A. & k. A. & kardiovaskulär & lumbal \\
\hline & MS7 & 42 & $\mathrm{~m}$ & k. A. & k. A. & k. A. & parietal \\
\hline & MS8 & 39 & w & $>10$ & PMS & V. a. lleus & frontal \\
\hline & MS9 & 77 & $w$ & $>3$ & k. A. & kardiovaskulär & frontal \\
\hline & MS10 & 59 & $\mathrm{~m}$ & 36 & SPMS & k. A. & frontal, zervikal \\
\hline & MS11 & 66 & $\mathrm{~m}$ & 12 & PPMS & Ileus & parietal \\
\hline & MS12 & 41 & $\mathrm{~m}$ & $>10$ & k. A. & kardiovaskulär & frontal \\
\hline
\end{tabular}




\begin{tabular}{|c|c|c|c|c|c|c|c|}
\hline Diagnose & Fall & Alter* & Geschl. & $\begin{array}{c}\text { KD } \\
\text { (Jahre) }\end{array}$ & Verlauf & Todesursache** & $\begin{array}{l}\text { NAWM in Großhirn } \\
\text { und Rückenmark }\end{array}$ \\
\hline \multirow[t]{12}{*}{ MS } & MS13 & 47 & w & 25 & SPMS & k. A. & frontal, parietal \\
\hline & MS14 & 74 & w & $>10$ & PMS & Infektion & parietal \\
\hline & MS15 & 54 & $\mathrm{~m}$ & 11 & SPMS & Tumor & thorakal, lumbal \\
\hline & MS16 & 66 & $\mathrm{~m}$ & $>10$ & PMS & kardiovaskulär & frontal $2 x$, C5-6, Th2, Th4-5 \\
\hline & MS17 & 60 & w & 14 & PPMS & kardiovaskulär & frontal $2 x$, lumbal \\
\hline & MS18 & 76 & $\mathrm{~m}$ & 34 & SPMS & kardiovaskulär & zervikal \\
\hline & MS19 & 59 & w & 16 & SPMS & Sepsis & parietal \\
\hline & MS20 & 66 & $\mathrm{~m}$ & 34 & SPMS & Infektion & frontal \\
\hline & MS21 & 59 & $w$ & 5 & k. A. & Tumor & frontal, zervikal \\
\hline & MS22 & 57 & $\mathrm{~m}$ & 15 & PPMS & k. A. & frontal $2 x$ \\
\hline & MS23 & 51 & $\mathrm{~m}$ & 8 & PPMS & kardiovaskulär & $\mathrm{C} 2$ \\
\hline & MS24 & k. A. & $w$ & 17 & SPMS & Infektion & $\mathrm{C} 4$ und $\mathrm{C} 8$ \\
\hline \multirow[t]{5}{*}{ NMO } & NMO1 & 69 & w & 18 & - & $\begin{array}{l}\text { schwerer } \\
\text { NMO-Schub mit } \\
\text { Hirnstammläsion }\end{array}$ & C6 \\
\hline & NMO2 & 49 & w & 0,3 & - & k. A. & temporal, frontal, Th3 $2 x$ \\
\hline & NMO3 & 44 & w & 1,25 & - & kardiovaskulär & zervikal-thorakal \\
\hline & NMO4 & 77 & $w$ & 24 & - & kardiovaskulär & frontal, parietal, C1 \\
\hline & NMO5 & 72 & $\mathrm{~m}$ & 0,75 & - & $\begin{array}{l}\text { schwerer } \\
\text { NMO-Schub mit } \\
\text { Hirnstammläsion }\end{array}$ & zerebral $2 x$, zervikal \\
\hline
\end{tabular}

* Alter zum Zeitpunkt des Todes; Geschl. = Geschlecht; KD (Jahre) = Krankheitsdauer in Jahren; ** Todesursache wenn möglich in Kategorien eingeordnet (für genaue Todesursache siehe Anhang Tabelle 11); Ktr. = Kontrollen; $\mathbf{m}=$ männlich $\mathbf{w}=$ weiblich; $\mathbf{k} . \mathbf{A}$. = keine Angaben hierzu im Befund vorhanden; $\mathbf{C}=$ zervikales Rückenmark; Th = thorakales Rückenmark; $\mathbf{L}$ = lumbales Rückenmark

\section{Gesunde altersentsprechende Kontrollen}

Als gesunde altersentsprechende Kontrollen wurden Patienten definiert, die nicht an neurologischen Erkrankungen litten oder verstorben waren. Das mittlere Alter zum Zeitpunkt des Todes ähnelt dem der MS- und NMO-Patienten. Die Patienten verstarben entweder an kardiovaskulären Ereignissen oder einer Sepsis im Alter von 42-81 Jahren (mittleres Alter: 62,62 \pm 12,10 Jahre) (siehe Tabelle 3 und Anhang Tabelle 12, Teil 1). Das Autopsiegewebe wurde, ebenso wie das Gewebe von MS- und NMO-Patienten, im Vorfeld histologisch überprüft um pathologische Veränderungen auszuschließen.

\section{Patienten mit Multipler Sklerose}

Das Autopsiegewebe der Patienten mit MS wurde primär nach dem Vorhandensein von NAWM ausgewählt. Bei der Auswahl dieser NAWM-Areale wurde darauf geachtet, ausreichend Abstand zu demyelinisierten Bereichen (MS-Läsionen), aber auch zur 
PPWM einzuhalten war. Wie oben beschrieben erfolgte die Beurteilung der NAWM histologisch. In erster Linie wurden hierzu LFB/PAS-Färbungen gesichtet. Zum Ausschluss morphologischer Veränderungen und entzündlicher Infiltrate wurden zusätzlich HE-Färbungen herangezogen. Die klinischen Befunde wurden ebenfalls durchgesehen, um Sonderformen der MS auszuschließen. Die Patienten wiesen, soweit im Befund angegeben, entweder einen primär oder sekundär progredienten Verlauf auf. Zum Zeitpunkt des Todes waren die Patienten 36-77 Jahre alt (mittleres Alter: $57,83 \pm 11,33$ Jahre). Die dokumentierte Erkrankungsdauer reichte von über drei bis hin zu 41 Jahren, bei sechs von 24 Patienten lagen hierzu jedoch keine Angaben vor. Unter den ausgewählten Fällen befanden sich zehn Frauen und 14 Männer. Alle bekannten klinischen Daten sind in Tabelle 3 zusammengefasst (siehe auch Tabelle 12, Teil $2 \mathrm{im}$ Anhang).

\section{Patienten mit Neuromyelitis optica}

Die Auswahl des Autopsiegewebes der Patienten mit NMO erfolgte analog zum beschriebenen Auswahlverfahren für MS, mit dem Unterschied, dass zusätzlich AQP4und GFAP-Färbungen hinzugezogen wurden, um einen GFAP- und AQP4-Erhalt in der NAWM bei NMO sicherzustellen. Das Alter zum Zeitpunkt des Todes betrug 4477 Jahre (mittleres Alter: 62,20 \pm 14,72 Jahre). Die vorliegende, dokumentierte Erkrankungsdauer lag zwischen vier Monaten und 24 Jahren. Unter den ausgewählten Fällen befanden sich vier Frauen und ein Mann. Alle bekannten klinischen Daten sind in Tabelle 3 zusammengefasst (siehe auch Tabelle 12, Teil 3 im Anhang).

\subsubsection{Mäuse mit chronischer EAE}

Zusätzlich wurden Veränderungen in der NAWM des Rückenmarks bei Mäusen mit chronischer experimenteller autoimmuner Enzephalomyelitis (EAE) charakterisiert und der Zusammenhang zwischen dem Ausmaß der spinalen Demyelinisierung und den Veränderungen der NAWM untersucht.

\section{Versuchstiere und Versuchsaufbau}

Für die vorliegende Studie wurde Gewebe von insgesamt 19 Versuchstieren untersucht: 14 Mäuse mit induzierter chronischer EAE und fünf gesunde Mäuse als Kontrollgruppe. Das Gewebe wurde aus dem Mausarchiv des Instituts für Neuropathologie der 
Universitätsmedizin Göttingen (UMG) ausgewählt, wobei die Tierversuche entsprechend den jeweiligen Tierversuchsgenehmigungen durchgeführt worden waren.

\section{Induktion der EAE}

Zur aktiven Induktion der EAE waren zehn bis elf Wochen alte weibliche C57Bl/6JMäuse mit dem enzephalitogenen Peptid Myelin-Oligodendrozyten-GlykoproteinAminosäuren 35-55 $\left(\mathrm{MOG}_{35-55}\right)$ in CFA (complete Freund's adjuvant, komplettes Freundsches-Adjuvans) immunisiert worden.

Pro Maus wurden $200 \mu \mathrm{l}_{\mathrm{MOG}_{35-55} / \mathrm{CFA}-E m u l s i o n}$ in vier Depots à $50 \mu 1$ an den Extremitäten subkutan injiziert, was einer Gesamtdosis von $200 \mu \mathrm{g}$ MOG $35-55$ entspricht. Am Tag der Immunisierung und 48 h p. i. (post injectionem, nach Injektion) wurden jeder Maus jeweils 400 ng Pertussis-Toxin (PTx) in $200 \mu 1$ PBS intraperitoneal appliziert. Die Mäuse der Kontrollgruppe erhielten keinerlei Behandlung.

\section{Gewebegewinnung: Perfusion und Präparation der Mäuse}

Am Tag 60 p. i. wurden die Mäuse mit $200 \mu 1$ 14\%igem Chloralhydrat intraperitoneal anästhesiert. Nachdem der Schmerz- und Blinkreflex erloschen war, wurde der Brustkorb eröffnet. Das Herz-Kreislaufsystem wurde daraufhin so lange mittels einer transkardialen Injektion von 1x PBS perfundiert, bis das Blut vollständig ausgespült war. Anschließend wurde das Gewebe mit 4\%igem Paraformaldehyd (PFA; pH 7,4) transkardial fixiert. Nach der Perfusion wurde die Wirbelsäule frei präpariert und zur Nachfixierung für zwei Tage in $4 \%$ igem PFA bei $4{ }^{\circ} \mathrm{C}$ gelagert. Dann wurde das Rückenmark vorsichtig in ganzer Länge aus seiner knöchernen Hülle heraus präpariert und in ein bis zwei Millimeter dicke Scheiben geschnitten. Anschließend wurden die Präparate durch einen vollautomatischen Einbettautomaten eingebettet.

\section{Einteilung der Versuchsgruppen}

Um zu untersuchen, wie das Ausmaß der spinalen Demyelinisierung Veränderungen in der NAWM bei Mäusen mit chronischer EAE beeinflusst, wurde die an EAE erkrankten Tiere in zwei Untergruppen eingeteilt. Die Zuteilung erfolgte nach der spinalen Läsionslast (Anteil der histologisch quantifizierten Demyelinisierung im Rückenmark) (siehe Kapitel 2.3.2.1). Die erste Untergruppe bestand aus Mäusen mit geringer Läsionslast ( $<5 \%$ der weißen Substanz entmarkt). Die zweite Untergruppe wurde von Mäusen gebildet, die eine hohe Läsionslast (10-15\% der weißen Substanz entmarkt) 
aufwiesen. Selbst beim Maximum von 15\% Demyelinisierung war noch ausreichend Fläche normal erscheinender weißer Substanz (NAWM) zur Auswertung vorhanden.

\subsection{Histopathologische Methoden}

\subsubsection{Anfertigen der histologischen Präparate}

Zur Herstellung der immunhistochemischen und histologischen Färbungen wurden vorab alle ausgesuchten Paraffinblöcke mit Hilfe eines Mikrotoms in $1 \mu \mathrm{m}$ dünne Scheiben geschnitten, auf Objektträger aufgezogen und über Nacht bei $37^{\circ} \mathrm{C} \mathrm{im}$ Wärmeschrank getrocknet. Anschließend wurden die Präparate entparaffiniert. Dazu wurden sie zunächst für $30 \mathrm{~min}$ bei $58^{\circ} \mathrm{C}$ im Wärmeschrank abgeschmolzen. Wenn nicht anders angegeben, wurden die Schnitte dann unter dem Abzug jeweils viermal für 10 min in Xylol geklärt und in einer absteigenden Alkoholreihe rehydriert, indem die Objektträger für $5 \mathrm{~min}$ in Isoxylol getaucht, dann zweimal für $5 \mathrm{~min}$ in 100\%iges Isopropanol und danach jeweils für 5 min in 90\%iges, 70\%iges und 50\%iges Isopropanol gestellt wurden. Zum Abschluss der Rehydrierung wurden die Objektträger mit Aqua dest. gespült.

Zur Konservierung der gefärbten Schnitte wurden die Präparate nach der Färbung wieder dehydriert. Um ein zu starkes Auswaschen des verwendeten Farbstoffes zu vermeiden, wurden die Objektträger jeweils nur kurz in die aufsteigende Alkoholreihe gestellt (50\%iges, 70\%iges, 90\%iges und zweimal in 100\%iges Isopropanol). Dann wurden sie je 2 min in Isoxylol getaucht, in Xylol geklärt und abschließend mit DePeX eingedeckt.

\subsubsection{Hämatoxylin-Eosin (HE)-Färbung}

Die HE-Färbung ist eine Routine-Übersichtsfärbung, die in der vorliegenden Arbeit zur Auswahl der ZNS-Gewebeblöcke mit NAWM genutzt wurde. Hämalaun färbt basophile Strukturen wie Chromatin und Ribosomen blau, wodurch insbesondere Zellkerne dargestellt werden. Eosin dagegen färbt azidophile Strukturen wie Zytoplasmaproteine und Kollagene rosa, wodurch insbesondere zytoplasmatische Bestandteile dargestellt werden. 
Nach der abgeschlossenen Entparaffinierung und Rehydrierung in einer absteigenden Alkoholreihe (siehe Kapitel 2.2.1) wurden die Schnitte in Aqua dest. gespült, zur Kernfärbung für 8 min in Mayers Hämalaun-Lösung inkubiert und anschließend erneut mit Aqua dest. abgespült. Daraufhin erfolgten die Differenzierung mit 1\%iger HClAlkohol-Lösung und das Bläuen unter fließendem Leitungswasser für 10 min. Für die Gegenfärbung wurden die Schnitte für 6 min in eine 1\%ige wässrige Eosin-Lösung gestellt. Abschließend wurden die Schnitte in Aqua dest. gespült und, wie oben beschrieben, prozessiert.

\subsubsection{LFB/PAS-Färbung (Luxol-Fast-Blue/Periodic acid Schiff reaction)}

Die LFB/PAS-Färbung ist eine Myelin-Färbung, die hier zum Ausschluss einer Demyelinisierung der ausgewählten ZNS-Gewebeblöcke genutzt wurde. Luxol-fastBlue (LFB) färbt Myelin türkisblau und Zellkerne tiefblau. Das Perjodsäure-Schiff'sche Reagenz (PAS, Periodic acid Schiff reaction) stellt durch das Anfärben von Polysacchariden das Parenchym und auch demyelinisierte Bereiche rosafarben dar.

Die zu färbenden Schnitte wurden in Xylol entparaffiniert und anschließend in einer absteigenden Alkoholreihe (siehe Kapitel 2.2.1) bis zum 90\%igen Isopropanol rehydriert. Dann wurden die Schnitte über Nacht bei $60{ }^{\circ} \mathrm{C}$ in einer zuvor hergestellten LFB-Lösung inkubiert. Am nächsten Tag wurden die Schnitte erneut für wenige Minuten in 90\%iges Isopropanol eingetaucht. Für die anschließende Differenzierung mussten die Schnitte in eine gebrauchsfertige 0,05\%ige Lithiumcarbonat-Lösung gestellt und danach kurz in 70\%iges Isopropanol getaucht werden. Abschließend wurde so lange mit Aqua dest. gespült, bis die überschüssige Färbelösung abgewaschen und nur noch das Myelin blau gefärbt war.

Für die nachfolgende PAS-Färbung wurden die Schnitte zunächst für 5 min in 1\%ige Perjodsäure (in Aqua bidest.) gestellt, dann 5 min mit fließendem Leitungswasser und gründlich mit Aqua dest. gespült. Nach erfolgter Inkubation für 20 min im Schiff'schen Reagenz und einer erneuten Spülung mit fließendem Leitungswasser für 5 min stellte sich das Parenchym rosa dar.

Im nächsten Arbeitsschritt wurde eine Gegenfärbung der Zellkerne mit Mayers Hämalaun für 3 min durchgeführt. Es folgte eine Spülung mit Aqua dest., dann die 
Differenzierung durch kurzes Eintauchen in 1\%igen HCl-Alkohol und das Bläuen für 10 min unter fließendem Leitungswasser. Abschließend wurden die Schnitte durch eine aufsteigende Alkoholreihe dehydriert (siehe Kapitel 2.2.1), in Isoxylol getaucht, mit Xylol geklärt und schließlich mit DePeX eingedeckt.

\subsubsection{Modifizierte Bielschowsky-Silberimprägnation}

Die Bielschowsky-Silberimprägnation wird zur Darstellung von Dendriten, Neurofibrillen und Axonen genutzt und erlaubte somit in der vorliegenden Arbeit die Beurteilung der Axondichte in der NAWM. Die genannten neuronalen Bestandteile stellen sich durch das Ausfällen von Silberoxid schwarz dar, das restliche Gewebe erscheint gelbbraun bis braun.

Zunächst wurde vorab der Entwickler aus Formalin, Aqua bidest., Zitronensäure und einem Tropfen konzentrierter Salpetersäure (65\%) hergestellt. Die zu färbenden Schnitte wurden nach dem bereits beschriebenen Vorgehen entparaffiniert und bis Aqua dest. rehydriert (siehe Kapitel 2.2.1). Darauf folgte eine Inkubation von 20 min in einer $20 \%$ igen Silbernitrat-Lösung ( $15 \mathrm{~g} \mathrm{AgNO}_{3} / 75 \mathrm{ml}$ Aqua dest.) mit anschließender Spülung in Aqua bidest. Zu der 20\%igen Silbernitrat-Lösung wurde, unter ständigem Rühren, tropfenweise eine gebrauchsfertige 32\%ige Ammoniaklösung zugeben, bis sich der anfänglich entstandene Niederschlag auflöste. Zwei weitere Tropfen Ammoniak wurden zugefügt und die Schnitte in dieser Silbernitrat-Ammoniak-Lösung für $15 \mathrm{~min}$ im Dunkeln inkubiert. Anschließend wurden die Schnitte in mit drei Tropfen Ammoniak versetztem Aqua bidest. gespült. Der Silbernitrat-Ammoniak-Lösung wurden zehn Tropfen des vorbereiteten Entwicklers zugefügt und die Schnitte darin 35 min entwickelt, bis die Axone unter mikroskopischer Kontrolle schwarz und der Hintergrund braun waren. Nach erneutem Spülen in Aqua bidest. erfolgte die Fixierung durch Inkubation der Schnitte für 2 min in einer 2\%igen Natrium-Thiosulfat-Lösung. Zum Schluss wurden die Schnitte in Aqua dest. gespült, in einer aufsteigenden Alkoholreihe dehydriert, dann in Isoxylol gestellt, danach in reinem Xylol geklärt und mit DePeX eingedeckt (siehe Kapitel 2.2.1). 


\subsubsection{Immunhistochemie (Avidin-Biotin-Methode)}

Die Immunhistochemie wird zur gezielten Identifizierung bestimmter Zell- und Gewebestrukturen mittels der Antigen-Antikörper-Reaktion genutzt. Hier kam die indirekte Avidin-Biotin-Methode (labelled avidin biotin technique, LAB) zur Anwendung. In Abbildung 1 ist schematisch der Ablauf der LAB-Methode dargestellt:

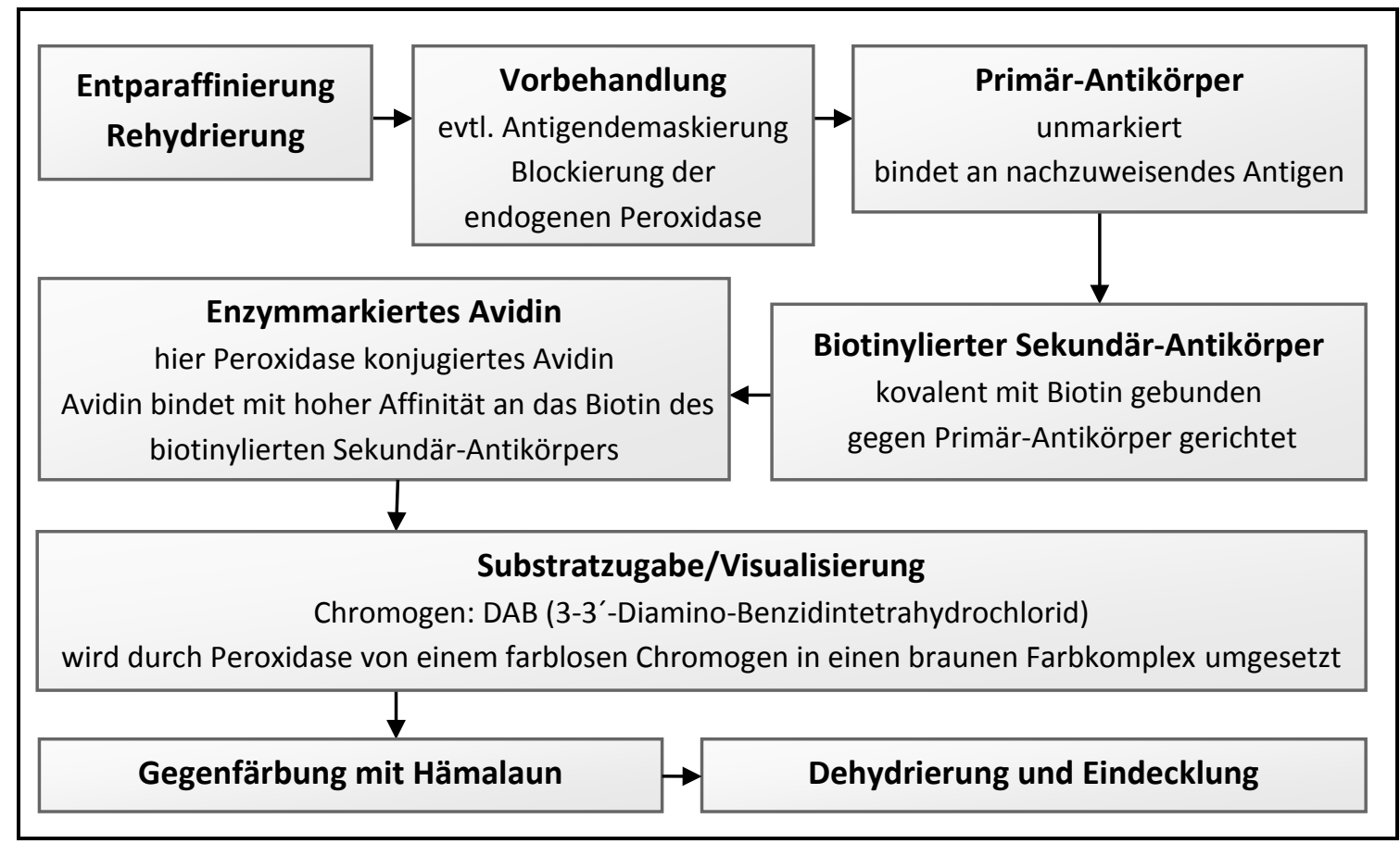

Abbildung 1: Schematischer Ablauf der indirekten immunhistochemischen Avidin-Biotin-Methode (LAB)

\section{Durchführung}

Die zu behandelnden Schnitte wurden nach dem bereits genannten Vorgehen entparaffiniert und rehydriert (siehe Kapitel 2.2.1). Bei einigen Antikörpern wurde eine Vorbehandlung zur Verbesserung der Antigendetektion durchgeführt, Antigendemaskierung genannt. Diese war notwendig, da die Formalinfixierung des Gewebes Proteinvernetzungen verursacht, welche die Antigene maskieren. Ohne Vorbehandlung wäre daher die Erkennung der Epitope durch den primären Antikörper erschwert. Je nach Antikörper erfolgte eine hitzeinduzierte Antigendemaskierung mit Citratpuffer (pH 6) oder TRIS/EDTA (pH 9) (siehe Tabelle 4). Dazu wurden die Schnitte jeweils mit dem entsprechenden Puffer fünfmal für je $3 \mathrm{~min}$ in einer Plastikküvette unter Verwendung einer handelsüblichen Mikrowelle bei einer maximalen Leistung von 800 Watt gekocht. Verdunstete Flüssigkeit wurde zwischen den Kochschritten abwechselnd mit Puffer oder Aqua bidest. aufgefüllt. Danach wurden die Schnitte 
30 min zum Abkühlen stehen gelassen, anschließend dreimal mit Aqua dest. gespült und dann in PBS gestellt. Bei dem Antikörper gegen GFAP (saures Gliafaserprotein) war eine Antigendemaskierung nicht nötig, so dass die Schnitte direkt in PBS gestellt werden konnten.

Anschließend wurde die Aktivität der endogenen Peroxidase blockiert, um bei der Entwicklung eine Umsetzung des Chromogens durch das endogene Enzym auszuschließen und eine unspezifische Hintergrundfärbung der Präparate zu vermeiden. Dazu wurden die Schnitte $20 \mathrm{~min}$ in einer 3\%igen Wasserstoffperoxid/PBS-Lösung bei $4{ }^{\circ} \mathrm{C}$ im Kühlschrank inkubiert und anschließend dreimal mit PBS gespült.

Im Anschluss wurden unspezifische Antikörper-Bindungsstellen mit $100 \mu 1$ einer 10\%igen FCS/PBS-Lösung (FCS, fetal calf serum oder fetales Kälberserum) in einer feuchten Kammer 20 min blockiert.

Nachdem die FCS/PBS-Lösung dekantiert und die Objektträger weitgehend trocken getupft worden waren, wurden je $100 \mu 1$ der Lösung mit dem primären Antikörper auf die Schnitte gegeben und diese mit Deckgläsern abgedeckt. Dafür wurde der primäre Antikörper zuvor auf die jeweilige optimale Konzentration in 10\%iger FCS/PBS-Lösung verdünnt (Konzentration der jeweiligen Antikörper siehe Tabelle 4). Darauf folgte eine Inkubation in der feuchten Kammer über Nacht bei $4{ }^{\circ} \mathrm{C}$ im Kühlschrank.

Am Folgetag wurden die Deckgläser entfernt, die Schnitte dann dreimal mit PBS gespült. Anschließend wurde die Lösung mit dem sekundären biotinylierten Antikörper auf die Schnitte gegeben. Dieser wurde ebenfalls zuvor auf die jeweilige optimale Konzentration in 10\%iger FCS/PBS-Lösung verdünnt (siehe Tabelle 5 für die Konzentration der Sekundärantikörper). Es folgte eine einstündige Inkubation bei Raumtemperatur in der feuchten Kammer.

Die Schnitte wurden erneut gut gespült. Nun erfolgte die einstündige Inkubation bei Raumtemperatur mit Avidin-konjugierter Peroxidase. Dazu wurden die Schnitte mit $100 \mu 1$ Avidin-konjugierter Peroxidase pro Objektträger (ExtrAvidin ${ }^{\circledR}$ auf 1:1000 in 10\% FCS verdünnt) beschichtet. Dabei bindet das Avidin mit sehr hoher Affinität an das Biotin des sekundären Antikörpers. Die für die Farbentwicklung wichtige Peroxidase befindet sich dadurch nahezu ausschließlich am Ort des Antigens.

Nun schloss sich die Visualisierung der Antigen-Antikörper-Reaktion an. Hierzu wurde das Chromogen DAB (3-3'-Diamino-Benzidintetrahydrochlorid) verwendet. Das 
farblose DAB wird von der gebundenen Peroxidase - mit Hilfe von $\mathrm{H}_{2} \mathrm{O}_{2}$ als Substrat oxidiert. Es entsteht ein unlöslicher brauner Niederschlag, der lichtmikroskopisch sichtbare Farbkomplex. Die Schnitte wurden erneut mit PBS gespült und in einer Küvette mit DAB-Lösung entwickelt. Die Entwicklungsdauer wurde unter mikroskopischer Kontrolle individuell festgelegt und somit die Farbintensität gesteuert. Ein mehrfaches Spülen mit PBS unterbrach dann die weitere Reaktionsentwicklung.

Einzelne ausgewählte Schnitte wurden zur besseren Darstellung durch die APAAPMethode (Alkalische-Phosphatase-Anti-Alkalische-Phosphatase) entsprechend eines Standardprotokolls mit Fast Red gefärbt, wobei als Sekundärantikörper der Antikörper „polyclonal Rabbit Anti-Mouse“ (Z0259) der Firma DAKO in der Verdünnung 1:50 eingesetzt wurde.

Abschließend wurden die Schnitte wie oben beschrieben mit Hämalaun gegengefärbt, dehydriert und mit DePeX eingedeckt (s.o.).

Tabelle 4: Verwendete Primär-Antikörper

\begin{tabular}{|c|c|c|c|c|c|c|}
\hline Marker für & Antigen & Zielgewebe & Spezies* & Klonalität & Verdünnung & Hersteller \\
\hline \multirow{2}{*}{ T-Lymphozyten } & CD3 (CD3-12) & human & Ratte & $\mathrm{mk}$ & $1: 50^{1)}$ & Serotec \\
\hline & CD3 (SP7) & Maus & Kaninchen & $\mathrm{mk}$ & $1: 150^{1)}$ & DCS \\
\hline \multirow{2}{*}{$\begin{array}{l}\text { Astrozyten/saures } \\
\text { Gliafaserprotein }\end{array}$} & GFAP (6F2) & human & Maus & mk & $1: 50^{2)}$ & Dako \\
\hline & GFAP (Z0334) & Maus & Kaninchen & pk & $1: 1000^{2)}$ & Dako \\
\hline $\begin{array}{l}\text { Amyloid-Vorläufer- } \\
\text { Protein/ akuter } \\
\text { axonaler Schaden }\end{array}$ & APP $(22 C 11)$ & $\begin{array}{l}\text { human/ } \\
\text { Maus }\end{array}$ & Maus & $\mathrm{mk}$ & $1: 2000^{1)}$ & Chemicon \\
\hline \multirow{2}{*}{$\begin{array}{l}\text { Mikroglia und } \\
\text { Makrophagen }\end{array}$} & KiM1P & human & Maus & $\mathrm{mk}$ & $1: 5000^{1)}$ & $\begin{array}{l}\text { Prof. Radzun, } \\
\text { Göttingen }\end{array}$ \\
\hline & MAC3(M3/84) & Maus & Ratte & $\mathrm{mk}$ & $1: 200^{1)}$ & Pharmingen \\
\hline Oligodendrozyten & $\begin{array}{l}\text { TPPP/p25 ** } \\
\text { (EPR3316) }\end{array}$ & $\begin{array}{l}\text { human/ } \\
\text { Maus }\end{array}$ & Kaninchen & $\mathrm{mk}$ & $1: 250^{3)}$ & Abcam \\
\hline $\begin{array}{l}\text { Neurofilament, } \\
\text { dephosphoryliert }\end{array}$ & SMI32 & $\begin{array}{l}\text { human/ } \\
\text { Maus }\end{array}$ & Maus & $\mathrm{mk}$ & $1: 500^{1)}$ & SMI \\
\hline Aquaporin-4 & AQP4 (A5971) & human & Kaninchen & pk & $1: 200^{1)}$ & Sigma \\
\hline
\end{tabular}

* Herkunftsspezies; mk= monoklonal; pk= polyklonal; 1) Vorbehandlung: Citratpuffer pH6: $5 x$ min in der Mikrowelle; 2) ohne Vorbehandlung; 3) TRIS/EDTA pH9: 5x 3min in der Mikrowelle; ** statt FCS wurde hier in allen Schritten goat serum verwendet! Hersteller: AbcamPLC, Cambridge, UK; Serotec Ltd., Kidlington, Oxford, UK; BD Biosciences - Pharmingen; Chemicon International, Temecula, CA, USA; Dako, Glostrup, Dänemark; DCS: Innovative Diagnostik-Systeme, Hamburg, Germany; Prof. Dr. H. Radzun, Universitätsmedizin Göttingen; Serotec Ltd., Kidlington, Oxford, UK; Sigma-Aldrich Chemie GmbH, Steinheim, Germany; SMI: Sternberger Monoclonals Inc., Lutherville, MD, USA 
Tabelle 5: Verwendete biotinylierte Sekundär-Antikörper

\begin{tabular}{lll}
\hline Antigen & Verdünnung & Hersteller \\
\hline \hline Schaf-anti-Maus & $1: 200$ & Amersham (RPN 1001) \\
\hline Ziege-anti-Kaninchen & $1: 500$ & Dianova (111-065-144) \\
\hline Ziege-anti-Ratte & $1: 200$ & Amersham (RPN 1005) \\
\hline
\end{tabular}

Amersham Pharmacia Biotech Europe GmbH, Freiburg, Germany; Dianova GmbH, Hamburg, Germany

\subsection{Histologische Auswertung}

Die histologische Auswertung erfolgte an einem Lichtmikroskop (BX-41, Olympus, Japan) unter Zuhilfenahme eines Gitterokulars mit standardisierten Gesichtsfeldern (10fache Vergrößerung, Zellzählgitter und Axonzählgitter, WH10X-H/22 Olympus, Japan). Die Eigenvergrößerung des Okulars wird bei folgenden Angaben mit der Vergrößerung der verwendeten Objektive (mit 4facher, 20facher, 40facher oder 100facher Vergrößerung) verrechnet und als Gesamtvergrößerung aufgeführt.

Bei jeder Färbung wurde im Vorfeld eine Probezählung durchgeführt, um die Anzahl der nötigen Gesichtsfelder und die geeignete Vergrößerung zu ermitteln und aussagekräftige Daten erheben zu können. Aus den ermittelten Einzelwerten pro Gesichtsfeld wurde anschließend der Mittelwert für jeden Gewebeblock eines Falles gebildet und unter Berücksichtigung der Vergrößerung in Zellen pro Quadratmillimeter umgerechnet.

Standen mehrere spinale oder zerebrale Gewebeblöcke pro Fall zur Verfügung, dann wurde der Mittelwert aus den Daten aller spinalen oder zerebralen Gewebeblöcke eines Autopsiefalls gebildet. In dieser Weise wurde bei allen nachfolgenden Auswertungen verfahren.

Zur Aufbereitung der erhobenen Daten wurde das Tabellenkalkulationsprogramm „Microsoft Office Excel ${ }^{\circledR} 2007$ “ genutzt (Microsoft Deutschland GmbH, Unterschleißheim).

Die digitale Fotodokumentation erfolgte mittels einer an das Mikroskop angeschlossenen 12,5 Megapixel-Kamera (Typ DP/71) und der zugehörigen Bildanalysesoftware „cellSense ${ }^{\mathbb{B} \text { “ }}$ (Olympus Soft Imaging Solutions GmbH). 


\subsubsection{Auswertung von Veränderungen in der NAWM bei humanen Autopsiefällen}

\subsubsection{Auswahl der NAWM anhand histologischer Färbungen}

Die Auswahl der NAWM wurde sowohl bei den Kontrollen, als auch bei MS und NMO primär anhand der Myelin-Färbung mit LFB/PAS getroffen. Demyelinisierte Bereiche erscheinen in dieser Färbung aufgrund der reduzierten Myelin-Färbung rosa. Gewebeblöcke mit erkennbaren demyelinisierten Bereichen wurden entweder gänzlich verworfen oder die Auswertung auf geeignete Areale begrenzt. Bei der Auswahl dieser NAWM-Areale wurde darauf geachtet, genügend Abstand $\mathrm{zu}$ demyelinisierten Bereichen (MS-/NMO-Läsionen), aber auch zur PPWM einzuhalten. Zum Ausschluss morphologischer Veränderungen und entzündlicher Infiltrate wurde auch die RoutineÜbersichtsfärbung mit Hämatoxylin-Eosin (HE) gesichtet.

Da NMO-Läsionen histologisch typischerweise durch das Fehlen von Aquaporin 4 (AQP4) und saurem Gliafaserprotein (glial fibrillary acidic protein, GFAP) gekennzeichnet sind, wurden zur Beurteilung des Gewebes von NMO-Fällen zusätzlich immunhistochemische AQP4- und GFAP-Färbungen hinzugezogen.

Die gesunden altersentsprechenden Kontrollen wurden ebenfalls mit Hilfe der LFB/PAS- und HE-Färbungen nach möglichen pathologischen Veränderungen überprüft.

\subsubsection{2 $\mathrm{CD3}^{+}$-T-Lymphozyten als Entzündungsparameter}

CD3 wird von allen T-Lymphozyten-Populationen exprimiert und gilt daher als Pan-TLymphozyten-Marker.

Um die T-Lymphozytendichte zu bestimmen und somit den Entzündungsgrad innerhalb der ausgewählten Fallgruppen beurteilen zu können, wurden die T-Lymphozyten immunhistochemisch anhand ihres CD3-Antigens braun gefärbt. Gezählt wurden positive Zellen, welche um einen rundlichen Zellkern herum einen schmalen braunen Zytoplasma-Saum aufwiesen. Die Auszählung der CD3 ${ }^{+}$-T-Lymphozyten erfolgte in 30 Gesichtsfeldern unter 200facher Vergrößerung. Die parenchymale Zelldichte wurde in $\mathrm{CD}^{+}$-Zellen pro $\mathrm{mm}^{2}$ angegeben.

Des Weiteren wurde neben der quantitativen Auszählung immunpositiver TLymphozyten im Parenchym auch ein semi-quantitativer Score angewandt. Dieser 
Score diente dazu, die Infiltration der $\mathrm{CD}^{+}{ }^{+}$-Zellen im Virchow-Robin-Raum (VRR) der NAWM, bzw. WM bei gesunden Kontrollen, zu beurteilen (siehe Tabelle 6). Der VRR ist der perivaskuläre Raum entlang der Gefäße im ZNS und Teil des Subarachnoidalraumes, welcher sich bis in den präkapillären Bereich fortsetzt. Dabei wurde die gesamte NAWM eines Gewebeblocks betrachtet und dann der durchschnittliche Gesamtscore bei lokal unterschiedlich ausgeprägter T-Lymphozyteninfiltration des VRR gemittelt.

Tabelle 6: Semi-quantitativer Score zur T-Lymphozyteninfiltration (CD3 ${ }^{+}$-Zellen) des Virchow-Robin-Raumes der NAWM/WM

\begin{tabular}{ll}
\hline Score & $\begin{array}{l}\text { Infiltration CD3 } \\
\text { des Virchow-Robin-Raumes }\end{array}$ \\
\hline \hline $\mathbf{0}$ & keine \\
\hline $\mathbf{1}$ & vereinzelt (1-2 Zellen) \\
\hline $\mathbf{2}$ & einige (>2 Zellen) \\
\hline $\mathbf{3}$ & einlagiger Saum \\
\hline $\mathbf{4}$ & mehrlagiger Saum $(\geq 2)$ \\
\hline
\end{tabular}

\subsubsection{Mikrogliaktivierung $\left(\mathrm{KiM1P}^{+}\right.$-Zellen $)$als Entzündungsparameter}

KiM1P gilt als Pan-Makrophagen-Marker (Bitsch et al. 1998). Der KiM1P-Antikörper detektiert im ZNS Mikroglia und Makrophagen. Diese Zellpopulationen lassen sich morphologisch gut voneinander unterscheiden, da Makrophagen sich aufgrund ihres schaumzelligen Zytoplasmas und ihrer Vakuolen „granulär“ anfärben.

Die Zellkerne der Mikroglia sind stäbchenförmig. Es wird zwischen einer ruhenden, physiologischen Form und einer, auf pathologische Reize reagierenden, (re-)aktiven Form der Mikroglia differenziert (Radzun et al. 1991). Aktivierte Mikroglia zeigen eine veränderte Morphologie und sind amöboid beweglich. Statt langer, dünn verzweigter Zytoplasmaausläufer der ruhenden Mikroglia (Paulus et al. 1992) sind bei aktivierten Mikroglia stark verkürzte und verdickte Zellfortsätze $\mathrm{zu}$ beobachten (Howell et al. 2010). Es können auch Mikrogliaknötchen auftreten (Howell et al. 2010).

Um den Grad der Mikrogliaktivierung als Entzündungsmarker zu quantifizieren, wurde hier die Mikrogliadichte bestimmt. Dazu wurde ein semi-quantitativer Score (siehe Tabelle 7) in Anlehnung an einen in der Literatur bereits verwendeten Score entwickelt (Seewann et al. 2009). Zunächst wurden alle gesunden Kontrollen betrachtet um das 
Spektrum der physiologischen Mikrogliadichte zu ermitteln. Hieraus wurde dann ein Referenz-Gewebeblock mit einer geringen, repräsentativen Mikrogliadichte ausgewählt und einem Score-Wert von 0 gleichgesetzt. Anschließend wurde jeder Gewebeblock mit dieser physiologischen Mikrogliadichte verglichen und der Score ermittelt. Dabei wurde die gesamte NAWM eines Gewebeblocks betrachtet und der Score bei lokal unterschiedlich ausgeprägter Dichte gemittelt. Ausgewertet wurde in der 200fachen Vergrößerung.

Tabelle 7: Semi-quantitativer Score zur Bestimmung der Dichte aktivierter Mikroglia (KiM1P ${ }^{+}$-Zellen) in der NAWM/WM

\begin{tabular}{ll}
\hline Score & Mikrogliaaktivierung \\
\hline $\mathbf{0}$ & normal (^ nicht erhöht) \\
\hline $\mathbf{1}$ & mäßig erhöht \\
\hline $\mathbf{2}$ & stark erhöht \\
\hline
\end{tabular}

Zusätzlich zur Mikrogliadichte wurde das Vorhandensein von Mikrogliaknötchen (MGK) untersucht. Dieser Score bewertet nur, ob Mikrogliaknötchen nachweisbar sind oder nicht (siehe Tabelle 8). Größe und Anzahl der MGK wurden nicht quantifiziert. Nach vorläufiger Durchsicht aller Autopsiefälle wurde eine Definition für Mikrogliaknötchen aufgestellt. Nach dieser Definition bestand ein Mikrogliaknötchen aus mindestens fünf MGK-assoziierten $\mathrm{KiM}^{+} \mathrm{P}^{+}$-Zellen, diese sollten zudem zusammen gelagert erscheinen und nicht perivaskulär lokalisiert sein Je nach Vorhandensein oder Fehlen von MGK wurden die Autopsiefälle Fälle mit oder ohne MGK eingeteilt. Für die graphische Darstellung und Auswertung wurde der prozentuale Anteil aller Autopsiefälle mit nachweisbaren MGK in der NAWM angegeben.

Tabelle 8: Abschließender Score zum Vorhandensein oder Fehlen von Mikrogliaknötchen in der NAWM/WM

\begin{tabular}{ll}
\hline Score & Mikrogliaknötchen (MGK) \\
\hline $\mathbf{0}$ & nicht nachweisbar \\
\hline $\mathbf{1}$ & vorhanden \\
\hline
\end{tabular}




\subsubsection{4 $\mathrm{APP}^{+}$-Axone als Zeichen der akuten axonalen Schädigung}

Das Amyloid-Vorläufer-Protein (APP, amyloid percursor protein) ist ein sensitiver Marker für Störungen des axonalen Transportes bei akuter axonaler Schädigung (Koo et al. 1990; Sherriff et al. 1994a; Sherriff et al. 1994b; Ferguson et al. 1997; Yam et al. 1997; Kornek et al. 2000). In gesunden Axonen ist die APP-Konzentration sehr gering und im Formalin-fixierten Gewebe mit herkömmlichen immunhistochemischen Methoden in der Regel nicht detektierbar (Ferguson et al. 1997). Bei axonaler Schädigung hingegen kommt es zur immunhistochemisch nachweisbaren Akkumulation von APP und schließlich zur spezifischen Sphäroidbildung (Sherriff et al. 1994a; Ferguson et al. 1997). Zur Darstellung kommen aufgetriebene, akut geschädigte Axone. Gezählt wurden homogen gefärbte und scharf begrenzte $\mathrm{APP}^{+}$-Axone mit einem Mindestdurchmesser eines Nukleolus. Die Auszählung erfolgte in 30 Gesichtsfeldern bei 400 facher Vergrößerung. Die Dichte der $\mathrm{APP}^{+}$-Axone wurde dann pro $\mathrm{mm}^{2}$ angegeben.

\subsubsection{SMI32 ${ }^{+}$-geschädigte Axone}

Der Antikörper gegen SMI32 detektiert dephosphorylierte Epitope des Neurofilaments H (Sternberger und Sternberger 1983; Schirmer et al. 2013). Physiologisch treten dephosphorylierte Neurofilamente häufig sowohl in neuronalen Zellkörpern als auch in Dendriten auf. In gesunden myelinisierten Axonen sind die Neurofilamente jedoch in der Regel stark phosphoryliert und lassen sich nicht mit SMI32-Antikörpern anfärben (Trapp et al. 1998). SMI32 ${ }^{+}$-Axone stellen in normal myelinisiertem Gewebe somit einen sensitiven Marker für eine pathologisch veränderte Phosphorylierung der Neurofilamente in geschädigten Axonen dar (Trapp et al. 1998; Schirmer et al. 2013). Hierbei werden demyelinisierte und pathologisch veränderte Axone durch eine diskontinuierliche Färbung dargestellt.

Die Auswertung der SMI32+-Axone wurde nur an Hirngewebe durchgeführt. Im Rückenmark war keine eindeutige Unterscheidung bzw. Auszählung von physiologischen und pathologischen $\mathrm{SMI}^{+} 2^{+}$-Axonen möglich, da bereits gesunde humane Kontrollfälle zahlreiche SMI32 ${ }^{+}$-Nervenfaserbündel in der WM aufwiesen, die von der GM aus hineinzogen. Die Auszählung erfolgte in 20 Gesichtsfeldern bei 400facher Vergrößerung. Die Dichte der SMI32+-Axone wurde dann pro $\mathrm{mm}^{2}$ angegeben. 


\subsubsection{Bielschowsky-Färbung zur Beurteilung der axonalen Dichte}

Die Bielschowsky-Silberimprägnation wird zur Darstellung von Axonen genutzt und erlaubt so die Beurteilung der axonalen Dichte in der NAWM. Axone stellen sich schwarz dar, das restliche Gewebe erscheint gelbbraun bis braun.

Die Auszählung der Bielschowsky ${ }^{+}$-Axone erfolgte bei 1000 facher Vergrößerung unter Verwendung eines Immersionsöls für Mikroskopie (Brechungsindex $n_{e}=1,518$, Carl Zeiss AG, Oberkochen, Deutschland). Im zerebralen Gewebe wurden die Kreuzungen der Axone mit dem Axonzählgitter an 25 Zählpunkten in 20 Gesichtsfelder gezählt. Im spinalen Gewebe wurde die axonale Dichte mit Hilfe des quadratischen Zellzählgitters mit 121 Zählpunkten in 10 Gesichtsfeldern ermittelt. Diese unterschiedliche Handhabung ist darauf zurückzuführen, dass im spinalen Gewebe der humanen Kontrollen die Dichte der Axone weitaus geringer und histologisch auftretende Hohlräume zwischen den Axonen weitaus größer sind als im zerebralen Gewebe. Um auch bei diesen spinalen Veränderungen eine ausreichende Sensitivität zu gewährleisten, wurde daher für humanes Rückenmarksgewebe das sensitivere quadratische Zählgitter mit mehr Schnittpunkten verwendet.

Alle Angaben zur axonalen Dichte wurden dann abschließend in Prozent relativ zur jeweiligen spinalen bzw. zerebralen gesunden Kontrollgruppe angegeben.

\subsubsection{TPPP/p25 ${ }^{+}$-Oligodendrozyten}

TPPP/p25 steht für Tubulin polymerization promoting protein/25 kDa brain specific protein. Es ist ein hirnspezifisches Protein (Takahashi et al. 1993) mit hoher Affinität zum mikrotubulären System (Hlavanda et al. 2002). TPPP/p25 wird spezifisch von reifen Oligodendrozyten exprimiert (Skjoerringe et al. 2006).

Der Antikörper gegen TPPP/p25 färbt somit reife myelinisierende Oligodendrozyten (Skjoerringe et al. 2006; Höftberger et al. 2010). Im Vergleich zu anderen Oligodendrozyten-Markern, wie MBP, PLP und CNP, färbt der Antikörper gegen TPPP/p25 primär den Zellkörper und Zellkern, aber nicht die Myelinscheiden (Höftberger et al. 2010). Dies macht eine zuverlässige Quantifizierung von reifen Oligodendrozyten möglich (Höftberger et al. 2010).

Zur Darstellung kommen kleine runde Zellen mit rundlichem Zellkern. Die Auszählung erfolgte in 10 Gesichtsfeldern bei 400 facher Vergrößerung. 
Um Unterschiede in der oligodendroglialen Dichte im Verhältnis zur axonalen Dichte zu erfassen, wurde die Oligodendrozytenzahl in Relation zur axonalen Dichte gesetzt (Quotient $=$ p25 $5^{+}$Zellen pro $\mathrm{mm}^{2} /$ axonale Dichte) .

\subsubsection{GFAP $^{+}$-Astrozyten}

Das saure Gliafaserprotein (glial fibrillary acidic protein, GFAP) wird zellspezifisch von reifen Astrozyten exprimiert (Reeves et al. 1989; Eng et al. 2000). GFAP wird als sensitiver und zuverlässiger immunhistochemischer Marker angesehen, der die meisten reaktiven, auf ZNS-Schädigung antwortenden Astrozyten markiert (Sofroniew und Vinters 2010).

Der Antikörper gegen GFAP färbt das Zytoplasma und die großen, nicht jedoch die feinen Ausläufern der Astrozyten. Zur Darstellung kommen Astrozyten mit sternförmigen Zellkörpern und randständigem Kern. Die Auszählung erfolgte in 22 Gesichtsfeldern bei 400facher Vergrößerung. Die Zelldichte wurde in GFAP $^{+}$-Zellen pro $\mathrm{mm}^{2}$ angegeben.

\subsubsection{Auswertung von Veränderungen in der NAWM bei gesunden Tieren und Mäusen mit chronischer EAE}

\subsubsection{Auswahl der NAWM anhand LFB/PAS-Färbungen und der Läsionslast}

Die Auswahl der NAWM bei Mäusen wurde ebenfalls primär anhand der LFB/PASFärbung getroffen.

Um den Anteil der entmarkten weißen Substanz (Demyelinisierung, DM) und somit die Läsionslast zu bestimmen, wurden jeweils alle zur Verfügung stehenden RückenmarkSchnitte pro Maus mit Hilfe der LFB/PAS-Färbung beurteilt. Mittels der Bildanalysesoftware ,analySIS ${ }^{*}$ “ (Olympus Soft Imaging System) wurden auf mindestens 7 Rückenmarksquerschnitten die Summe der demyelinisierten Fläche (WML) bestimmt und dann durch die Summe der spinalen WM-Fläche geteilt. Daraus ergab sich der Anteil der entmarkten spinalen weißen Substanz, im Folgenden auch als sogenannte Läsionslast bezeichnet $\left(\frac{\mathrm{WML}}{\mathrm{WM}} \times 100=\right.$ Läsionslast [\%]). Der Anteil der entmarkten weißen Substanz lag bei keinem EAE-Tier über 15\%, so dass ausreichend normal erscheinende weiße Substanz unter Einhaltung eines Sicherheitsabstandes zur PPWM für die Auswertung zur Verfügung stand. Gesunde Kontrolltiere wiesen keine Läsionen und damit eine Läsionslast von $0 \%$ auf. 


\subsubsection{Vorgehen bei der histologischen Auswertung von Mausgewebe}

Grundsätzlich ähnelte das Vorgehen bei der histologischen Auswertung von Mausgewebe dem von humanem Autopsiegewebe. Aufgrund der physiologisch geringeren Fläche von NAWM im murinen Gewebe, die für die Auswertung zur Verfügung stand, wurden jedoch zusätzliche Anforderungen an das Vorgehen bei der histologischen Auswertung definiert.

Prinzipiell wurde darauf geachtet nur die NAWM der tiefen WM auszuwerten. Dabei sollte ein möglichst großer Abstand zu Läsionen, PPWM und unscharfen Übergängen zwischen Grey matter und White matter bestehen. Zudem wurde die subpiale WM bei der Auswertung vernachlässigt, da diese Randbereiche mit steigender Läsionslast zunehmend von Läsionen der WM betroffen waren.

Generell wurde ein Mindest-Sicherheitsabstand zu Läsionen von 0,05 mm (entspricht 2 Kästchen der 10x10 Kästchen des Gesichtsfeldes in 400facher Vergrößerung) eingehalten. Wenn möglich wurde ein größerer Abstand verwendet. Außerdem wurden immer 10 Gesichtsfelder in konstanter 400facher Vergrößerung von mindestens drei verschiedenen Rückemarksquerschnitten. Mit Ausnahme der Auszählung von Bielschowsky ${ }^{+}$-Axonen, welche unter 1000 facher Vergrößerung erfolgte (s.u.). Die Auswertung der Rückenmärker erfolgte grundsätzlich ohne Kenntnis der jeweiligen Läsionslast.

Das Maus-Gewebe wurde hinsichtlich entzündlicher, axonaler und glialer Parameter analog zu den humanen Autopsien untersucht (siehe Kapitel 2.3.1). Dabei kamen die bereits genannten Färbungen zur Anwendung. Lediglich bei den Entzündungsmarkern wurde statt der KiM1P-Färbung (siehe Kapitel 2.3.1.3) das murine Äquivalent zum Nachweis der Mikroglia verwendet. Es handelt sich hierbei um den ebenfalls immunhistochemisch etablierten Marker MAC3, wobei MAC3 bei den Mäusen vorwiegend von aktivierten Mikrogliazellen exprimiert wird. Die MAC3-Färbung wurde ebenfalls anhand eines Scores zur Dichte der aktivierten Mikrogliazellen ausgewertet. Der MAC3-Score wurde analog zur humanen KiM1P-Färbung erhoben, wobei sowohl das physiologische, als auch das pathologische Ausmaß der aktivierten Mikrogliazellen im murinen Gewebe deutlich geringer war. Um bei diesem geringen Aktivierungsausmaß noch mögliche geringere Unterschiede zwischen gesunden Tieren und Mäusen mit chronischer EAE und geringer Läsionslast detektieren zu können, wurde bei den Tieren ein zusätzlicher Zwischenwert im Score bei der Auswertung 
verwendet (Score 0,5 ^ gering erhöht) (vergleiche auch Kapitel 2.3.1.3). Insgesamt fiel die Dichte der aktivierten Mikrogliazellen pro jeweiligen MAC3-Score-Wert deutlich geringer aus als bei der humanen KiM1P-Färbung. Die Definition eines Mikrogliaknötchens war für humanes und murines Gewebe identisch (siehe auch Kapitel 2.3.1.3).

Zudem fiel die Zählung SMI32+-Axone weg, da keine eindeutige Auswertung möglich war (siehe auch Kapitel 2.3.1.5). Denn wie im Rückenmark humaner Autopsien, zeichnete sich auch im spinalen Gewebe der gesunden Mäuse eine breite, unscharfe Begrenzung zwischen GM und WM mit etlichen SMI32 ${ }^{+}$-Axonen ab. Da aufgrund der subpialen Läsionen prinzipiell insbesondere die innen liegende WM ausgewertet wurde, wurde in der vorliegenden Arbeit von einer Auswertung der SMI32 ${ }^{+}$-Axone in diesem Bereich der WM wie auch im humanen Rückenmark abgesehen.

Die Auszählung der Bielschowsky ${ }^{+}$-Axone erfolgte bei 1000facher Vergrößerung unter Verwendung eines Immersionsöls für Mikroskopie (siehe auch Kapitel 2.3.1.6). Im spinalen Gewebe der Mäuse wurden die Kreuzungen der Axone wie im zerebralen, humanen Gewebe, mit dem Axonzählgitter an 25 Zählpunkten in 20 Gesichtsfelder gezählt. Hier war die Sensibilität des Axonzählgitters ausreichend und eine Anpassung der Methodik nicht nötig. Auch hier wurde die axonale Dichte als prozentualer Wert relativ zum Referenzwert angegeben, welcher aus den gesunden Kontrollen ermittelt worden war (vergleiche mit Kapitel 2.3.1.6).

Die quantitative Dichte der $\mathrm{CD}^{+}{ }^{-}, \mathrm{GFAP}^{+}$- und $\mathrm{p} 25^{+}$-Zellen wurde ebenso wie die Dichte der $\mathrm{APP}^{+}$-Axone pro $\mathrm{mm}^{2}$ angegeben. 


\subsection{Statistische Auswertung}

Die graphische Darstellung und statistische Analyse wurden mit Hilfe der Software GraphPad Prism $6^{\circledR}$ (Graph Pad Software, Inc., San Diego, CA, USA) für Windows durchgeführt. Alle Daten werden als Mittelwerte (MW) mit Standardabweichung angegeben ( $\mathrm{MW} \pm$ Standardabweichung). Die Normalverteilung einer Stichprobengruppe wurde mittels des nichtparametrischen Kolmogorov-Smirnov-Tests mit Lilliefor-Korrektur sowie des Shapiro-Wilk-Tests überprüft. Um zwei unabhängige Gruppen zu vergleichen wurden für parametrische Daten ungepaarte t-Tests verwendet, für nicht parametrische Daten „Mann-Whitney-U“-Tests. Bei den NMO-Autopsiefällen war es aufgrund der meist zu geringen Fallzahl nicht möglich, die Normalverteilung mit einem statistischen Test $\mathrm{zu}$ prüfen, so dass von nicht normalverteilten Stichprobenwerten ausgegangen und der Mann-Whitney-Test herangezogen wurde. Der Unterschied zwischen den verglichenen Gruppen wurde ab einem $p$-Wert $\leq 0,05$ als statistisch signifikant definiert (drei Signifikanzniveaus werden unterschieden: $* \mathrm{p} \leq 0,05 ; * * \mathrm{p} \leq 0,01 ; * * * \mathrm{p} \leq 0,001)$. P-Werte $\leq 0,1$ wurden als Trend definiert. 


\section{Ergebnisse}

\subsection{Veränderungen in der NAWM bei MS, NMO und gesunden Kontrollen humaner Autopsiefälle}

Um Veränderungen in der NAWM bei MS, NMO und Kontrollfällen zu charakterisieren, wurde das Parenchym hinsichtlich entzündlicher, axonaler und glialer Parameter untersucht. Hierzu wurden 13 Fälle gesunder altersentsprechender Kontrollen, 24 Fälle mit MS und fünf Fälle mit NMO herangezogen (siehe Kapitel 2.1.1).

Da nicht jede Färbung auf dem Gewebe aller Fälle etabliert werden konnte, werden nachfolgend in den jeweiligen Abbildungslegenden in Klammern jeweils die Anzahl (n) der ausgewerteten Fälle und die Summe der ausgewerteten Blöcke angegeben.

\section{NAWM bei Kontrollen, MS und NMO}

Die Auswahl der NAWM wurde sowohl bei den altersentsprechenden gesunden Kontrollen als auch bei MS und NMO primär anhand der Myelin-Färbung mit LFB/PAS getroffen (siehe Abb. 3 und 4). Zur Beurteilung des Parenchyms von NMOFällen wurden zusätzlich die immunhistochemischen AQP4- und GFAP-Färbungen herangezogen (siehe auch Abb. 3 und 4). Ferner wurden zum Ausschluss morphologischer Veränderungen und entzündlicher Infiltrate bei allen drei Gruppen auch HE-Färbungen gesichtet (siehe auch Kapitel 2.3.1.1 „Auswahl der NAWM anhand histologischer Färbungen“).

Die LFB-PAS-Färbungen der zerebralen (Abb. 3) und spinalen (Abb. 4) NAWM zeigten eine regelrechte Myelindichte bei Kontroll-, MS- und NMO-Fällen. Bei den NMO-Fällen waren in der NAWM regelrecht Astrozyten in der AQP4- und GFAPFärbung sowohl zerebral (Abb. $3 \mathrm{D}$ und E) als auch spinal (Abb.4 D und E) nachweisbar. 

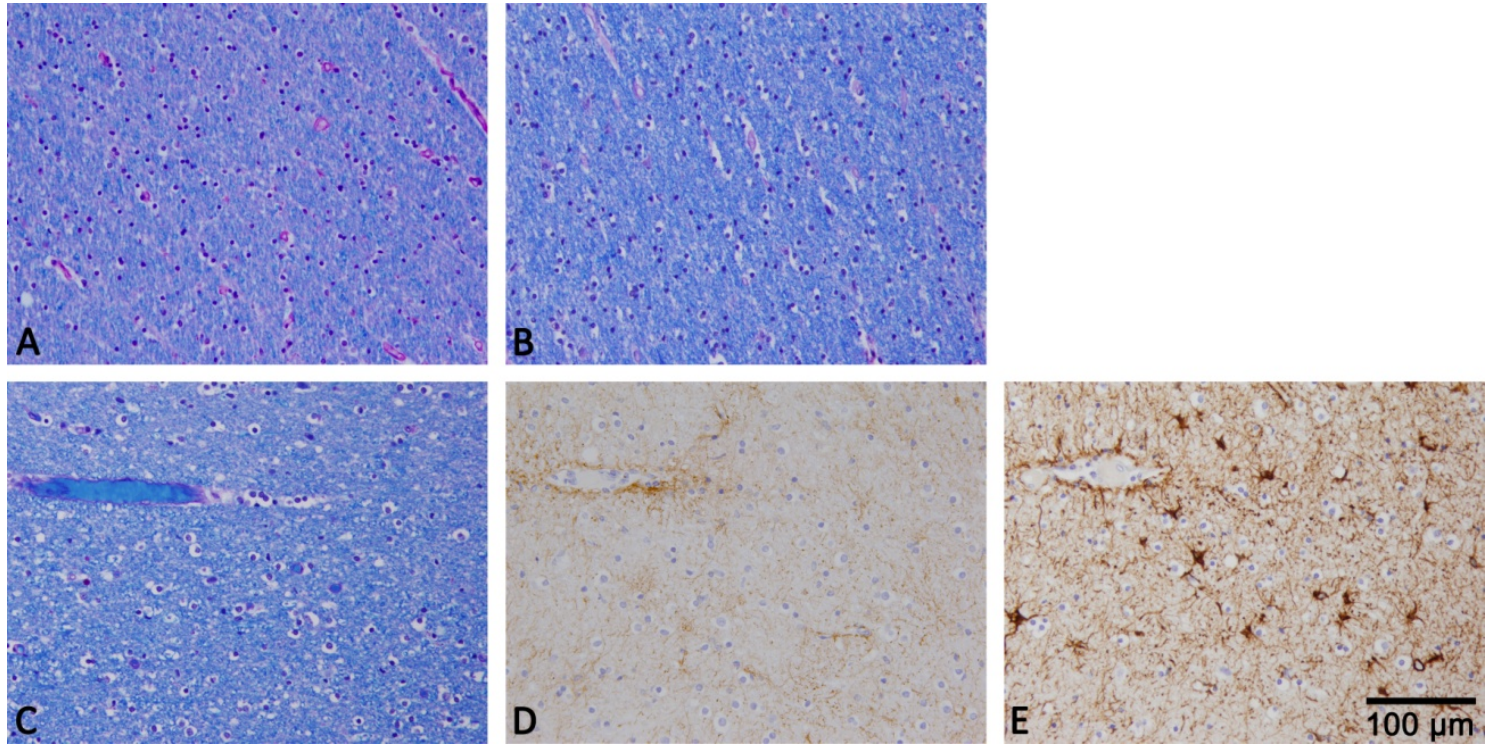

Abbildung 2: Zerebrale NAWM humaner Autopsiefälle. 200fache Vergrößerung. (A-C) Regelrechte Myelindichte in der LFB/PAS-Färbung bei Kontroll- (A), MS- (B) und NMO-Fällen (C). Kein Verlust von AQP4 (D) und GFAP (E) in der NAWM bei NMO.
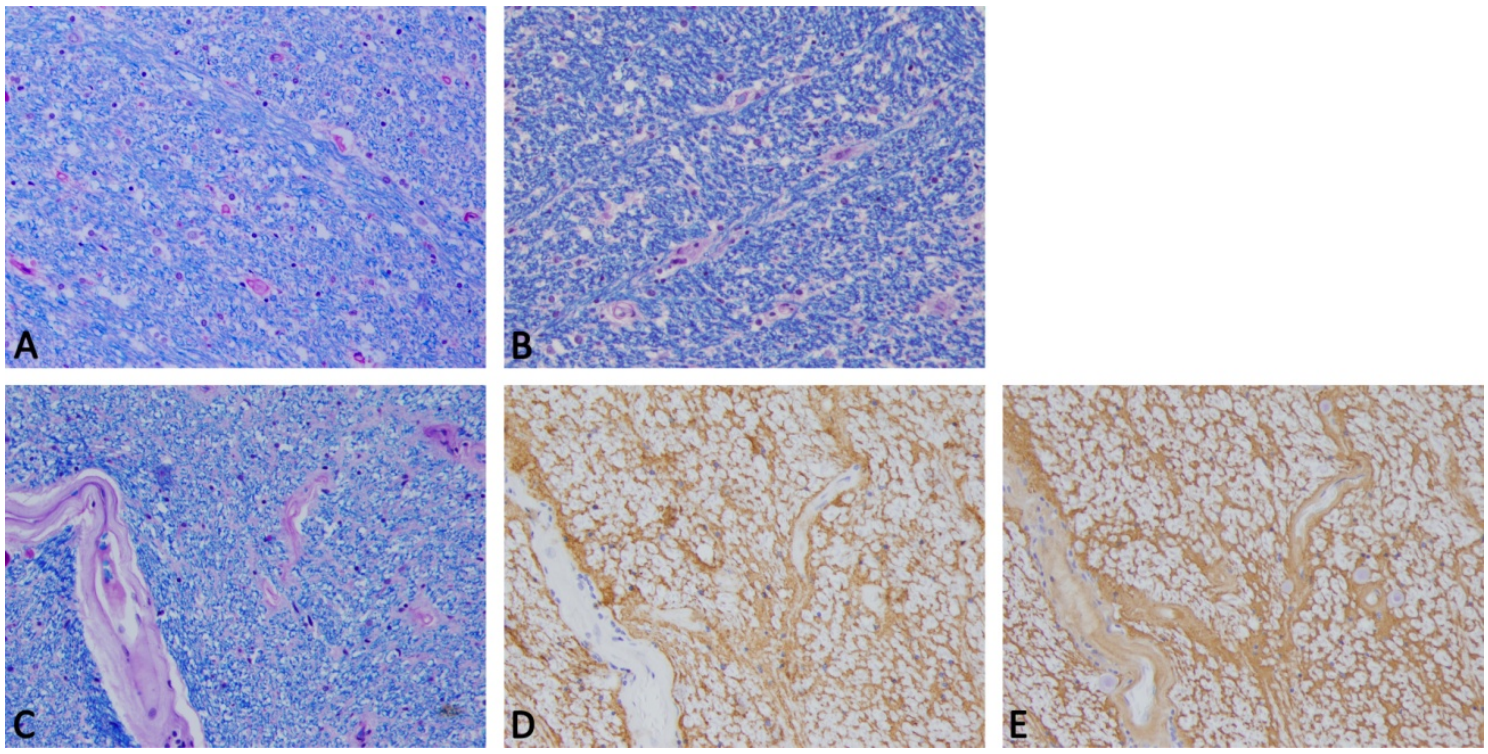

Abbildung 3: Spinale NAWM humaner Autopsiefälle. 200fache Vergrößerung. (A-C) Regelrechte Myelindichte in der LFB/PAS-Färbung bei Kontroll- (A), MS- (B) und NMO-Fällen (C). Kein Verlust von AQP4 (D) und GFAP (E) in der NAWM bei NMO. 


\subsubsection{Erhöhte T-Lymphozytendichte in der NAWM bei MS und NMO im Vergleich zu Kontrollfällen}

Um zu ermitteln, ob sich die T-Lymphozytendichte in der NAWM zwischen MS, NMO und der WM altersentsprechender gesunder Kontrollen unterscheidet, wurden die Zellen im Parenchym der ausgewählten Fälle mit Hilfe einer CD3-Färbung detektiert.

Im Gehirn zeigte sich in der NAWM sowohl bei MS (Abb. 4 B) als auch bei NMO (Abb. 4 C) eine erhöhte T-Lymphozytendichte, verglichen mit der WM altersentsprechender Kontrollen (Abb.4 A). Bei den gesunden Kontrollen waren kaum $\mathrm{CD}^{+}$-Zellen in der WM vorhanden, wohingegen in der NAWM bei MS und NMO $\mathrm{CD}^{+}$-Zellen vereinzelt auftraten. Die quantitative T-Lymphozytendichte (Abb. $4 \mathrm{G}$ ) war in der NAWM bei MS (MW: 0,52 $\pm 0,36$ T-Lymphozyten $/ \mathrm{mm}^{2}$ ) im Vergleich zu den Kontrollen signifikant erhöht (MW: 0,19 0,14 T-Lymphozyten $/ \mathrm{mm}^{2}$; $\mathrm{p}=0,001^{* *}$ ). In der NAWM der NMO-Fälle (MW: 0,64 $\pm 0,05$ T-Lymphozyten $/ \mathrm{mm}^{2}$ ) war die T-Lymphozytendichte im Vergleich zu den Kontrollen ähnlich stark erhöht wie bei MS.

Im Rückenmark (Abb. 4 C-F) zeigte sich insgesamt bei allen drei Gruppen eine etwas höhere T-Lymphozytendichte als im Gehirn. Auch im Rückenmark zeigte sich in der NAWM sowohl bei MS (Abb. 4 E) als auch bei NMO (Abb. 4 F) eine erhöhte TLymphozytendichte, verglichen mit der WM altersentsprechender Kontrollen (Abb. 4 D). In der WM der Kontrollen waren $\mathrm{CD}^{+}$-Zellen nur vereinzelt vorzufinden. Sowohl bei MS als auch bei NMO war die T-Lymphozytenzahl deutlich höher als im Kontrollgewebe. Es traten überwiegend einzelne Zellen im Parenchym verteilt auf, selten aber auch paarweise. Die quantitative T-Lymphozytendichte (Abb. $4 \mathrm{G}$ ) war in der NAWM bei MS (MW: 1,54 \pm 1,01 T-Lymphozyten $/ \mathrm{mm}^{2}$ ) im Vergleich zu den Kontrollen signifikant erhöht (MW: 0,87 $\pm 0,52$ T-Lymphozyten $/ \mathrm{mm}^{2} ; \mathrm{p}<0,05 *$ ). In der NAWM der NMO-Fälle (MW: 1,268 $\pm 0,618$ T-Lymphozyten $/ \mathrm{mm}^{2}$ ) war die TLymphozytendichte im Vergleich zu den Kontrollen ebenfalls erhöht, allerdings erreichte der Unterschied keine statistische Signifikanz ( $p=0,229$ n. s.). Auch der Vergleich zwischen NMO und MS ergab keinen signifikanten Unterschied ( $p=0,706$ n. s.). 

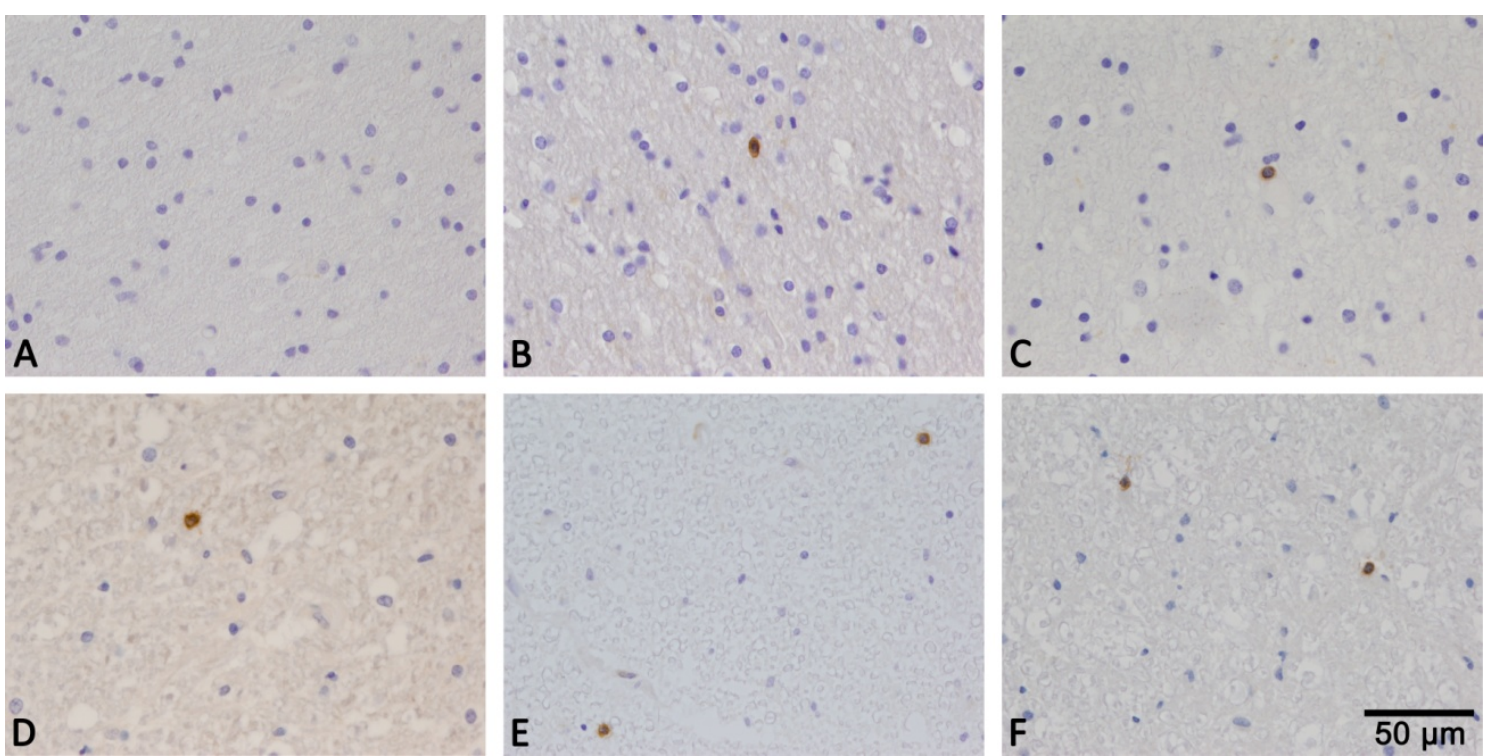

\section{T-Lymphozytendichte}

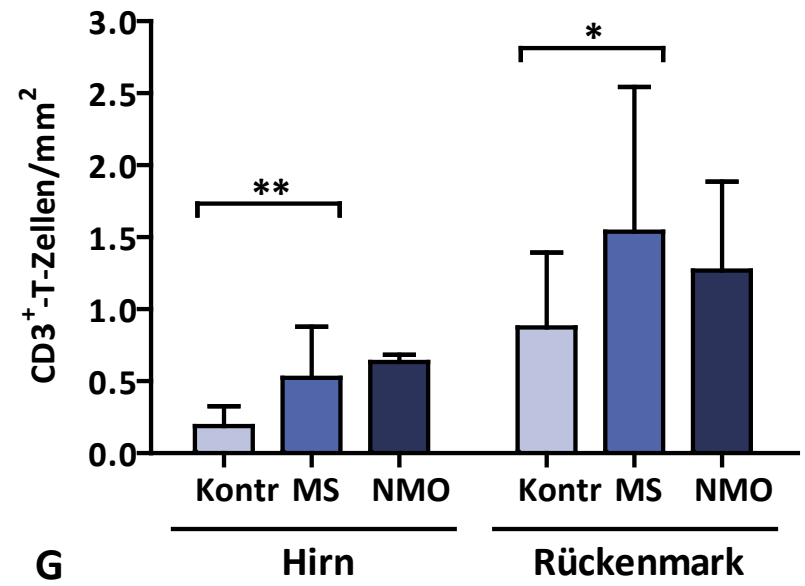

Abbildung 4: Erhöhte T-Lymphozytendichte in der NAWM bei MS und NMO im Vergleich zu Kontrollfällen. 400fache Vergrößerung. CD3-Färbung. Fotos A-C zeigen zerebrale, D-F spinale NAWM; In der zerebralen WM gesunder Kontrollen (A) sind kaum $\mathrm{CD}^{+}$-Zellen vorhanden, hier keine im Bild. In der NAWM bei MS (B) treten nur vereinzelte $\mathrm{CD}^{+}$-Zellen auf. Auch bei NMO (C) sind $\mathrm{CD}^{+}$-Zellen nur vereinzelt in der NAWM zu sehen. In der spinalen WM gesunder Kontrollen (D) sind $\mathrm{CD}^{+}$-Zellen nur vereinzelt vorzufinden. In der NAWM bei MS (E) sind einzelne CD3 ${ }^{+}$-Zellen in der NAWM vorhanden. Zum Teil treten auch zwei Zellen gemeinsam auf. Bei NMO (F) treten ebenfalls teilweise zwei CD3 ${ }^{+}$ Zellen in der NAWM gemeinsam auf. (G) Graph. Gehirn: Signifikant erhöhte T-Lymphozytendichte bei MS ( $n=14 ; 18$ Blöcke) im Vergleich zu Kontrollen ( $n=13 ; 22$ Blöcke; $p=0,001 * *$, Mann-Whitney-Test). Ähnlich hohe T-Lymphozytendichte bei NMO ( $n=2 ; 4$ Blöcke) verglichen mit MS (keine statistische Auswertung aufgrund geringer NMO-Fallzahl). Rückenmark: Signifikant erhöhte T-Lymphozytendichte bei MS ( $n=12 ; 16$ Blöcke) im Vergleich zu Kontrollen $(n=12 ; 18$ Blöcke; $p<0,05 *$, t-Test). Nicht signifikante Unterschiede zwischen MS und NMO ( $n=4 ; 4$ Blöcke; n. s., Mann-Whitney-Test) als auch zwischen NMO und Kontrollen (n. s., Mann-Whitney-Test). 


\section{T-Lymphozyteninfiltration des Virchow-Robin-Raumes}

Zur Beurteilung der T-Lymphozyteninfiltration ( $\mathrm{CD}^{+}{ }^{+}$-Zellen) des Virchow-RobinRaumes (VRR) in der NAWM/WM wurde ein semi-quantitativer Score entwickelt (siehe Kapitel 2.3.1.2 mit Score-Übersicht Tabelle 6). Die Bewertung erfolgte in der gesamten NAWM eines Gewebeblocks. Aus den Werten aller verfügbaren spinalen bzw. zerebralen Blöcke eines Patienten wurde dann der Mittelwert gebildet.

Im Gehirn zeigte sich kein Unterschied in der T-Lymphozyteninfiltration des VirchowRobin-Raumes. Auch im Rückenmark war kein signifikanter Unterschied zu beobachten.

Bei den gesunden Kontrollen waren überwiegend vereinzelte $\mathrm{CD}^{+}$-Zellen im VRR (Score 1) der WM zu finden, es wurden aber auch Gefäße ohne oder mit einigen CD ${ }^{+}$Zellen im VRR beobachtet (Abb. 5). Sehr ähnlich sah es auch in der NAWM bei MS aus, es traten nur vereinzelt mehr $\mathrm{CD}^{+}$-Zellen auf (Abb. 5). Zudem wurden nur geringfügig häufiger Score-Werte von 2 (d. h. einige $\mathrm{CD}^{+}$-Zellen) erreicht. In der NAWM bei NMO traten in den Fällen mit auswertbarer CD3-Färbung überwiegend einige $\mathrm{CD}^{+}{ }^{+}$-Zellen im VRR (Score 2) auf, insgesamt war der Unterschied jedoch nicht signifikant (Abb. 5).

Im Rückenmark wurde eine ähnliche Situation beobachtet (Abb. 5). Die Gruppen erreichten jedoch insgesamt geringgradig niedrigere Score-Werte. Bei den gesunden Kontrollen wurde etwas seltener der Score 2 vorgefunden. Bei MS gab es keinen Unterschied im Vergleich zum Gehirn. Bei NMO fiel die T-Lymphozyteninfiltration geringer aus als im Gehirn, der Score-Wert war mit dem bei MS vergleichbar. 

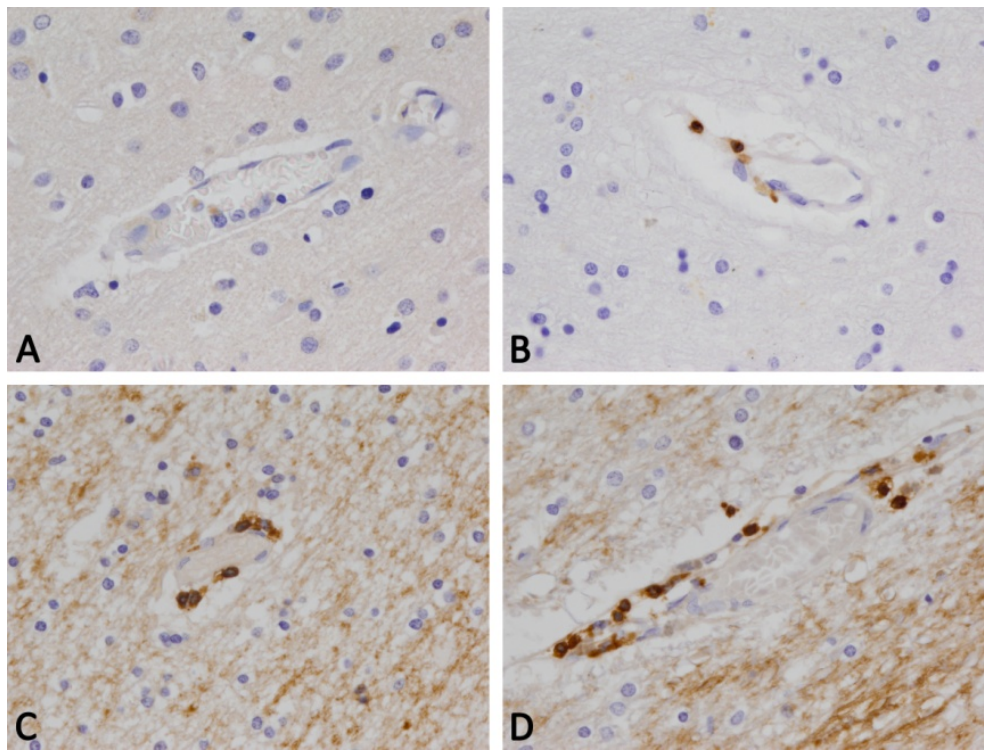

\section{T-Zellen im Virchow-Robin-Raum}

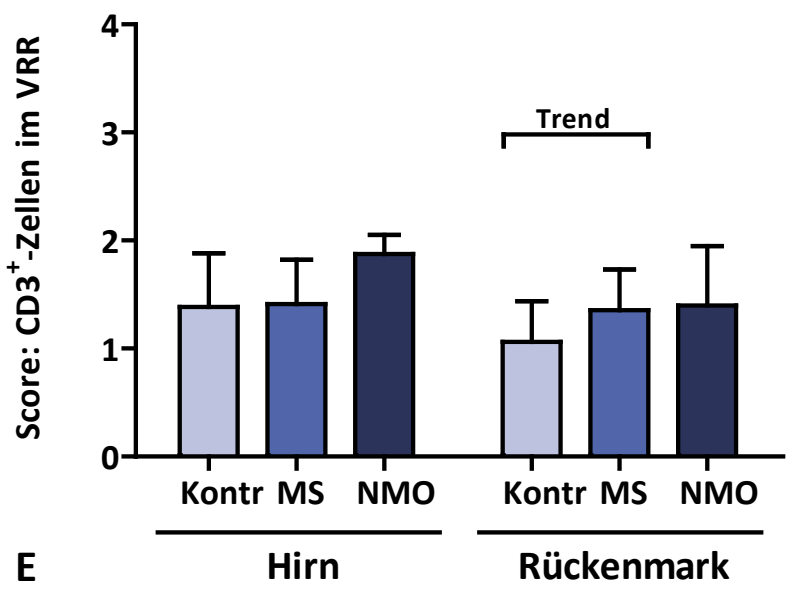

Abbildung 5: Kein signifikanter Unterschied der T-Lymphozyteninfiltration im Virchow-Robin-Raum (VRR) der NAWM humaner Autopsiefälle. 400fache Vergrößerung. CD3-Färbung. Fotos A-D zeigen Beispiele für den erhobenen Score für den VRR in der NAWM des Gehirns; (A) Score 0: (Kontrolle) Es sind keine $\mathrm{CD}^{+}$-Zellen vorhanden. (B) Score 1: (Kontrolle) Es treten nur vereinzelt [1-2 Zellen] CD3 ${ }^{+}$-Zellen auf. (C) Score 2: (MS) Es sind einige [> 2 Zellen] $\mathrm{CD}^{+}$-Zellen zu sehen. Jedoch können auch deutlich mehr positive Zellen vorkommen, wie Beispiel (D) zeigt (MS). (E) Graph. Gehirn: Mittelwerte Score: Kontrollen: 1,39 $\pm 0,50 ; M S: 1,41 \pm 0,41$; NMO: 1,88 $\pm 0,18$. Der Unterschied zwischen den Gruppen ist sehr gering und statistisch nicht signifikant (Mann-Whitney-Test). Rückenmark: Mittelwerte Score:

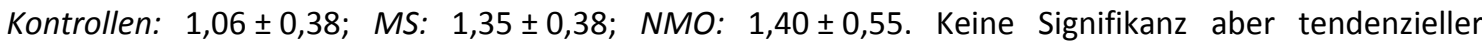
Unterschied zwischen Kontrollen und MS ( $p=0,0611$ Trend, Mann-Whitney-Test). Keine Signifikanz sowohl zwischen Kontrollen und NMO als auch zwischen MS und NMO (Mann-Whitney-Test). 


\subsubsection{Vermehrte spinale Mikrogliaaktivierung in der NAWM bei MS und NMO im Vergleich zu Kontrollfällen}

Um den Grad der Mikrogliaaktivierung in der NAWM bei MS, NMO und der WM altersentsprechender gesunder Kontrollen $\mathrm{zu}$ quantifizieren, wurde hier die Mikrogliadichte als Parameter für einen semi-quantitativen Score herangezogen (Score $0 \triangleq$ normal/nicht erhöht, $1 \bumpeq$ mäßig erhöht, $2 \bumpeq$ stark erhöht) und in der KiM1PFärbung beurteilt.

Die Mikrogliadichte war bei allen drei Gruppen im Rückenmark ausgeprägter als im Gehirn (Abb. 6 E).

Im Gehirn wurde in der NAWM kein signifikanter Unterschied in der Mikrogliadichte zwischen Kontrollen, MS und NMO festgestellt. Die Mikrogliadichte in der NAWM von MS-Patienten (MW Score: 0,50 \pm 0,38) entsprach der gesunder Kontrollen (MW Score: $0,50 \pm 0,35)$. Im Gewebe von NMO-Patienten wurde eine leicht erhöhte Mikrogliadichte beobachtet (MW Score: 0,83 $\pm 0,29 ;$ n. s.).

Im Rückenmark zeigte sich eine erhöhte Mikrogliadichte sowohl bei MS als auch bei NMO, verglichen mit den Kontrollen. Die Kontrollen wiesen eine ähnlich geringgradig erhöhte Mikrogliadichte wie im Gehirn (MW Score: 0,64 0,52) auf. Bei MS war die Mikrogliadichte überwiegend mäßig bis teilweise stark erhöht (MW Score: 1,26 $\pm 0,57$ ) und deutlich höher als bei den Kontrollen $\left(\mathrm{p}=0,0177^{*}\right)$. Auch bei NMO war die Mikrogliadichte überwiegend mäßig erhöht (MW Score: 1,15 \pm 0,22), erreichte jedoch im Vergleich zur Kontrollgruppe keine statistische Signifikanz $(p=0,0708$ Trend). Zwischen MS und NMO war der Unterschied gering und somit statistisch nicht signifikant. 

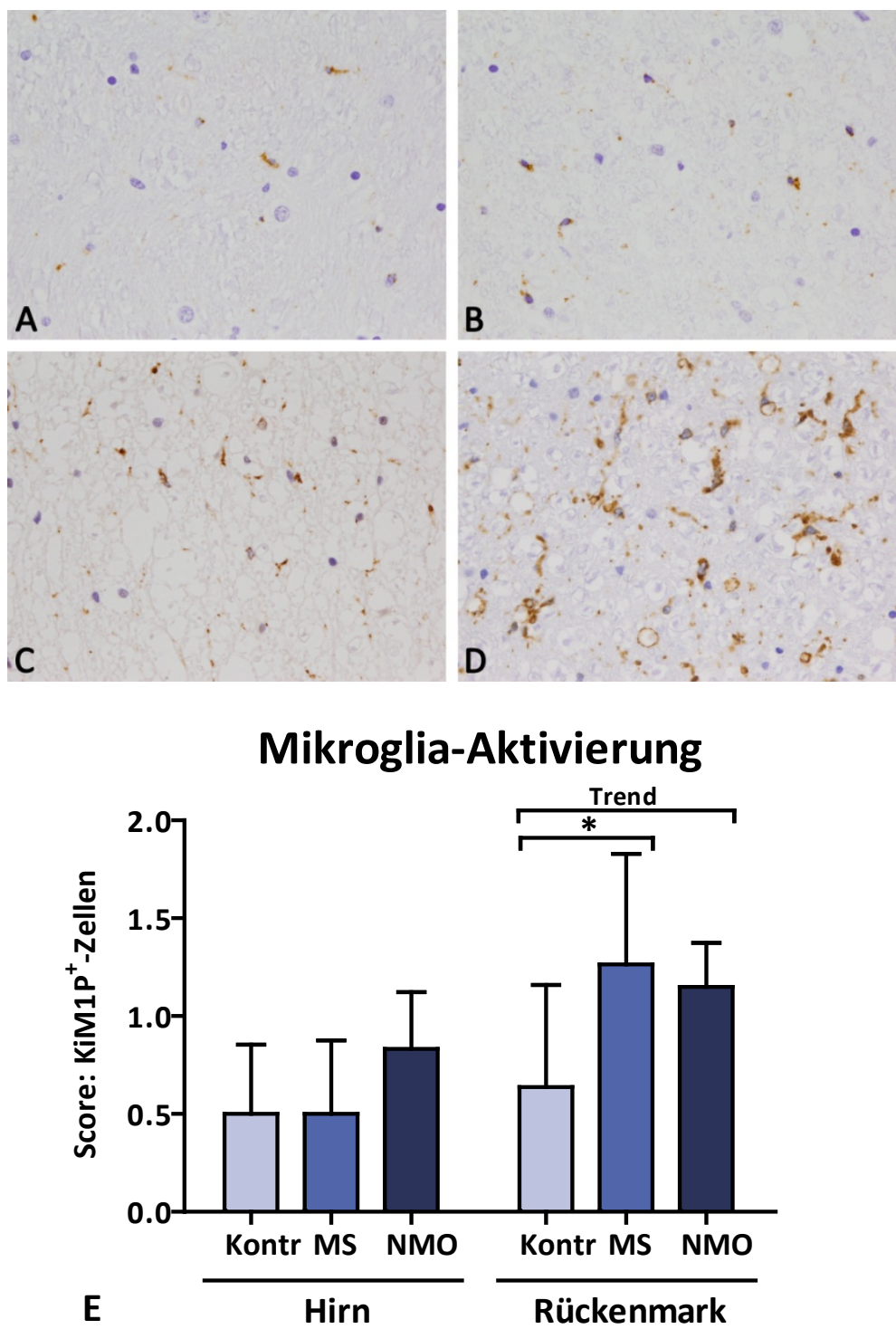

Abbildung 6: Vermehrte spinale Mikrogliaaktivierung (Score: Mikrogliadichte anhand KiM1P ${ }^{+}$-Zellen) in der NAWM bei MS und NMO im Vergleich zu Kontrollfällen. 400fache Vergrößerung. KiM1PFärbung. Fotos A-D zeigen Beispiele für spinale NAWM; (A) Score 0: (Kontrolle) Die Mikrogliadichte ist normal. (B) Score 0,5: (MS) Die Mikrogliadichte ist gering erhöht (und/oder schwankt innerhalb der WM zwischen normal bis mäßig erhöht). (C) Score 1: (MS) Die Mikrogliadichte ist mäßig erhöht. (D) Score 2: (MS) Die Mikrogliadichte ist stark erhöht. (E) Graph. Gehirn: Der Unterschied zwischen den Gruppen ist gering und statistisch nicht signifikant (n. S., Mann-Whitney-Test). Kontrollen ( $n=13$; 22 Blöcke); MS ( $n=16 ; 20$ Blöcke); NMO ( $n=3 ; 6$ Blöcke). Rückenmark: Signifikant erhöhte Mikrogliadichte bei MS ( $n=12 ; 16$ Blöcke) im Vergleich zu gesunden Kontrollen ( $n=12 ; 18$ Blöcke; $\mathrm{p}=0,0177 *$, Mann-Whitney-Test). Nicht signifikant aber tendenziell erhöhte Mikrogliadichte bei NMO ( $n=4 ; 4$ Blöcke) verglichen mit gesunden Kontrollen ( $p=0,0708$ Trend, Mann-Whitney-Test). Kein signifikanter Unterschied ist zwischen MS und NMO festzustellen (Mann-Whitney-Test). 


\section{Mikrogliaknötchen (MGK)}

Zusätzlich wurden alle Gewebeblöcke nach Mikrogliaknötchen durchsucht (Definition des MGK und Scores siehe 2.3.1.3 inkl. Tabelle 8). Der Score bewertete nur das Vorhandensein $(\stackrel{=}{=}$ Score 1$)$ oder Fehlen $(\triangleq$ Score 0$)$ von Mikrogliaknötchen. Nach Erhebung des Scores wurde der prozentuale Anteil der Autopsiefälle in den Gruppen errechnet, die Mikrogliaknötchen in der NAWM/WM aufwiesen.

Im Gehirn konnten sowohl bei einigen Kontrollen als auch bei mehreren MS-Fällen MGK in der NAWM nachgewiesen werden (Abb. 7 A-C, G). Teilweise traten auch mehrere MGK pro Fall auf. Bei MS (43,75\%) traten MGK insgesamt häufiger auf als bei den Kontrollen (15,38\%). In der zerebralen NAWM der NMO-Fälle konnten keine MGK nachgewiesen werden. Trotz der quantitativen Unterschiede konnte im Gehirn keine statistische Signifikanz zwischen den Gruppen festgestellt werden.

Im Rückenmark war die Zahl der Autopsiefälle mit nachweisbaren MGK in der NAWM insgesamt deutlich höher (Abb. 7 D-F, G). Das Verhältnis zwischen den Gruppen war jedoch ähnlich wie im Gehirn, die Unterschiede waren spinal allerdings ausgeprägter. 33,33\% der Kontrollen wiesen im Gehirn MGK auf. Bei MS traten MGK bei den meisten Fällen auf (83,33\%). Bei NMO konnte im Rückenmark nur bei einem Fall ein MGK nachgewiesen werden (20,00\%). Der Unterschied zwischen Kontrollen und MS war hier signifikant $(\mathrm{p}=0,0361 *)$. Auch der Unterschied zwischen MS und NMO war statistisch signifikant $(p=0,0276 *)$. Zwischen Kontrollen und NMO war kein signifikanter Unterschied festzustellen (n. s.). 

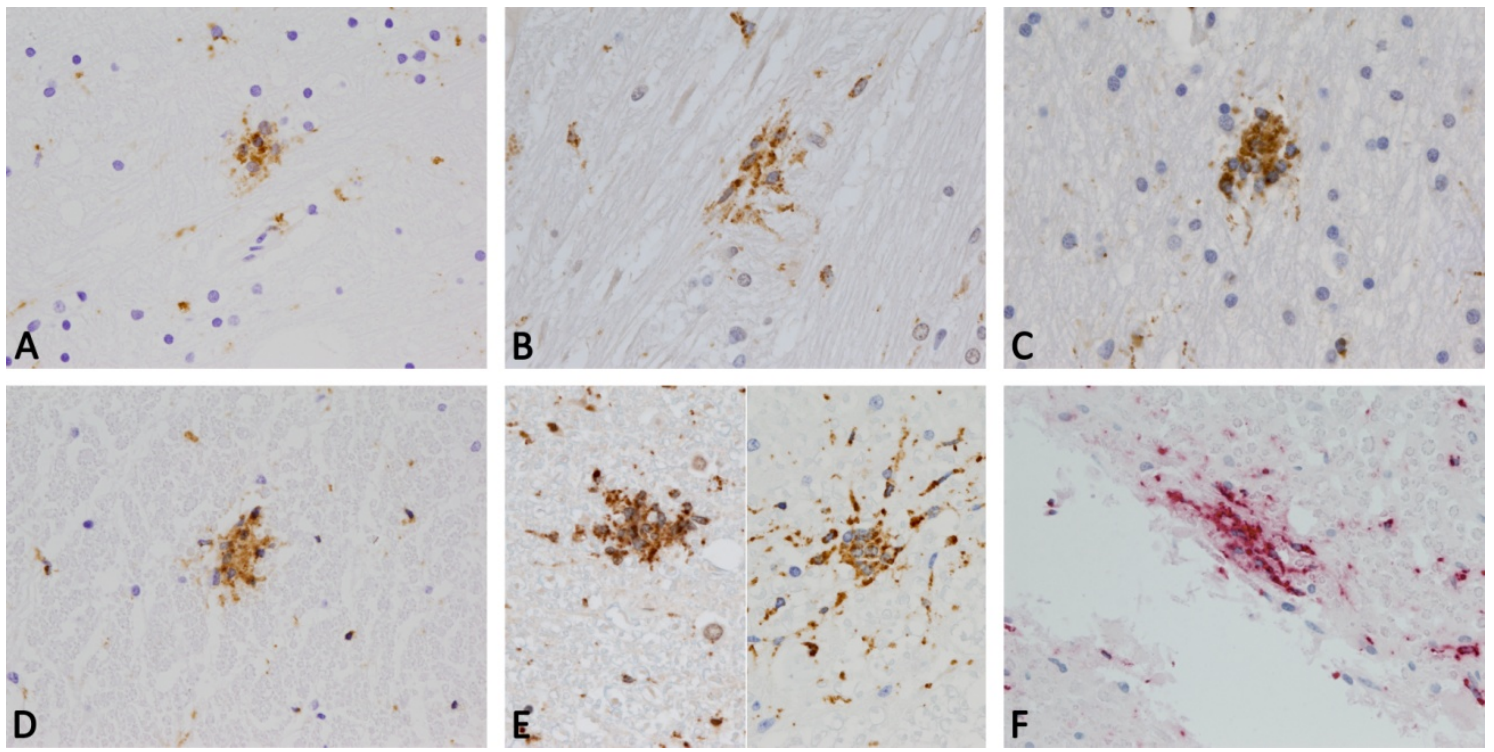

\section{Präsenz von Mikrogliaknötchen}

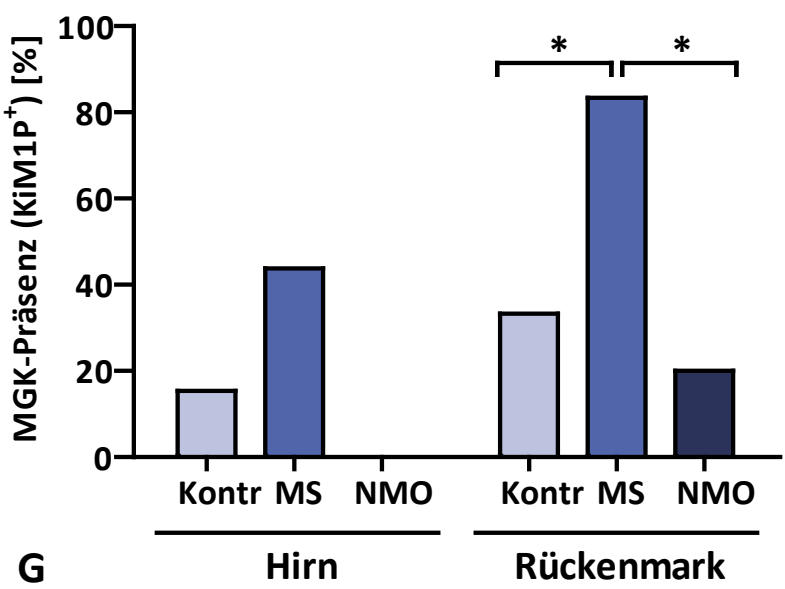

Abbildung 7: Vermehrt vorhandene Mikrogliaknötchen (MGK; KiM1P ${ }^{+}$-Zellen) in der NAWM bei MS. 400fache Vergrößerung. KiM1P-Färbung. Fotos A-C zeigen zerebrale, Fotos D-F spinale NAWM; MGK sind in der NAWM in unterschiedlicher Häufung und Größe anzutreffen. Diese Abbildung stellt das in der NAWM anzutreffende Spektrum an MGK-assoziierten KiM1P+-Zellen dar. Es gibt kleine MGK, wie hier mit fünf MGK-assoziierten KiM1P ${ }^{+}$-Zellen in der WM einer Kontrolle (A) oder der NAWM eines MSFalles (B). Die MGK können jedoch weitaus größer werden, wie hier im Gehirn eines MS-Patienten mit zehn MGK-assoziierten KiM1P ${ }^{+}$-Zellen (C), oder wie im Rückenmark einer Kontrolle (D) mit elf MGKassoziierten KiM1P ${ }^{+}$-Zellen. Die größten MGK wiesen jeweils über 20 MGK-assoziierten KiM1P ${ }^{+}$-Zellen auf, wie in (E) von zwei verschiedenen MS-Fällen zu sehen ist. MGK bei NMO finden sich nur im Rückenmark (F). Hier ist ein MGK mit 14 eindeutig MGK-assoziierten KiM1P ${ }^{+}$-Zellen zu sehen, zur besseren Darstellung mit Fast Red gefärbt. (G) Graph. Das Vorhandensein von MGK in der NAWM ist als prozentualer Anteil in den Gruppen dargestellt. Gehirn: Zwischen den Gruppen ist zwar ein quantitativer, jedoch kein statistisch signifikanter Unterschied vorhanden (n. S., Mann-Whitney-Test). Kontrollen ( $n=13 ; 22$ Blöcke); MS ( $n=16 ; 20$ Blöcke); NMO ( $n=3 ; 6$ Blöcke). Rückenmark: Signifikanter Unterschied zwischen WM der Kontrollen ( $n=12 ; 18$ Blöcke) und NAWM bei MS ( $n=12 ; 16$ Blöcke; $p=0,0361 *$, Mann-Whitney-Test). Kein signifikanter Unterschied zwischen NMO ( $n=4 ; 4$ Blöcke) und gesunden Kontrollen (n. S., Mann-Whitney-Test). Signifikanter Unterschied zwischen MS und NMO ( $p=0,0276^{*}$, Mann-Whitney-Test). 


\subsubsection{Axonaler Verlust in der NAWM bei MS im Vergleich zu Kontrollfällen}

Um die axonale Dichte in der NAWM zu bestimmen und somit auftretende axonale Verluste zu detektieren, wurden die Axone in der Bielschowsky-Färbung quantifiziert und in Relation $\mathrm{zu}$ den Werten gesunder Kontrollfälle angegeben (siehe Kapitel 2.3.1.6).

Der axonale Verlust war sowohl bei MS als auch bei NMO im Rückenmark stärker ausgeprägt als im Gehirn (Abb. 8).

Im Gehirn (Abb. 8 D) zeichnete sich eine signifikant reduzierte axonale Dichte in der NAWM von MS (MW: 94,79 $\pm 7,77 \%$ ) ab, verglichen mit der physiologischen axonalen Dichte der gesunden Kontrollen (MW: 100,00 $\pm 6,64 \% ; p=0,0327 *$ ). In der NAWM der NMO-Fälle (MW: 101,62 $\pm 3,96 \%$ ) entsprach die axonale Dichte dem Ausmaß der Kontrollen und war somit nicht signifikant. Auch zwischen MS und NMO war der Unterschied nicht signifikant, obwohl die axonale Dichte bei MS im Vergleich zu NMO quantitativ reduziert war.

Im Rückenmark (Abb. 8 A-D) war die axonale Dichte im Vergleich zu den Kontrollen sowohl bei MS als auch bei NMO sehr deutlich reduziert. Die Reduktion der axonalen Dichte in der NAWM bei MS (MW: 59,86 \pm 7,57\%) stellte sich im Vergleich zu den Kontrollen (MW: $100 \pm 10,58 \%)$ als hoch signifikant heraus $(\mathrm{p}<0,001 * * *)$. In der NAWM bei NMO (MW: 57,22 $\pm 4,49 \%$ ) war die axonale Dichte im Vergleich zu den gesunden Kontrollen ähnlich stark reduziert wie bei MS, entsprechend war der Unterschied ebenfalls statistisch ebenfalls hoch signifikant $(\mathrm{p}<0,001 * * *)$. Bei MS und NMO lag der Verlust auf einem ähnlichen Niveau und war daher nicht signifikant unterschiedlich. 

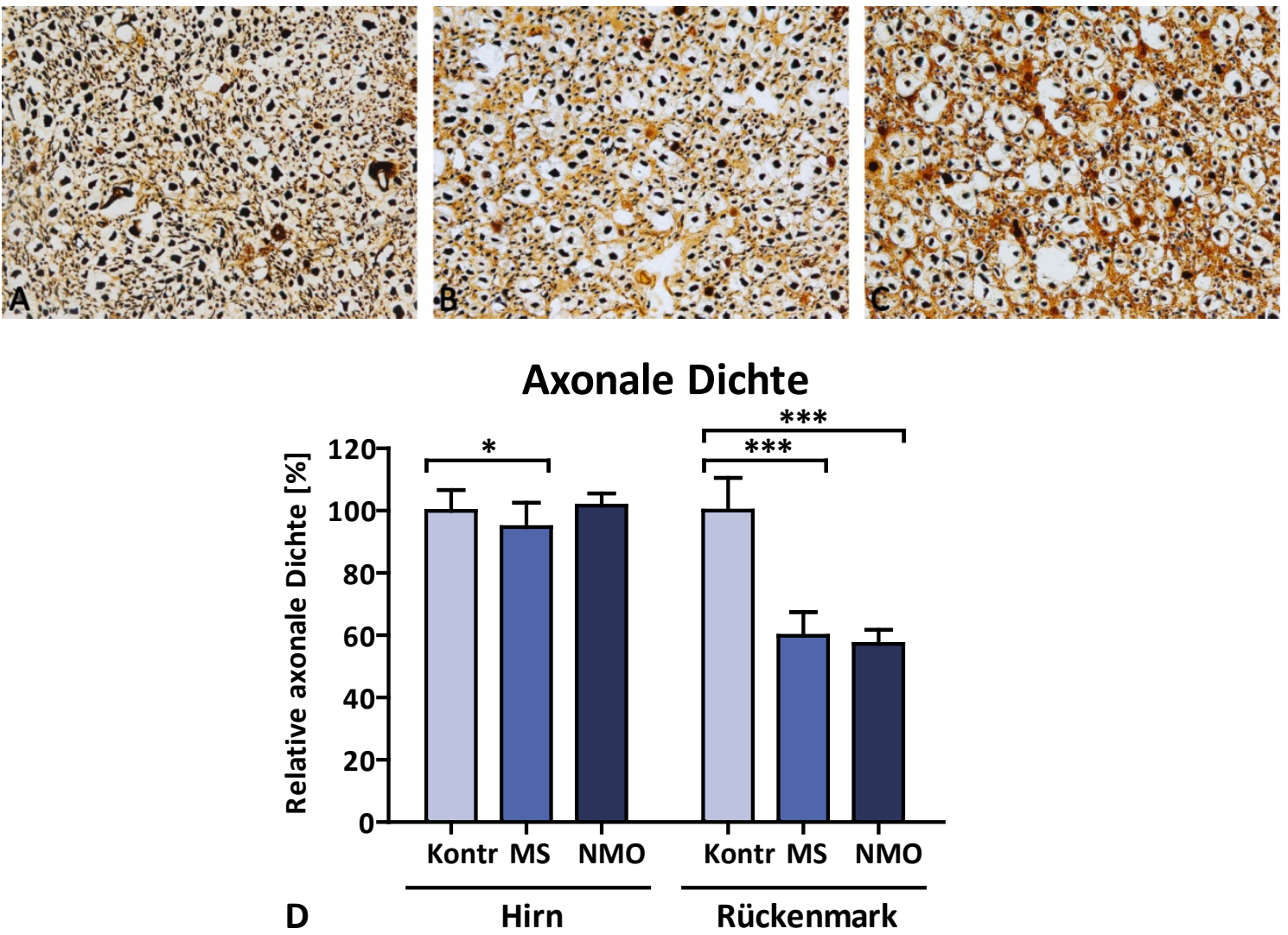

Abbildung 8: Reduzierte relative axonale Dichte [\%] in der NAWM von MS und NMO. 400fache Vergrößerung. Bielschowsky-Färbung. Fotos A-C zeigen spinale NAWM; In der zerebralen NAWM war die axonale Dichte bei MS, nicht jedoch bei NMO reduziert (hier nicht dargestellt). In der spinalen NAWM war die axonale Dichte dagegen sowohl bei MS (B) als auch bei NMO (C) deutlich reduziert, verglichen mit den physiologischen Werten gesunder Kontrollen (A). (D) Graph. Gehirn: Signifikanter Unterschied zwischen gesunden Kontrollen ( $n=13 ; 22$ Blöcke) und MS ( $n=16 ; 20$ Blöcke; $p=0,0327 *$, MannWhitney-Test). Jedoch kein signifikanter Unterschied zwischen gesunden Kontrollen und NMO ( $n=3$; 5 Blöcke), bzw. MS und NMO (n. s., Mann-Whitney-Test). Rückenmark: Signifikant reduzierte axonale Dichte bei MS ( $n=12 ; 16$ Blöcke) verglichen mit gesunden Kontrollen ( $n=12 ; 18$ Blöcke; $p<0,001 * * *$, $\mathrm{t}$-Test). Ähnlich stark reduzierte axonale Dichte bei NMO ( $n=5 ; 6$ Blöcke) wie bei MS ( $n$. s., t-Test). Signifikant reduzierte axonale Dichte bei NMO verglichen mit gesunden Kontrollen $(p<0,001 * * *$, tTest). 


\subsubsection{Vermehrte spinale akute axonale Schädigung bei MS im Vergleich zu NMO- und Kontrollfällen}

Um zu untersuchen, ob sich die akute axonale Schädigung in der NAWM zwischen MS, NMO und der WM altersentsprechender gesunder Kontrollen unterscheidet, wurde das Parenchym in der APP-Färbung untersucht.

Im Gehirn (Abb. 9 A-C) war eine vermehrte akute axonale Schädigung sowohl bei MS als auch bei NMO festzustellen, verglichen mit den Kontrollen. Doch auch die Kontrollen wiesen ganz vereinzelt $\mathrm{APP}^{+}$-Axone auf. Bei MS (MW: 12,13 \pm 5,67 $\mathrm{APP}^{+}$Axone $/ \mathrm{mm}^{2}$ ) zeigte sich im Vergleich zu den Kontrollen (MW: 4,70 $\pm 2,22 \mathrm{APP}^{+}$Axone $/ \mathrm{mm}^{2}$ ) eine hoch signifikant vermehrte akute axonale Schädigung in der NAWM $(\mathrm{p}<0,001 * * *)$ (Abb. 9 G). Das Ausmaß der akuten Schädigung lag bei NMO zwischen dem von MS und den Kontrollen. Im Vergleich $\mathrm{zu}$ den Kontrollen war die akute axonale Schädigung in der NAWM bei NMO (MW: 8,71 $\pm 1,72 \mathrm{APP}^{+}$-Axone $/ \mathrm{mm}^{2}$ ) ebenfalls signifikant erhöht $(\mathrm{p}=0,0304 *)$. Der Unterschied zwischen MS und NMO erwies sich indessen als statistisch nicht signifikant.

Im Rückenmark (Abb. 9 D-F) war die akute axonale Schädigung bei MS sehr deutlich ausgeprägt. Dagegen war der Grad der akuten Schädigung bei NMO auf dem Niveau der Kontrollen (n. s.). Doch auch hier wiesen die Kontrollen bereits vereinzelte APP $^{+}$Axone auf. Bei MS (MW: 33,19 $\pm 12,87 \mathrm{APP}^{+}$-Axone $/ \mathrm{mm}^{2}$ ) zeigte sich im Vergleich zu den Kontrollen (MW: 7,08 \pm 2,73 $\mathrm{APP}^{+}$-Axone $/ \mathrm{mm}^{2}$ ) eine hoch signifikant vermehrte akute axonale Schädigung in der NAWM ( $p<0,001 * * *)$ (Abb. 9 G). Auch im Vergleich zur NMO (MW: 8,40 $\pm 2,51 \mathrm{APP}^{+}$-Axone/mm²) war die akute Schädigung bei MS signifikant erhöht $\left(\mathrm{p}=0,0011^{* *}\right)$.

Eine Korrelation zwischen $\mathrm{CD}^{+}$-Zellen und $\mathrm{APP}^{+}$-Axonen bei MS konnte weder im Gehirn noch im Rückenmark nachgewiesen werden (Korrelationskoeffizient nach Pearson $r=0,05243 ; p=0,8587$ im Hirn und $r=-0,3374 ; p=0,2835)$. 

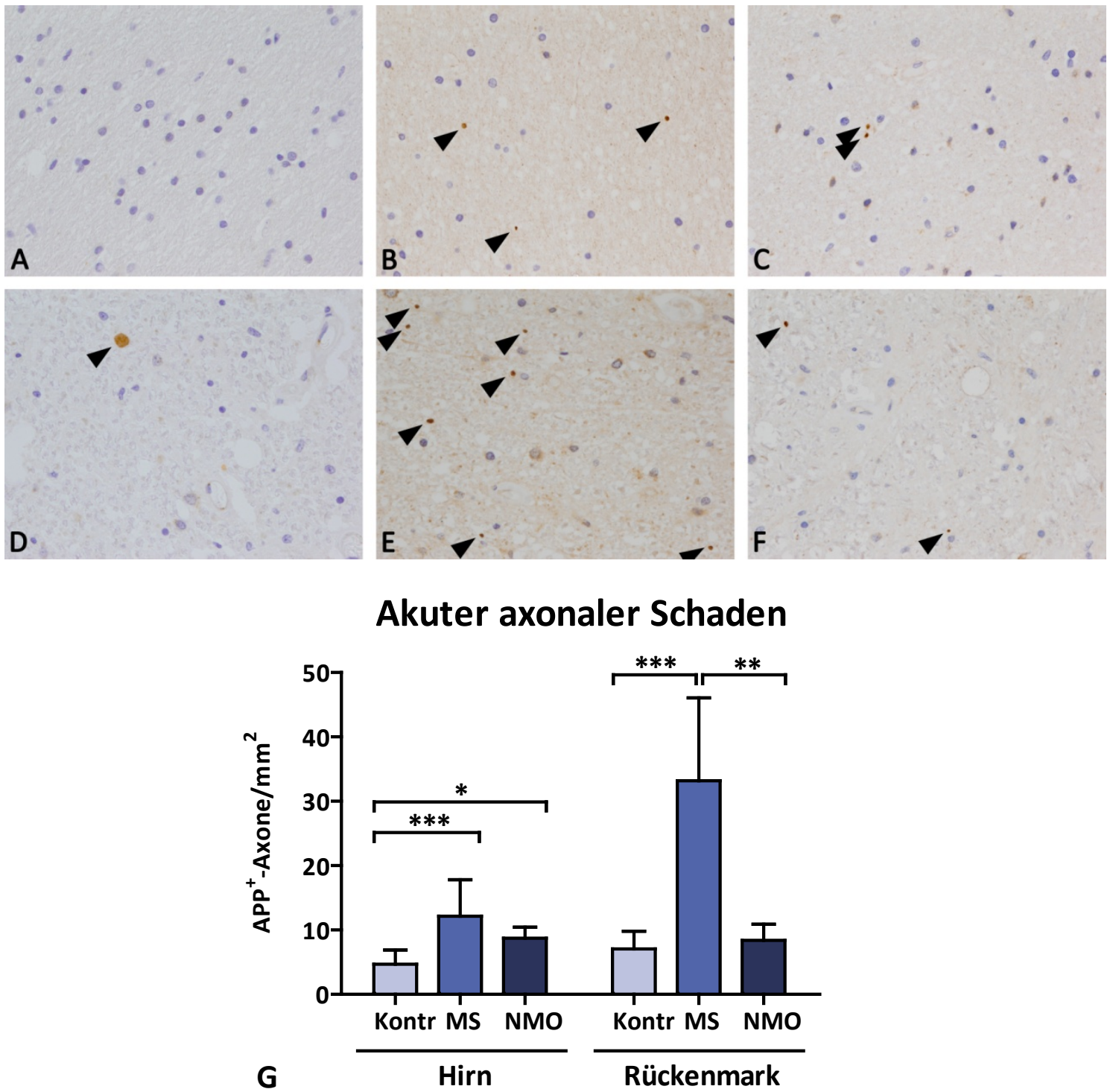

Abbildung 9: Akuter axonaler Schaden in der spinalen NAWM bei MS. 400fache Vergrößerung. APP-Färbung. Fotos A-C zeigen zerebrale, Fotos D-F spinale NAWM; In der zerebralen NAWM gesunder Kontrollen (A) sind nur ganz vereinzelt $\mathrm{APP}^{+}$-Axone zu sehen, hier jedoch keine APP ${ }^{+}$-Axone im Bild. Bei MS (B) sind dagegen einzelne $\mathrm{APP}^{+}$-Axone zu finden, hier drei im Bild. Auch bei NMO (C) treten vereinzelte $\mathrm{APP}^{+}$-Axone auf, hier zwei im Bild. In der zerebralen NAWM gesunder Kontrollen (D) sind ebenfalls nur ganz vereinzelt $\mathrm{APP}^{+}$-Axone zu finden, hier eins im Bild. Dagegen sind bei MS (E) im Rückenmark einige $\mathrm{APP}^{+}$-Axone im Parenchym verteilt zu sehen, hier sind sieben im Bild. Bei NMO (F) vereinzelte spinale $\mathrm{APP}^{+}$-Axone zu sehen, hier zwei im Bild. G) Graph. Gehirn: Signifikant vermehrte akute axonale Schädigung bei MS ( $n=16 ; 20$ Blöcke) verglichen mit den Kontrollen ( $n=13 ; 22$ Blöcke; $p<0,001^{* * *}, \mathrm{t}$-Test). Ebenfalls signifikant vermehrte akute axonale Schädigung bei NMO $(n=3$; 6 Blöcke) verglichen mit den Kontrollen ( $p=0,0304^{*}$, Mann-Whitney-Test). Kein signifikanter Unterschied der akuten axonalen Schädigung zwischen NMO und MS (n. s., Mann-Whitney-Test). Rückenmark: Signifikant vermehrte akute axonale Schädigung bei MS ( $n=12 ; 16$ Blöcke) verglichen mit den Kontrollen ( $n=12 ; 18$ Blöcke; $p<0,001 * * *$, Mann-Whitney-Test). Kein signifikanter Unterschied zwischen der akuten axonalen Schädigung bei NMO $(n=4 ; 4$ Blöcke) und den Kontrollen (n. s., MannWhitney-Test). Der Unterschied zwischen MS und NMO erwies sich wiederum als statistisch signifikant ( $p=0,0011 * *$, Mann-Whitney-Test). 


\subsubsection{Mehr desphosphorylierte Axone in der NAWM bei MS im Vergleich zu NMO- und Kontrollfällen}

Um die axonale Schädigung (SMI32+-Axone) in der NAWM bei MS, NMO und gesunden Kontrollen zu untersuchen, wurden dephosphorylierte Axone in der NAWM im Gehirn humaner Autopsiefälle anhand der SMI32-Färbung quantifiziert. In der spinalen NAWM war dagegen eine eindeutige Auswertung nicht sinnvoll möglich (siehe Kapitel 2.3.1.5).

Es konnte im Gehirn ein deutlich erhöhter Anteil dephosphorylierter Axone in der NAWM bei MS festgestellt werden (Abb. 10). Doch auch bei den Kontrollen ließen sich ganz vereinzelt SMI32 $2^{+}$-Axone nachweisen. Bei NMO traten ebenfalls SMI32 ${ }^{+}$ Axone nur vereinzelt auf, jedoch häufiger als bei den Kontrollen. Die dephosphorylierten Axone waren bei MS (MW: 41,95 $\pm 26,77 \mathrm{SMI} 32^{+}$-Axone $/ \mathrm{mm}^{2}$ ) hoch signifikant vermehrt, verglichen mit gesunden Kontrollen (MW: $4,43 \pm 2,08$ SMI32 ${ }^{+}$-Axone $\left./ \mathrm{mm}^{2} ; \mathrm{p}<0,001 * * *\right)$. Bei NMO (MW: 7,60 $\pm 9,46 \mathrm{SMI} 32^{+}-$ Axone $/ \mathrm{mm}^{2}$ ) waren die dephosphorylierten Axone zwar im Vergleich zu den Kontrollen quantitativ leicht vermehrt, jedoch nicht signifikant. Der Unterschied in der Anzahl desphosphorylierter Axone zwischen NMO und MS war statistisch signifikant $\left(\mathrm{p}=0,0245^{*}\right)$. 

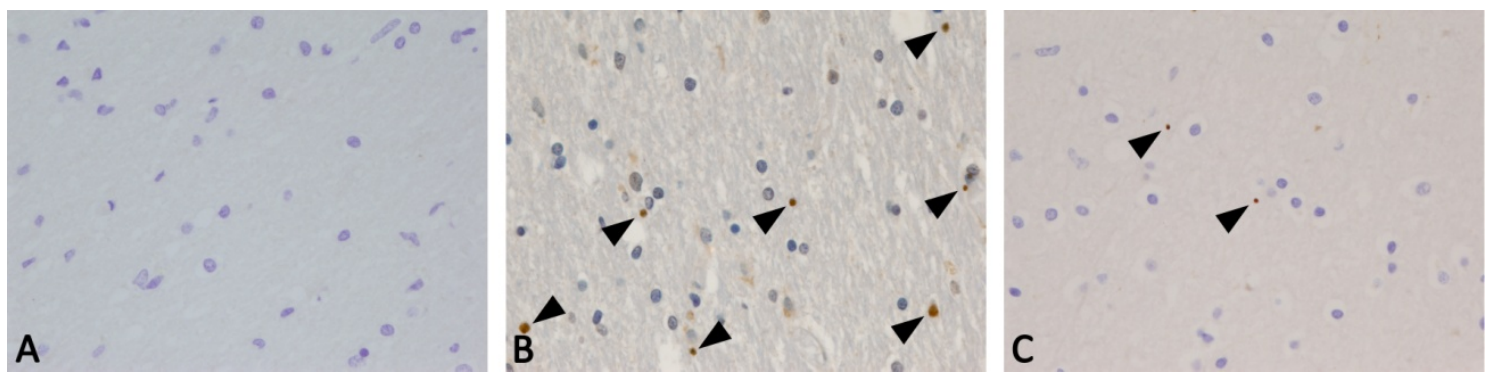

\section{Axonaler Schaden}

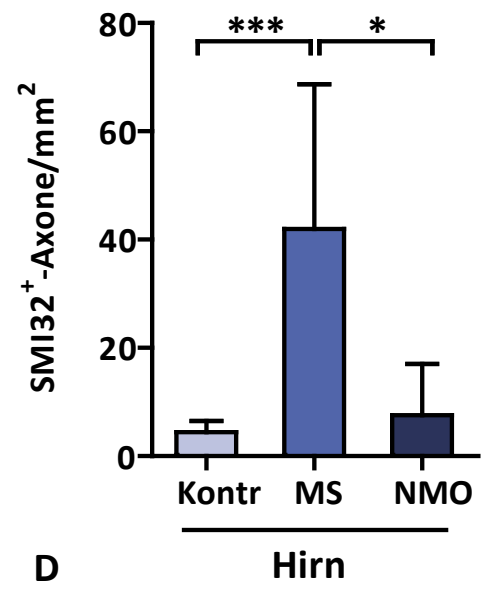

Abbildung 10: Mehr desphosphorylierte Axone (SMI32 ${ }^{+}$-Axone) in der NAWM bei MS im Vergleich zu NMO- und Kontrollfällen. 400fache Vergrößerung. SMI32-Färbung. Fotos A-C zeigen zerebrale NAWM; In zerebraler NAWM von gesungen Kontrollen (A) sind nur ganz vereinzelt SMI32 ${ }^{+}$-Axone zu sehen, hier jedoch keines im Bild. Bei MS (B) sind dagegen bereits einige SMI32 ${ }^{+}$-Axone im Parenchym verteilt, hier sieben im Bild. In der NAWM von NMO-Fällen (C) sind wieder nur vereinzelte SMI32 ${ }^{+}$-Axone zu beobachten, hier zwei im Bild. (D) Graph. Hoch signifikant erhöhte Dichte desphosphorylierter Axone bei MS ( $n=16 ; 20$ Blöcke) verglichen mit gesunden Kontrollen ( $n=13 ; 22$ Blöcke; $p<0,001 * * *$, $t$-Test). Quantitativ leicht vermehrt desphosphorylierte Axone bei NMO ( $n=3 ; 6$ Blöcke) verglichen mit gesunden Kontrollen (n.s., Mann-Whitney-Test). Signifikanter Unterschied in der Anzahl desphosphorylierte Axone zwischen NMO und MS ( $p=0,0245^{*}$, Mann-Whitney-Test). 


\subsubsection{Erhöhte Dichte von TPPP/p25 ${ }^{+}$-Oligodendrozyten in der NAWM bei MS}

Um Veränderungen der Dichte reifer Oligodendrozyten in der NAWM bei MS und NMO zu bestimmen, wurden die p25 -Oligodendrozyten in zerebraler und spinaler NAWM quantifiziert.

Die absolute Anzahl von p25 -Zellen war in allen drei Gruppen im Hirn höher als im Rückenmark (Abb. 11 A-F), wobei die höchste Anzahl in der zerebralen NAWM von MS-Patienten auftrat (Abb. $11 \mathrm{G}$ ).

Da insbesondere im Rückenmark ein ausgeprägter axonaler Verlust sowohl bei MS als auch bei NMO nachweisbar war, wurde im folgenden die Oligodendrozytenzahl in Relation zur axonalen Dichte gesetzt, um Unterschiede in der oligodendroglialen Dichte im Verhältnis zur jeweiligen axonalen Dichte erfassen zu können. Hierzu wurde der Quotient von p $25^{+}$-Zellen zur axonalen Dichte ermittelt. Das Verhältnis von $25^{+}$-Zellen zur axonalen Dichte war bei der MS sowohl in der zerebralen $(p=0,0304 *)$ als auch spinalen NAWM $\left(\mathrm{p}=0,0014{ }^{* *}\right)$ im Vergleich zu den Kontrollen signifikant erhöht, während es bei NMO vergleichbar zu den Kontrollfällen war (Abb. $11 \mathrm{G}$ ). Auch zwischen MS und NMO war das Verhältnis von $25^{+}$-Zellen zur axonalen Dichte in der zerebralen NAWM tendenziell ( $\mathrm{p}=0,0972$ Trend) und in der spinalen NAWM signifikant erhöht $(p=0,0398 *)($ Abb. $11 \mathrm{G})$. 

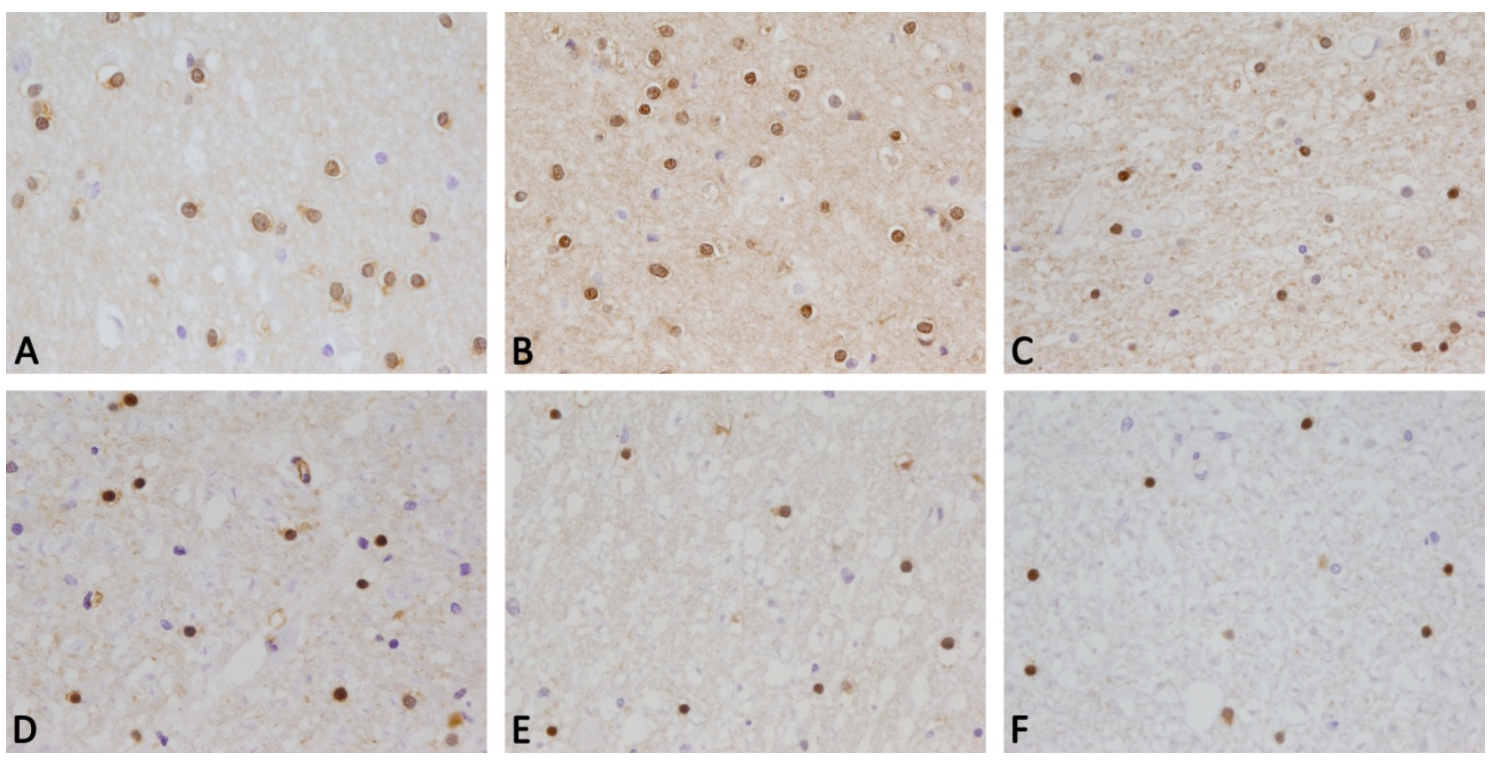

\section{Oligodendrogliale Dichte relativ zur axonalen Dichte}

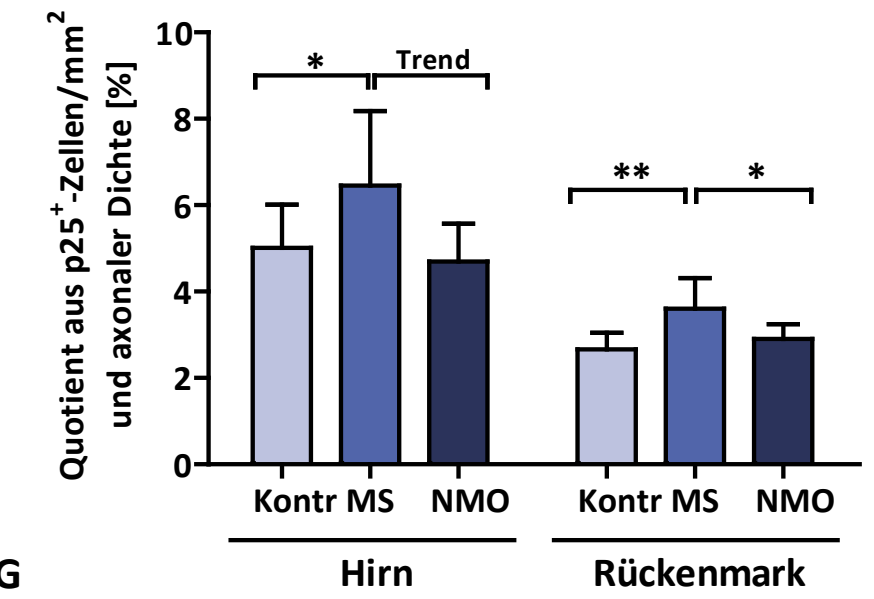

Abbildung 11: Erhöhte Oligodendrozytendichte in der zerebralen NAWM bei MS. 400fache Vergrößerung. TPPP/p25-Färbung. Fotos A-C zeigen zerebrale, Fotos D-F spinale NAWM; In der zerebralen WM gesunder Kontrollen (A) sind zahlreiche p $25^{+}$-Zellen zu sehen, hier 19 im Bild. Bei MS (B) sind mehr p25 $5^{+}$-Zellen in der NAWM zu finden, hier $24 \mathrm{im}$ Bild. Wie bei den Kontrollen sind auch bei NMO (C) zahlreiche p25 -Zellen zu sehen, hier $17 \mathrm{im}$ Bild. In der spinalen WM gesunder Kontrollen (D) sind deutlich weniger p25 $5^{+}$-Zellen zu sehen als im Gehirn, hier neun im Bild. Auch in der NAWM bei MS (E) ist die absolute Anzahl p25 $5^{+}$-Zellen geringer als im Gehirn, jedoch auch stärker reduziert als bei den Kontrollen, hier acht Zellen im Bild. Bei NMO (F) ist die absolute Zahl p25-Zellen sogar noch geringer, hier sechs im Bild. (G) Graph. Um die oligodendrogliale Dichte in Abhängigkeit von der axonalen Dichte zu betrachten, wurde folgend der Quotient $\mathrm{p} 25^{+}$-Zellen zur axonalen Dichte ermittelt. Gehirn: Signifikant erhöhte Oligodendrozytendichte im Verhältnis zur axonalen Dichte bei MS ( $n=15$; 19 Blöcke) verglichen mit gesunden Kontrollen ( $n=13 ; 22$ Blöcke; $p=0,0304$ *, Mann-Whitney-Test). Kein signifikanter Unterschied bei NMO ( $n=3 ; 6$ Blöcke) verglichen mit gesunden Kontrollen ( $n$. s., Mann-Whitney-Test), aber tendenziell erhöht bei MS verglichen mit NMO ( $p=0,0972$ Trend, MannWhitney-Test). Rückenmark: Signifikant erhöhte Oligodendrozytendichte im Verhältnis zur axonalen Dichte bei MS ( $n=12 ; 16$ Blöcke) verglichen mit gesunden Kontrollen ( $n=12 ; 18$ Blöcke; $p=0,0014 * *$, Mann-Whitney-Test). Keine signifikanter Unterschied bei NMO ( $n=4 ; 4$ Blöcke) verglichen mit gesunden Kontrollen (n. s., Mann-Whitney-Test). Jedoch erhöhte Oligodendrozytendichte im Verhältnis zur axonalen Dichte bei MS verglichen mit NMO ( $p=0,0398$ *, Mann-Whitney-Test). 


\subsubsection{Spinal vermehrte Astrogliose in der NAWM bei MS im Vergleich zu Kontrollfällen}

Um den Grad der Astrogliose in der NAWM von MS, NMO und der WM altersentsprechender gesunder Kontrollen zu untersuchen, wurden die sternförmigen, reaktiven Astrozyten mit Hilfe der GFAP-Färbung quantifiziert.

Die Zahl der reaktiven Astrozyten war bei allen drei Gruppen im Rückenmark höher als im Gehirn (Abb. 12).

Im Gehirn (Abb. 12 A-C, G) war nur bei NMO (Abb. 12 C) die Anzahl der reaktiven Astrozyten erhöht. Die Zellzahl war bei MS dagegen auf dem Niveau der Kontrollen. Dementsprechend ergab sich kein signifikanter Unterschied in der Dichte von reaktiven Astrozyten bei MS (MW: 77,96 $\pm 13,63 \mathrm{GFAP}^{+}$-Zellen/ $\mathrm{mm}^{2}$ ) verglichen mit gesunden Kontrollen (MW: 80,56 9,00 GFAP ${ }^{+}$Zellen $/ \mathrm{mm}^{2}$ ). Dagegen war die Zahl von reaktiven Astrozyten bei NMO (MW: 99,51 $\pm 6,61 \mathrm{GFAP}^{+}$-Zellen/mm²) sowohl im Vergleich zu den Kontrollen ( $\left.\mathrm{p}=0,0071^{* *}\right)$, als auch im Vergleich zur MS signifikant erhöht $(\mathrm{p}=0,0098 * *)$.

Im Rückenmark (Abb. 12 D-F, G) war die Anzahl der reaktiven Astrozyten bei MS und NMO im Vergleich zu den Kontrollen erhöht. Die Kontrollen wiesen im Rückenmark bereits mehr reaktive Astrozyten auf als im Gehirn. In der NAWM bei NMO war die Zellzahl auch spinal höher als bei MS. So erwies sich die erhöhte Dichte von reaktiven Astrozyten bei MS (MW: 144,03 $\pm 23,23 \mathrm{GFAP}^{+}$-Zellen/ $/ \mathrm{mm}^{2}$ ) verglichen mit gesunden Kontrollen (MW: 110,93 $\pm 8,73 \mathrm{GFAP}^{+}$-Zellen $/ \mathrm{mm}^{2} ; \quad \mathrm{p}<0,001 * * *$ ) als hoch signifikant. Auch der Vergleich zwischen NMO (MW: 166,98 $\pm 25,97$ GFAP $^{+}$Zellen $/ \mathrm{mm}^{2}$ ) und den Kontrollen stellte sich als hoch signifikant heraus ( $\left.\mathrm{p}<0,001 * * *\right)$. Bei NMO war im Vergleich zur MS die Dichte der reaktiven Astrozyten lediglich tendenziell erhöht ( $p=0,0925$ Trend). 

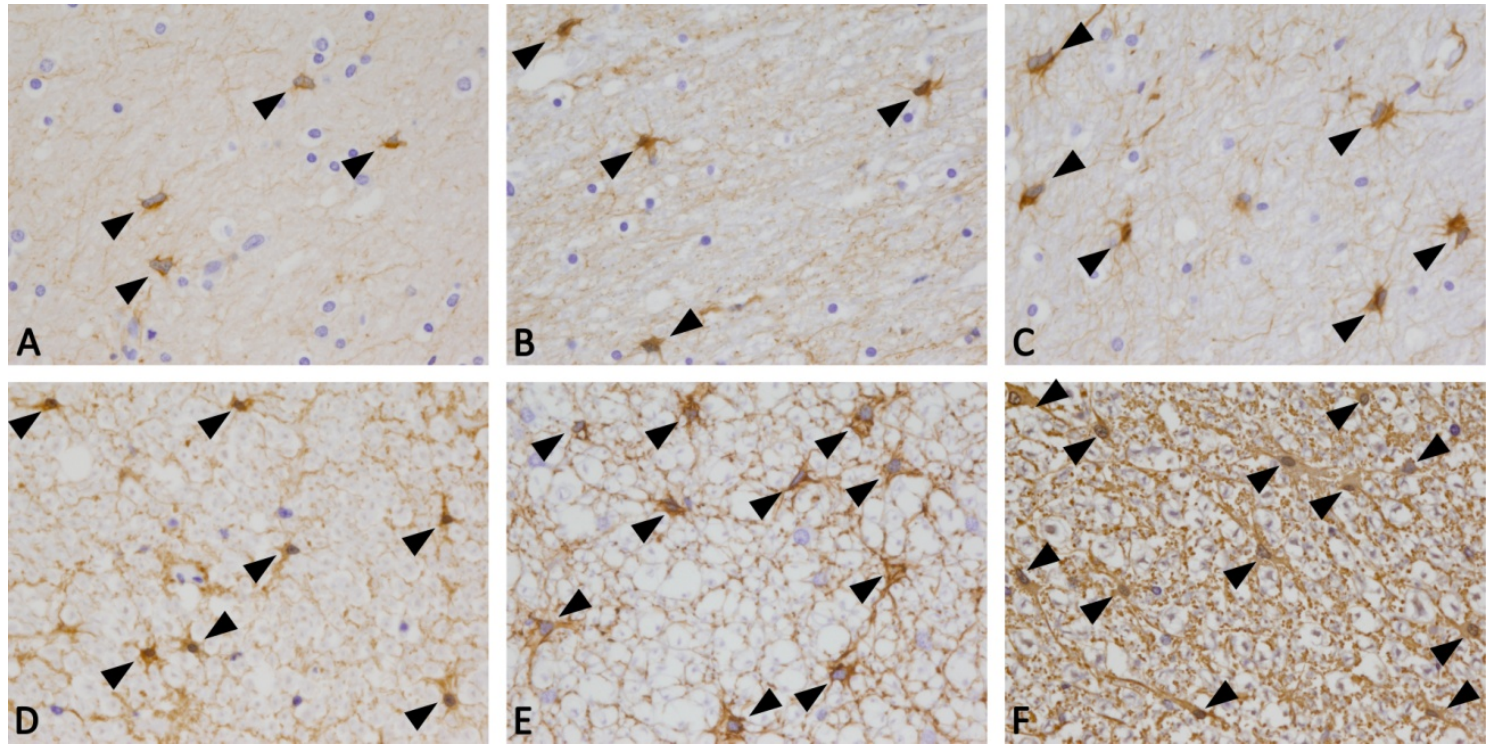

\section{Reaktive Astrozyten}

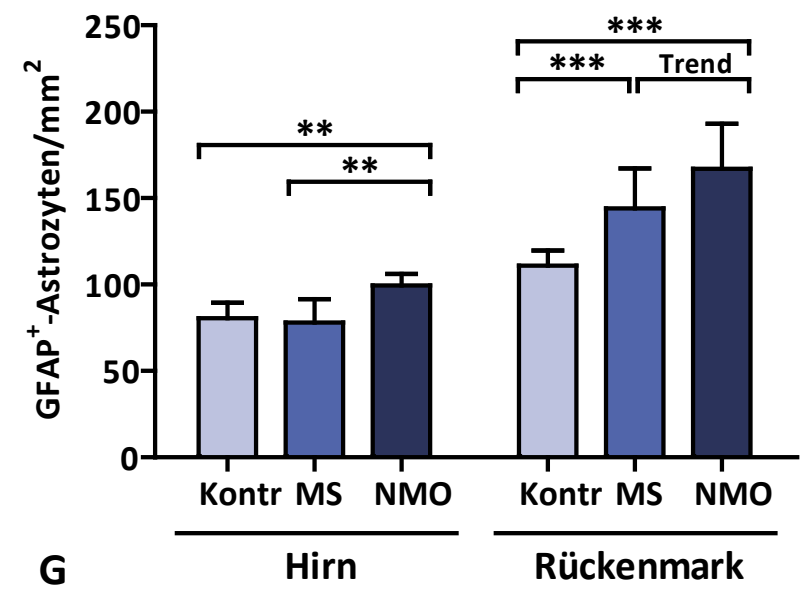

Abbildung 12: Spinal vermehrt reaktive Astrozyten in der NAWM bei MS im Vergleich zu Kontrollfällen. 400fache Vergrößerung. GFAP-Färbung. Fotos A-C zeigen zerebrale, Fotos $D-F$ spinale NAWM; In der zerebralen WM gesunder Kontrollen $(\mathrm{A})$ sind einige GFAP ${ }^{+}$-Zellen zu sehen, hier vier im Bild. Bei MS (B) sind ebenfalls einige GFAP ${ }^{+}$-Zellen zu finden, hier vier im Bild. In der NAWM bei NMO (C) sind dagegen mäßig viele GFAP ${ }^{+}$-Zellen zu sehen, hier sechs im Bild. In der spinalen NAWM gesunder Kontrollen (D) sind mehr GFAP ${ }^{+}$-Zellen als im Gehirn zu sehen, hier sieben im Bild. Auch bei MS (E) steigt die Zahl reaktiver Astrozyten, es sind zahlreiche GFAP ${ }^{+}$-Zellen zu beobachten, hier zehn im Bild. Wie bereits im Gehirn, ist auch im spinalen Gewebe bei NMO (F) die Zahl reaktiver Astrozyten am höchsten. Es sind viele GFAP ${ }^{+}$-Zellen zu sehen, hier zwölf im Bild. (G) Graph. Gehirn: Kein signifikanter Unterschied in der Dichte von reaktiven Astrozyten bei MS ( $n=15 ; 19$ Blöcke) verglichen mit gesunden Kontrollen ( $n=13 ; 22$ Blöcke; n. s., t-Test). Signifikant erhöhte Dichte von reaktiven Astrozyten bei NMO ( $n=3$; 6 Blöcke) verglichen mit gesunden Kontrollen ( $p=0,0071 * *$, Mann-Whitney-Test). Signifikant erhöhte Dichte von reaktiven Astrozyten bei NMO verglichen mit MS ( $p=0,0098 * *$, Mann-Whitney-Test). Rückenmark: Hoch signifikant erhöhte Dichte von reaktiven Astrozyten bei MS ( $n=12 ; 16$ Blöcke) verglichen mit gesunden Kontrollen ( $n=12 ; 18$ Blöcke; $p<0,001 * * *$, t-Test). Hoch signifikant erhöhte Dichte von reaktiven Astrozyten bei NMO ( $n=4 ; 4$ Blöcke) verglichen mit gesunden Kontrollen ( $p<0,001 * * *, t-T e s t)$. Tendenziell erhöhte Dichte von reaktiven Astrozyten bei NMO verglichen mit MS ( $p=0,0925$ Trend, $t$-Test). 


\subsection{Spinale Veränderungen in der NAWM bei Mäusen mit chronischer EAE}

Um die Veränderungen in der NAWM auch bei Mäusen mit EAE zu charakterisieren, erfolgten die entsprechenden Untersuchungen auch an Mäusen mit EAE und an gesunden Kontrollmäusen. Um zu ermitteln, ob und - wenn ja wie - Veränderungen in der NAWM bei den EAE-Tieren durch die Läsionslast beeinflusst werden, wurden die EAE-Tiere nach dem Schweregrad der spinalen Demyelinisierung in zwei Gruppen eine mit geringer $\left(<5 \%\right.$ der weißen Substanz entmarkt; EAE $\left.{ }^{\text {gering }}\right)$ und die andere mit hoher (10-15\% der weißen Substanz entmarkt; EAE ${ }^{\text {hoch }}$ ) Läsionslast - eingeteilt.

Wie zu erwarten, zeigten diese beiden Gruppen der Tiere mit EAE (Abb. 13 B und E) einen statistisch hoch signifikanten Unterschied in der Läsionslast (EAE ${ }^{\text {gering. }} \mathrm{MW}$ : $2,40 \pm 1,26 \%$ der weißen Substanz entmarkt, EAE hoch ${ }^{\text {: }}$ MW: $11,83 \pm 1,62 \%$ der weißen Substanz entmarkt; $\mathrm{p}<0,0001 * * *, \quad \mathrm{t}$-Test) (Abb. $13 \mathrm{D}$ ). Ergänzend wurden Rückenmärker fünf gesunder Tiere zum Vergleich herangezogen (siehe Abb. $13 \mathrm{~A}$ und D). Alle drei Gruppen wurden wie die humanen Autopsiefälle hinsichtlich entzündlicher, axonaler und glialer Parameter untersucht. 

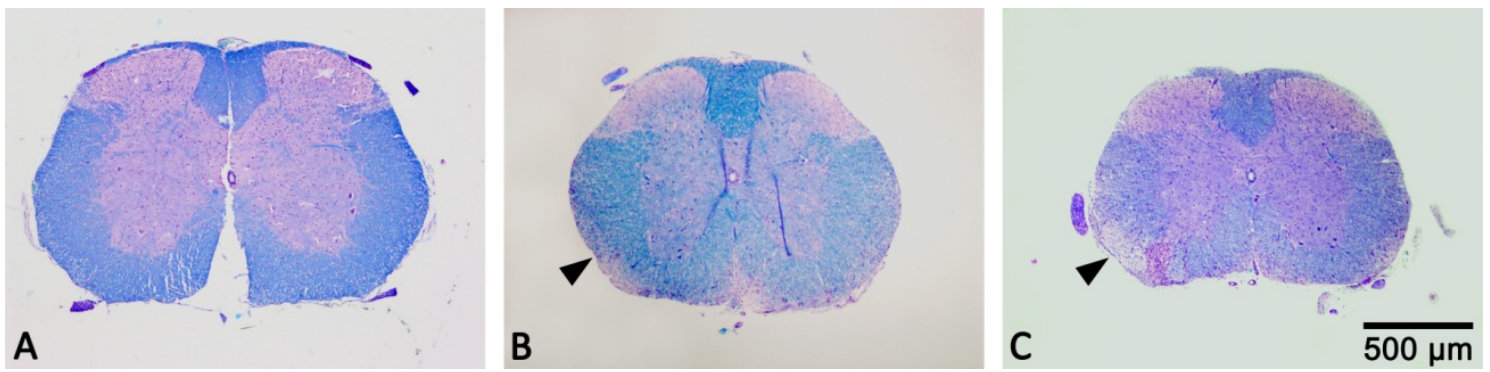

Läsionslast

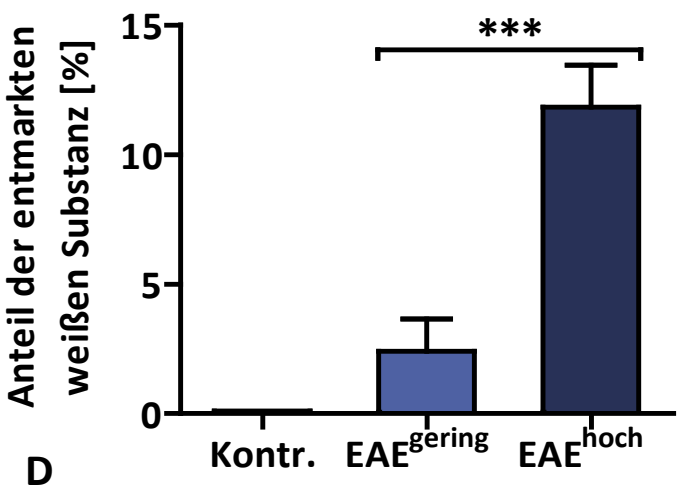

Abbildung 13: Anteil demyelinisierter weißer Substanz im Rückenmark von gesunden Tieren und Mäusen mit chronischer EAE. 40fache Vergrößerung. LFB/PAS-Färbung. Die WM einer gesunden Maus (A) ist regulär myelinisiert. Bei Mäusen mit chronischer EAE der Gruppe mit geringer Läsionslast (B) $\left(<5 \%\right.$ bzw. EAE ${ }^{\text {gering; }}$; bei diesem Tier durchschnittlich 3,08\% der weißen Substanz entmarkt) sind bereits in der Übersichts-Vergrößerung demyelinisierte Bereiche der WM sichtbar. Die Demyelinisierung ist besonders im äußeren Randbereich der WM subpial konzentriert (siehe Pfeil). Bei Mäusen mit

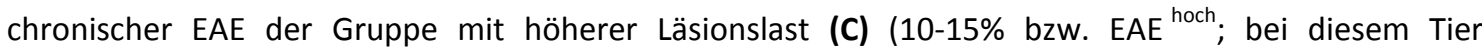
durchschnittlich 11,91\% der weißen Substanz entmarkt) ist die Demyelinisierung nicht mehr nur primär auf den äußeren Randbereich konzentriert. Die Läsionen sind ausgeprägter und reichen tiefer in die WM (siehe Pfeil). (D) Graph. Hoch signifikanter Unterschied in der Läsionslast zwischen beiden Gruppen der Tiere mit $\operatorname{EAE}\left(p<0,0001^{* * *}\right.$, t-Test). Zum Vergleich wurden fünf Rückenmärker gesunder Tiere herangezogen. 


\subsubsection{Erhöhte T-Lymphozytendichte in der NAWM bei Mäusen mit EAE in Abhängigkeit von der Läsionslast}

Um zu untersuchen, ob sich die parenchymale Lymphozytendichte in der NAWM zwischen gesunden Tieren und den beiden Gruppen von Mäusen mit chronischer EAE unterscheidet, wurde das spinale Parenchym mit Hilfe der CD3-Färbung untersucht.

In der NAWM von Mäusen mit EAE stieg die T-Lymphozytendichte mit dem Grad der Demyelinisierung. In der WM der Kontrollen waren kaum T-Lymphozyten vorhanden (MW: 0,32 \pm 0,72 T-Lymphozyten $/ \mathrm{mm}^{2}$ ) (Abb. $\left.14 \mathrm{~A}\right)$. In der NAWM der Mäuse mit geringer Läsionslast waren dagegen bereits einige $\mathrm{CD}^{+}$-Zellen nachweisbar (MW: $24,00 \pm$ 4,62 T-Lymphozyten $/ \mathrm{mm}^{2}$ ) (Abb. 14 B). Verglichen mit den Kontrollen ergab sich daraus eine signifikant erhöhte T-Lymphozytendichte bei Mäusen mit geringer Läsionslast $\left(\mathrm{p}=0,0025^{* *}\right)$ (Abb. $\left.14 \mathrm{D}\right)$. Auch bei den Mäusen mit hoher Läsionslast (MW: 43,43 \pm 3,51 T-Lymphozyten/ $/ \mathrm{mm}^{2}$ ) war die T-Lymphozytendichte im Vergleich zu gesunden Kontrollen signifikant erhöht $(\mathrm{p}=0,0013 * *)$. Mäuse mit hohe Läsionslast wiesen eine hoch signifikant erhöhte T-Lymphozytendichte im Vergleich zu den Tieren mit geringer Läsionslast auf ( $\mathrm{p}<0,001 * * *)$ (Abb. 14 B-D).

Der Score zur T-Lymphozyteninfiltration des VRR wurde bei den Mäusen nicht erhoben, da keine eindeutige Zuordnung der T-Lymphozyten zum VRR möglich war. 

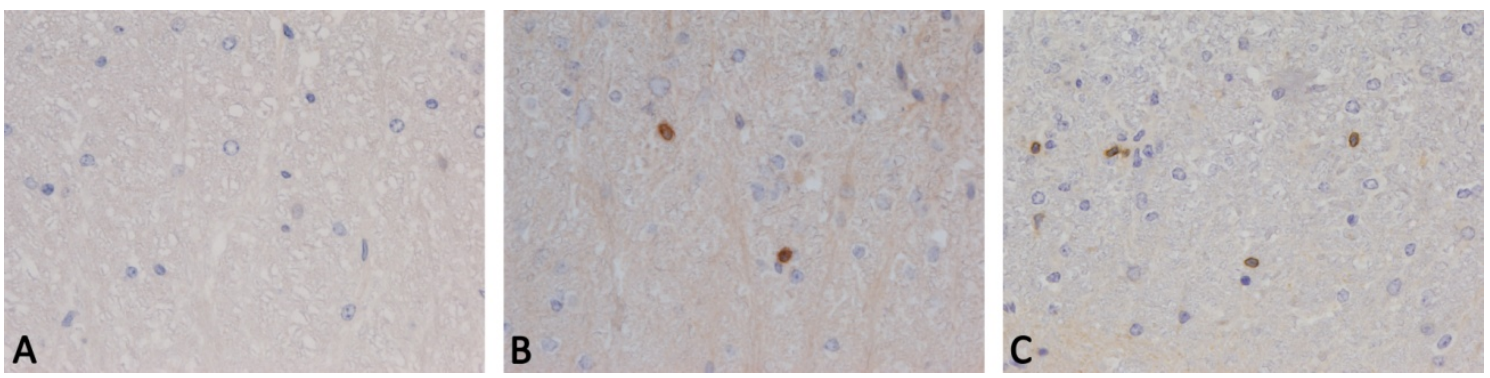

\section{T-Lymphozytendichte}

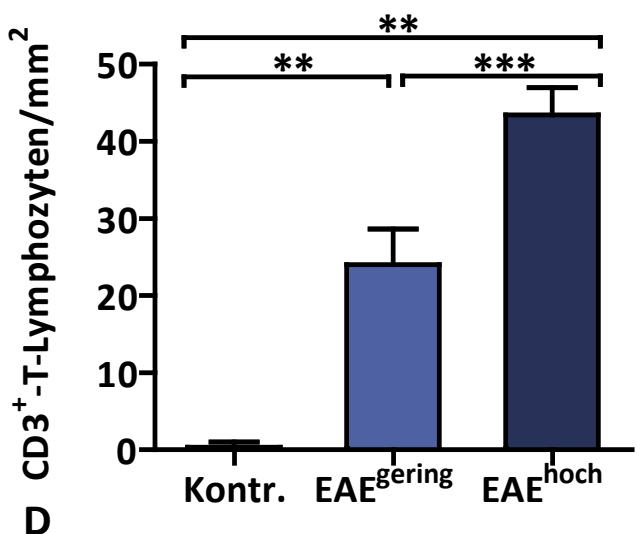

Abbildung 14: Erhöhte T-Lymphozytendichte in der spinalen NAWM bei Mäusen mit EAE in Abhängigkeit von der Läsionslast. 400fache Vergrößerung. CD3-Färbung. In der WM gesunder Mäuse (A) sind nur ganz vereinzelt T-Lymphozyten anzutreffen, hier jedoch keine im Bild. In der NAWM von Mäusen mit geringer Läsionslast (B) (EAE ${ }^{\text {gering }}$ ) sind einzelne bis einige T-Lymphozyten in der NAWM zu

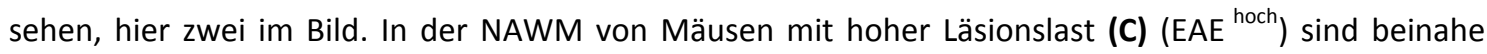
doppelt so viele T-Lymphozyten wie bei Mäusen mit geringer Läsionslast nachweisbar, hier vier Zellen im Bild. (D) Graph. Signifikant erhöhte T-Lymphozytendichte bei Mäusen mit EAE und geringer Läsionslast im Vergleich zu den Kontrollen ( $p=0,0025 * *$, Mann-Whitney-Test). Signifikant erhöhte TLymphozytendichte bei Mäusen mit EAE und hoher Läsionslast im Vergleich zu den Kontrollen $\left(p=0,0013^{* *}\right.$, Mann-Whitney-Test) und zu Mäusen mit EAE und geringer Läsionslast $(p<0,001 * * *, t-$ Test). 


\subsubsection{Vermehrte Mikrogliaaktivierung in der NAWM bei Mäusen mit EAE}

Um den Grad der Mikrogliaaktivierung in der NAWM von Mäusen mit EAE und gesunden Tieren zu untersuchen, wurde hier die Dichte der aktivierten Mikroglia als Parameter für einen semi-quantitativen Score in der MAC3-Färbung ermittelt. Der MAC3-Score (Score $0 \hat{=}$ normal/nicht erhöht, Score $0,5 \bumpeq$ leicht erhöht; $1 \bumpeq$ mäßig erhöht, $2 \bumpeq$ stark erhöht) war an den Score für die KiM1P-Färbung angelehnt (siehe 2.3.2.2; vergl. KiM1P-Score in Kapitel 2.3.1.3; vergl. Beispielfotos KiM1P-Score Kapitel 3.1.2).

Die Dichte der aktivierten Mikroglia war bei beiden EAE-Gruppen deutlich erhöht, auch wenn sie insgesamt recht gering - insbesondere im Vergleich zu den humanen Erkrankungen - ausfiel (Abb. 15). Bei den Kontrollen waren keine MAC3 ${ }^{+}$-Zellen in der WM zu finden (MW Score: 0,0 $\pm 0,0$ ) (Abb. 15 A). In der NAWM der Mäusen mit geringer Läsionslast waren einzelne $\mathrm{MAC}^{+}$-Zellen nachweisbar (MW Score: $0,57 \pm 0,19$ ) (Abb. 15 B). Daraus ergab sich eine signifikant erhöhte Dichte aktivierter Mikroglia bei Mäusen mit geringer Läsionslast im Vergleich zu den Kontrollen $\left(\mathrm{p}=0,0013^{* *}\right)$ (Abb. 15 D). In der NAWM von Mäusen mit hoher Läsionslast war die Dichte der aktivierten Mikroglia mäßig erhöht (MW Score: 0,86 0,38) (Abb. 15 C). Auch bei den Mäusen mit hoher Läsionslast war die Dichte der aktivierten Mikroglia im Vergleich zu den Kontrollen signifikant erhöht ( $p=0,0013 * *)$ (Abb. 15 D). Dagegen ergab der Vergleich der beiden EAE-Gruppen keine signifikanten Unterschiede. 

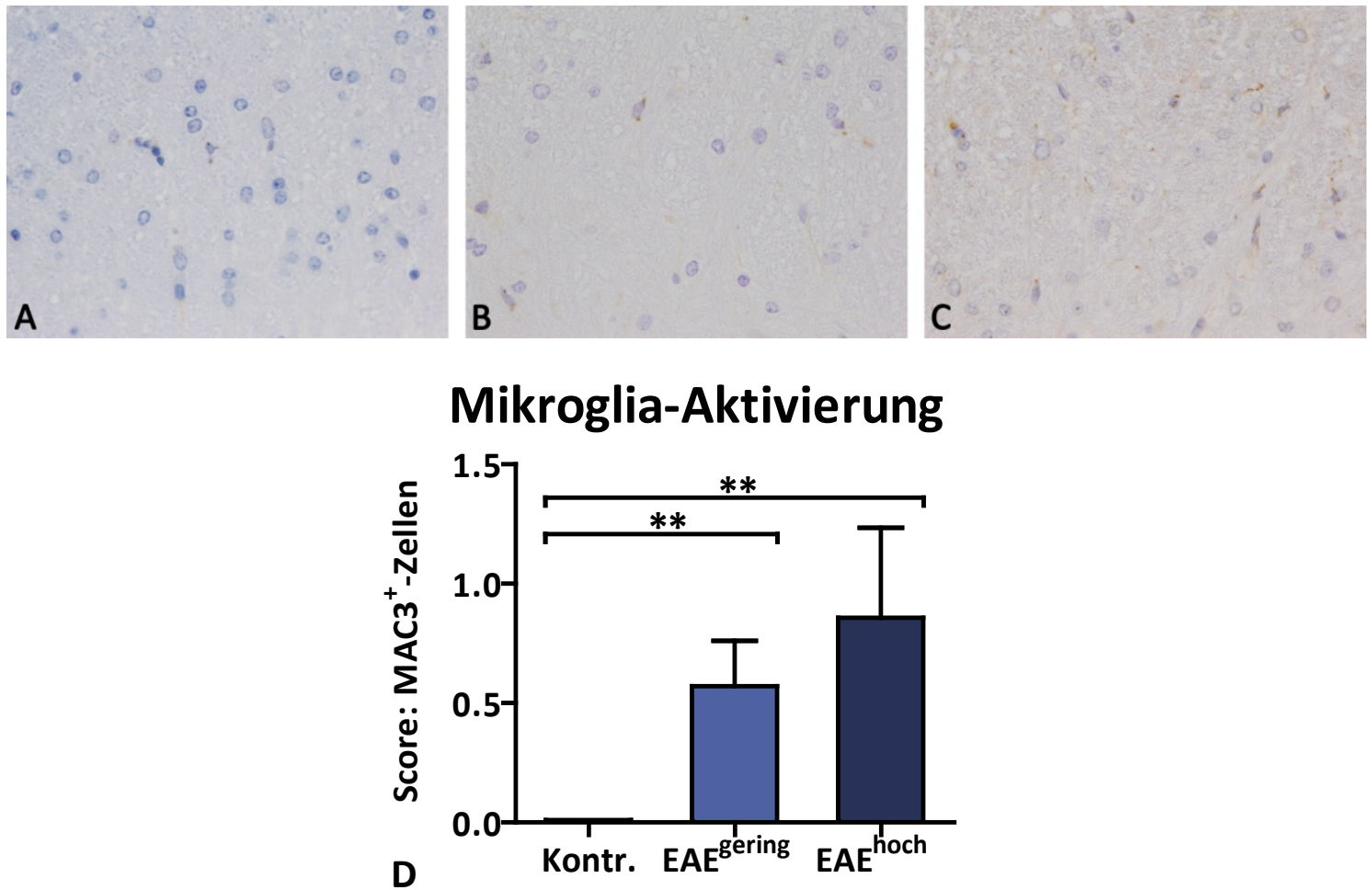

Abbildung 15: Vermehrte Mikrogliaaktivierung (Score: Dichte der aktivierten Mikrogliazellen anhand der MAC3 ${ }^{+}$-Zellen) in der spinalen NAWM von Mäusen mit chronischer EAE. 400fache Vergrößerung. MAC3-Färbung. Generell ist die Mikrogliaaktivierung geringer als im humanen Gewebe (vergl. KiM1PScore). Keine Maus zeigte eine Score von 2. In der WM gesunder Mäuse (A) sind keine MAC3 ${ }^{+}$-Zellen

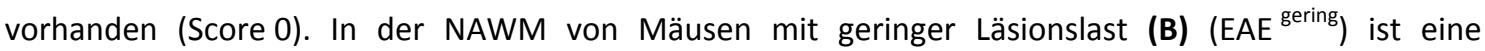
überwiegend leicht erhöhte Dichte aktivierter Mikroglia zu sehen (Score 0,5). Bei Mäusen mit hoher Läsionslast (C) (EAE ${ }^{\text {hoch }}$ ) tritt vorwiegend eine mäßig erhöhte Dichte aktivierter Mikroglia auf (Score 1). (D) Graph. Signifikant erhöhte Dichte aktivierter Mikroglia bei Mäusen mit EAE und geringer Läsionslast im Vergleich zu den Kontrollen ( $p=0,0013^{* *}$, Mann-Whitney-Test). Signifikant erhöhte Dichte aktivierter Mikroglia bei Mäusen mit EAE und hoher Läsionslast im Vergleich zu den Kontrollen ( $p=0,0013^{* *}$, Mann-Whitney-Test). Keine signifikanten Unterschiede zwischen Mäusen mit hoher und geringer Läsionslast (n. s., Mann-Whitney-Test).

\section{Mikrogliaknötchen}

Zusätzlich zur Dichte der aktivierten Mikroglia wurden alle Gewebeblöcke nach Mikrogliaknötchen (MGK) durchsucht. Der Score bewertet auch hier das Vorhandensein (Score 1) oder Fehlen (Score 0) von MGK bei einem Tier in der spinalen NAWM (bzw. WM bei den gesunden Mäusen). Größe und Anzahl der MGK wurden nicht quantifiziert. Die Definition eines MGK war für humanes und murines Gewebe identisch (siehe Kapitel 2.3.2.2 und auch 2.3.1.3 mit Score-Übersicht Tabelle 8). Nach Erhebung des Scores wurde der prozentuale Anteil der Mäuse in den Gruppen errechnet, die MGK in der NAWM/WM aufwiesen. 
MGK waren bei keinem Kontrolltier nachweisbar (Abb. 16). In der NAWM von Mäusen mit geringer Läsionslast waren sie dagegen bei vielen zu sehen (MW: $85,71 \pm 37,80 \%$ ) (Abb. 16 A). Daraus ergab sich ein signifikant erhöhtes Vorhandensein von MGK bei Mäusen mit geringer Läsionslast im Vergleich zu den Kontrollen (MW: 0,0 0,0\%; p=0,0152*) (Abb. 16 B). Bei den Mäusen mit hoher Läsionslast waren MGK sogar in allen Fällen vorhanden (MW: 100,00 $\pm 0,00 \%$ ), woraus im Vergleich zu gesunden Mäusen ein signifikanter Unterschied resultierte $\left(p=0,0013^{* *}\right)($ Abb. 16 B). Dagegen war die Zahl nachweisbarer MGK bei Mäusen mit hoher Läsionslast im Vergleich zu Mäusen mit geringer Läsionslast zwar quantitativ erhöht, der Unterschied war jedoch statistisch nicht signifikant (Abb. 16 B).

\section{Präsenz von Mikrogliaknötchen}
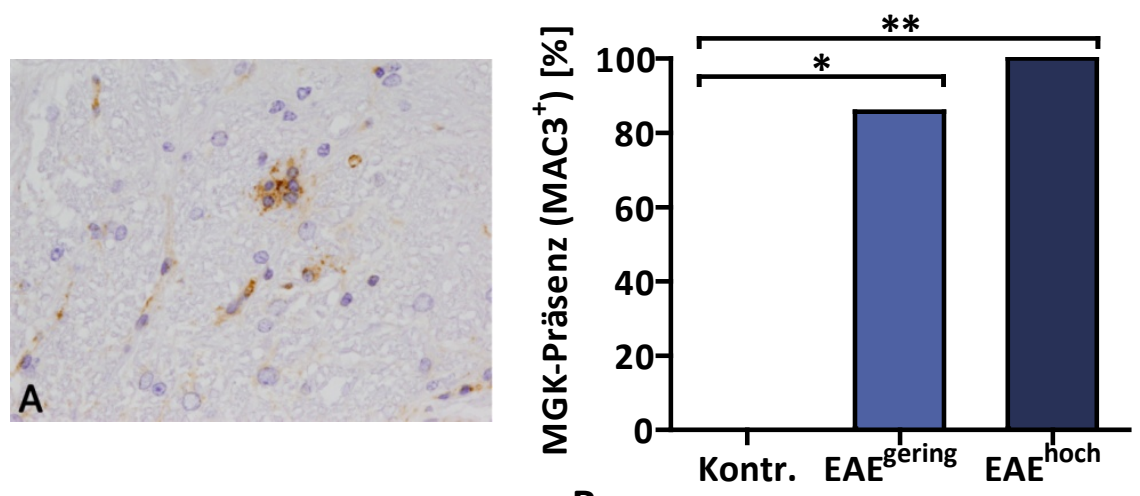

Abbildung 16: Vermehrt vorhandene Mikrogliaknötchen (MGK) in der spinalen NAWM von Mäusen mit chronischer EAE im Vergleich zu gesunden Tieren. Das Vorhandensein von MGK als Score erfasst und als prozentualen Anteil innerhalb der Gruppen angegeben. 400fache Vergrößerung. MAC3-Färbung. (A) Beispiel für ein MGK (EAE ${ }^{\text {gering }}$, hier mit 2,47\% der weißen Substanz entmarkt): Es sind fünf MGKassoziierte MAC3 ${ }^{+}$-Zellen zu sehen. (B) Graph. Signifikant erhöhte Zahl von MGK bei EAE-Mäusen mit geringer Läsionslast im Vergleich zu den Kontrollen ( $p=0,0152 *$, Mann-Whitney-Test). Ebenfalls signifikant erhöhte Zahl von MGK bei Mäusen mit EAE und hoher Läsionslast im Vergleich zu den Kontrollen ( $p=0,0013^{* *}$, Mann-Whitney-Test). Zwar quantitativ erhöhte Zahl von MGK bei Mäusen mit EAE und hoher Läsionslast im Vergleich zu Mäusen mit EAE und geringer Läsionslast, der Unterschied ist jedoch statistisch nicht signifikant (n. s., Mann-Whitney-Test). 


\subsubsection{Reduktion der axonalen Dichte in der NAWM bei Mäusen mit EAE in Abhängigkeit von der Läsionslast}

Um die axonale Dichte in der NAWM zu bestimmen, wurde das Rückenmark aller Mäuse mit Hilfe der Bielschowsky-Färbung untersucht und in Relation zu den Werten gesunder Kontrolltiere angegeben (siehe Kapitel 2.3.2.2 und 2.3.1.6).

Es zeigte sich eine Reduktion der axonalen Dichte mit steigender Läsionslast der Mäuse (Abb. 17). Die statistische Auswertung ergab eine signifikant reduzierte axonale Dichte in der NAWM von Mäuse mit geringer Läsionslast (MW: 87,32 $\pm 7,18 \%$ ) im Vergleich zu den Kontrollen (MW: 100,00 $\pm 5,54 \% ; p=0,0081 * *$ ) (Abb. 17 A, B und D). Bei den Mäusen mit hoher Läsionslast (MW: 78,98 $\pm 3,73 \%$ ) (Abb. 17 C) war die axonale Dichte verglichen mit den Kontrollen sogar hoch signifikant reduziert $(\mathrm{p}<0,001 * * *)$ (Abb. $17 \mathrm{D})$. Darüber hinaus wiesen Tiere mit hoher Läsionslast ebenfalls eine signifikant reduzierte axonale Dichte im Vergleich zu Mäusen mit geringer Läsionslast auf $(\mathrm{p}=0,0184 *)($ Abb. $17 \mathrm{D})$. 

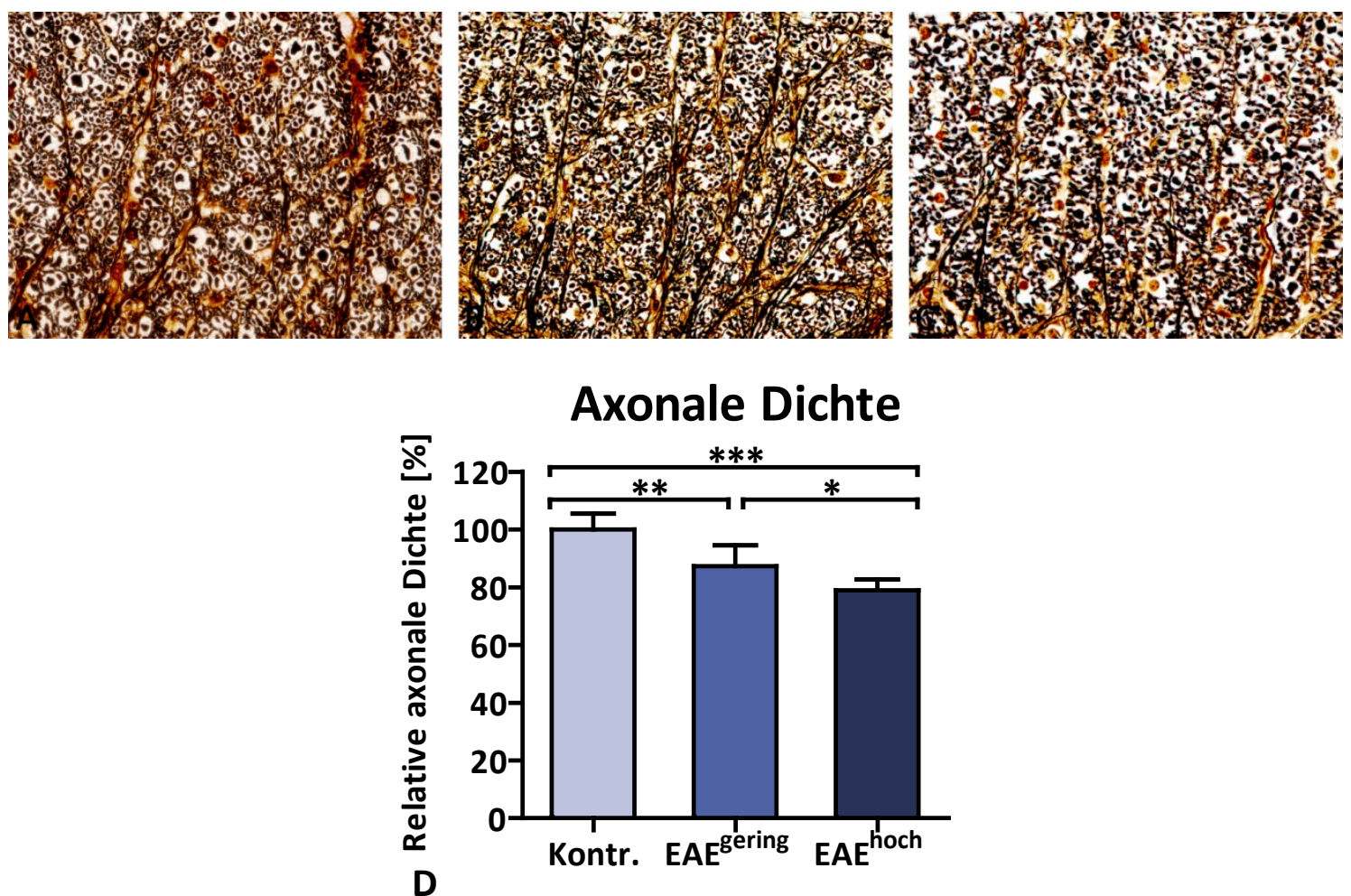

Abbildung 17: Reduzierte relative axonale Dichte in der spinalen NAWM von Mäusen mit chronischer EAE in Abhängigkeit von der Läsionslast. Verglichen wurde mit der physiologischen axonalen Dichte gesunder Tiere. 400fache Vergrößerung. Bielschowsky-Färbung. In der WM gesunder Kontrollen (A) ist eine physiologische axonale Dichte zu sehen. In der NAWM von Mäusen mit geringer Läsionslast (B) $\left(E A E^{\text {gering }}\right.$ ) ist eine leicht reduzierte axonale Dichte zu beobachten. Bei hoher Läsionslast (C) (EAE ${ }^{\text {hoch }}$ ) ist dagegen eine deutlichere Reduktion der axonalen Dichte zu sehen. (D) Graph. Signifikant reduzierte axonale Dichte bei Mäusen mit EAE und geringer Läsionslast im Vergleich zu den Kontrollen ( $p=0,0081$ **, t-Test). Signifikant reduzierte axonale Dichte bei Mäusen mit EAE und hoher Läsionslast im Vergleich zu Mäusen mit geringer Läsionslast ( $p=0,0184^{*}$, t-Test). Signifikant reduzierte axonale Dichte bei EAEMäusen mit hoher Läsionslast verglichen mit gesunden Kontrollen ( $p<0,001 * * *, t-T e s t)$. 


\subsubsection{Vermehrte akute axonale Schädigung in der NAWM bei kranken Tieren mit hoher Läsionslast}

Um das Ausmaß der akuten axonalen Schädigung in der NAWM des Rückenmarks bei Mäusen mit chronischer EAE im Vergleich zu gesunden Tieren zu untersuchen, wurden akut geschädigte Axone anhand der APP-Färbung quantifiziert.

Die akute axonale Schädigung war nur bei Mäusen mit einer hohen Läsionslast vermehrt (Abb. 18). Bei Kontrollen und auch bei Mäusen mit geringer Läsionslast zeigte sich ein ähnliche geringe Dichte $\mathrm{APP}^{+}$-Axone (Kontrollen: MW: $34,56 \pm 10,89 \mathrm{APP}^{+}$-Axone $/ \mathrm{mm}^{2}$, Mäuse mit geringer Läsionslast: $36,11 \pm 8,31 \mathrm{APP}^{+}$Axone $/ \mathrm{mm}^{2}$ ) (Abb. $18 \mathrm{~A}, \mathrm{~B}$ und D). Bei Mäusen mit hoher Läsionslast (MW: $62,86 \pm 10,88 \mathrm{APP}^{+}$-Axone $/ \mathrm{mm}^{2}$ ) (Abb. $18 \mathrm{C}$ ) war die akute axonale Schädigung im Vergleich $\mathrm{zu}$ den Mäusen mit geringer Läsionslast $\left(\mathrm{p}=0,0006^{* * *}\right)$ und $\mathrm{zu}$ den Kontrolltieren statistisch hoch signifikant erhöht $\left(p=0,0013^{* *}\right)$ (Abb. 18 D). 

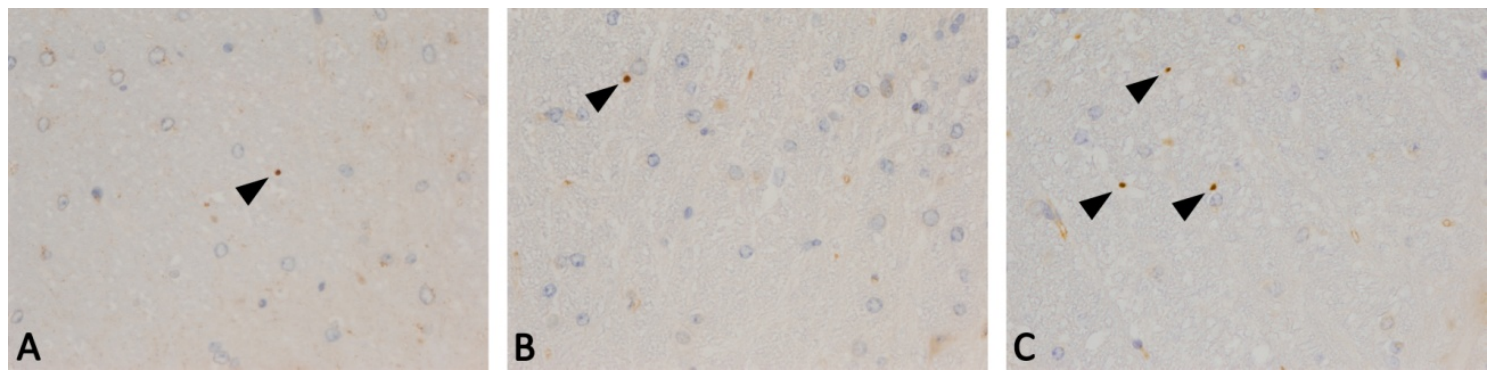

\section{Akuter axonaler Schaden}

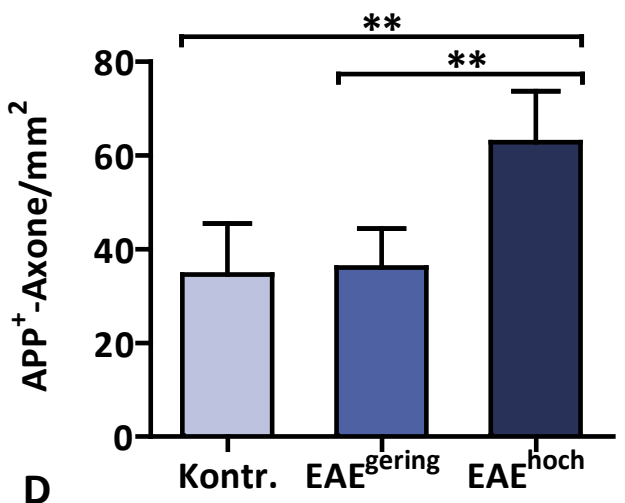

Abbildung 18: Vermehrte akute axonale Schädigung in der spinalen NAWM von Mäusen mit chronischer EAE und hoher Läsionslast. 400fache Vergrößerung. APP-Färbung. In der WM von gesunden Kontrollen (A) sind nur vereinzelt APP ${ }^{+}$-Axone zu sehen, hier eins im Bild. In der NAWM von Mäusen mit geringer Läsionslast (B) (EAE ${ }^{\text {gering }}$ ) sind ebenfalls nur vereinzelt $\mathrm{APP}^{+}$-Axone zu finden, hier

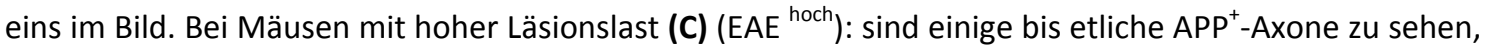
hier drei im Bild. (D) Graph. Kein signifikanter Unterschied in der akuten axonalen Schädigung bei EAEMäusen mit geringer Läsionslast im Vergleich zu gesunden Kontrollen (n. S., Mann-Whitney-Test). Hoch signifikant vermehrte akute axonale Schädigung bei EAE-Mäusen mit hoher Läsionslast im Vergleich zu Mäusen mit geringer Läsionslast ( $p=0,0006 * * *$, Mann-Whitney-Test). Ebenfalls signifikant vermehrte akute axonale Schädigung bei EAE-Mäusen mit hoher Läsionslast verglichen mit gesunden Kontrollen $\left(p=0,0013^{* *}, t-T e s t\right)$. 


\subsubsection{Erhöhte Dichte von TPPP/p25 ${ }^{+}$-Oligodendrozyten in der NAWM in Abhängigkeit von der Läsionslast}

Um die Oligodendrozytendichte in der NAWM von gesunden Tieren und Mäusen mit chronischer EAE zu bestimmen, wurde das Parenchym mit Hilfe der TPPP/p25-Färbung untersucht.

Es zeigte sich eine signifikant erhöhte Oligodendrozytendichte mit steigender Läsionslast (Abb. 19). Die statistische Auswertung ergab in der NAWM der Mäuse mit geringer Läsionslast (MW: 740,11 $\pm 56,97$ p25 $5^{+}$Zellen $/ \mathrm{mm}^{2}$ ) (Abb. $19 \mathrm{~B}$ ) eine hoch signifikant erhöhte Oligodendrozytendichte im Vergleich zu den Kontrollen (MW: $567,36 \pm 38,81 \mathrm{p} 25^{+}-$Zellen $\left./ \mathrm{mm}^{2} ; \mathrm{p}=0,0002 * * *\right)$ (Abb. 19 A und D). Ebenfalls hoch signifikant erhöht war die Oligodendrozytendichte in der NAWM der Mäusen mit hoher Läsionslast (MW: 834,97 $\pm 72,69$ p25 - Zellen $/ \mathrm{mm}^{2}$ ) (Abb. 19 C), verglichen mit den Kontrollen $\left(\mathrm{p}<0,0001^{* * *}\right)$ (Abb. 19 A und D). Beim Vergleich der EAE-Gruppen untereinander war die Oligodendrozytendichte bei hoher Läsionslast im Vergleich zur geringen Läsionslast signifikant erhöht $(\mathrm{p}=0,0187 *)$ (Abb. 19 D). 

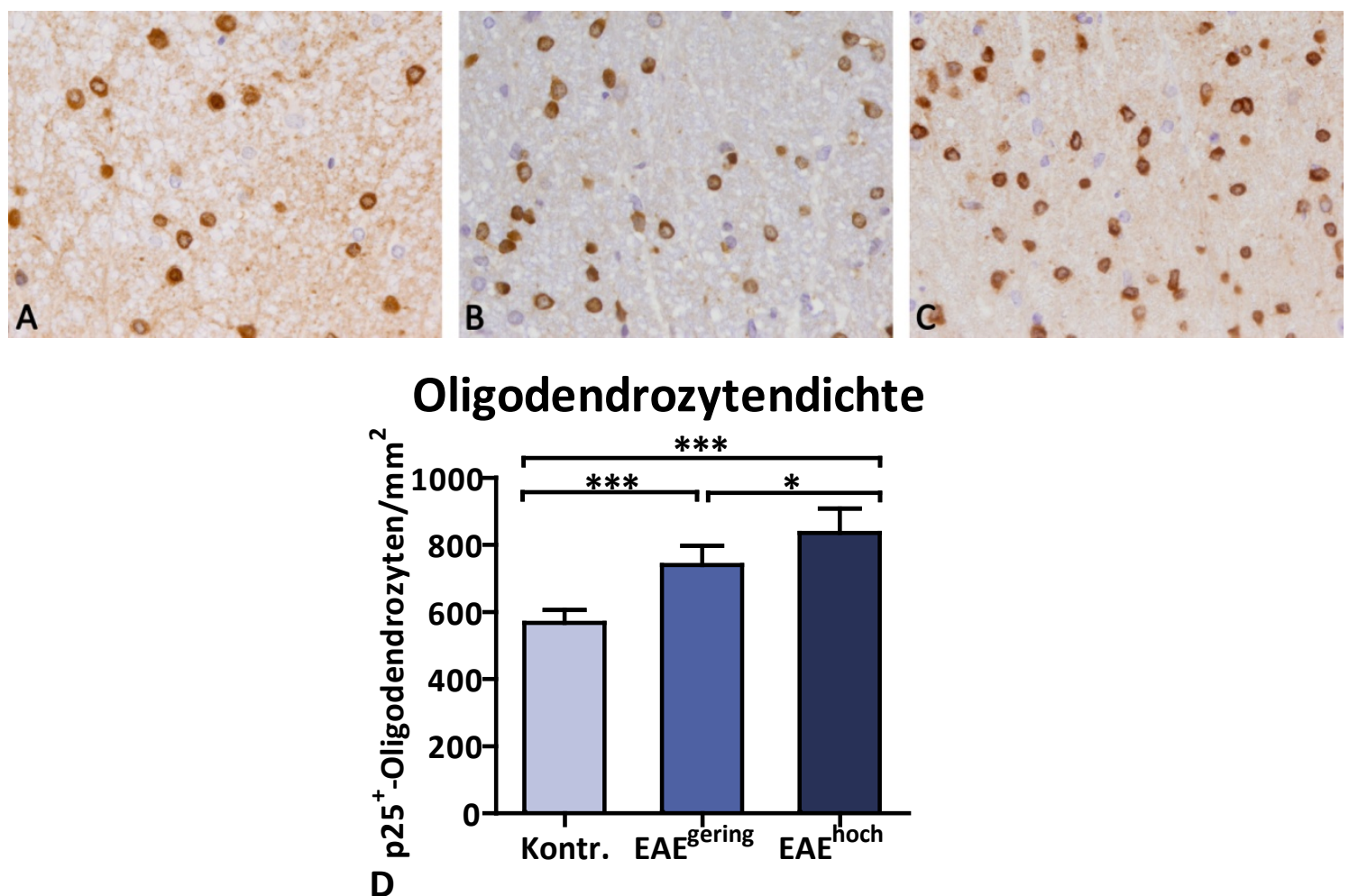

Abbildung 19: Erhöhte Oligodendrozytendichte in der spinalen NAWM von Mäusen mit chronischer EAE in Abhängigkeit von der Läsionslast. 400fache Vergrößerung. TPPP/p25-Färbung. In der WM gesunder Kontrollen (A) sind mäßig viele p $25^{+}$-Zellen zu sehen. In der NAWM von Mäusen mit geringer Läsionslast (B) (EAE ${ }^{\text {gering }}$ ) sind etliche p25 ${ }^{+}$-Zellen zu beobachten. Bei Mäusen mit hoher Läsionslast (C) (EAE ${ }^{\text {hoch }}$ ) sind noch mehr p25 -Zellen zu sehen. (D) Graph. Hoch signifikant vermehrte Oligodendrozytendichte bei Mäusen mit EAE und geringer Läsionslast im Vergleich zu den Kontrollen ( $p=0,0002 * * *, t-T e s t)$. Ebenfalls hoch signifikant erhöhte Oligodendrozytendichte bei Mäusen mit EAE und hoher Läsionslast im Vergleich zu den Kontrollen $(p<0,0001 * * *$, t-Test). Signifikant erhöhte Oligodendrozytendichte bei Mäusen mit EAE und hoher Läsionslast im Vergleich zu Mäusen mit EAE und geringer Läsionslast ( $\left.p=0,0187^{*}, t-T e s t\right)$. 


\subsubsection{Vermehrte Astrogliose in der NAWM insbesondere bei Tieren mit hoher Läsionslast}

Um zu untersuchen, ob eine vermehrte Astrogliose in der NAWM bei Mäusen mit chronischer EAE nachweisbar ist, wurde die Dichte reaktiver Astrozyten mit Hilfe der GFAP-Färbung bestimmt.

Die Zahl reaktiver Astrozyten stieg mit der Läsionslast der Tiere (Abb. 20). In der NAWM der Mäuse mit geringer Läsionslast (MW: 195,43 $\pm 29,49$ GFAP ${ }^{+}$-Zellen $/ \mathrm{mm}^{2}$ ) (Abb. 20 B) ergab sich eine signifikant erhöhte Dichte reaktiver Astrozyten $\left(\mathrm{p}=0,0457^{*}\right) \quad(\mathrm{Abb} .20 \mathrm{D})$ im Vergleich $\mathrm{zu}$ den gesunden Kontrollen (MW: 163,84 $\pm 9,64 \mathrm{GFAP}^{+}$-Zellen $/ \mathrm{mm}^{2}$ ) (Abb. $20 \mathrm{~A}$ ). Bei Mäusen mit einer hohen Läsionslast (MW: 229,26 \pm 40,94 GFAP ${ }^{+}$-Zellen $/ \mathrm{mm}^{2}$ ) (Abb. 20 C) war die Dichte der reaktiven Astrozyten signifikant vermehrt, verglichen mit den Kontrollen $(p=0,0061$ **) (Abb. 20 D). Bei dem Vergleich der EAE-Gruppen untereinander stellte sich lediglich eine tendenziell vermehrte Dichte reaktiver Astrozyten bei den Mäusen mit hoher Läsionslast heraus ( $p=0,1014$ Trend, t-Test) (Abb. 20 D). 

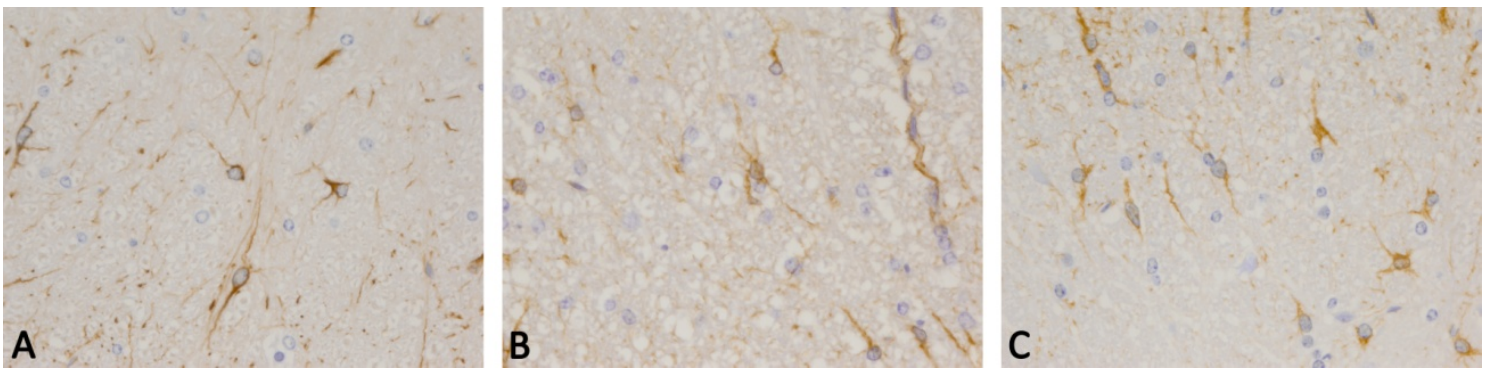

\section{Reaktive Astrozyten}

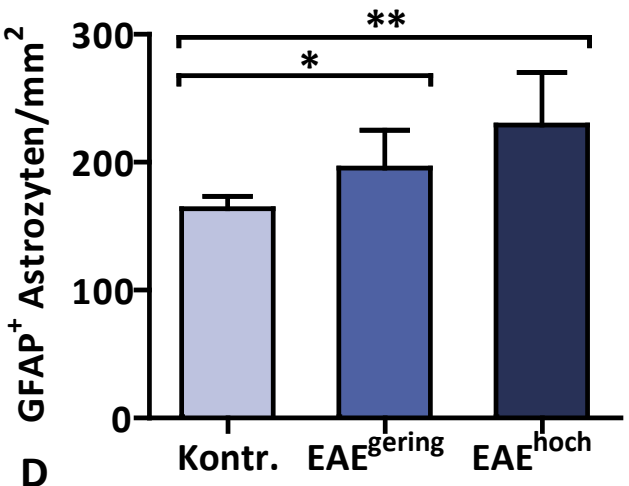

Abbildung 20: Vermehrt reaktive Astrozyten in der spinalen NAWM insbesondere bei Mäusen mit chronischer EAE. 400fache Vergrößerung. GFAP-Färbung. In der WM gesunder Kontrollen (A) sind einzelne GFAP ${ }^{+}$-Zellen zu sehen, hier vier im Bild. In der NAWM bei Mäusen mit geringer Läsionslast (B) $\left(\mathrm{EAE}^{\text {gering }}\right.$ ) sind einige GFAP ${ }^{+}$-Zellen zu finden, hier sechs im Bild. Bei Mäusen mit hoher Läsionslast (C) $\left(E A E^{\text {hoch }}\right.$ ) sind zahlreiche GFAP ${ }^{+}$-Zellen zu sehen, hier neun im Bild. (D) Graph. Signifikant vermehrte Dichte reaktiver Astrozyten bei Mäusen mit EAE und geringer Läsionslast im Vergleich zu den Kontrollen ( $p=0,0457 *$, t-Test). Signifikant vermehrte Dichte reaktiver Astrozyten bei Mäusen mit EAE und hoher Läsionslast im Vergleich zu den Kontrollen ( $p=0,0061^{* *}, \mathrm{t}$-Test). Es zeigte sich ein Trend für eine vermehrte Dichte reaktiver Astrozyten bei Mäusen mit EAE und hoher Läsionslast im Vergleich zu Mäusen mit geringer Läsionslast ( $p=0,1014$ Trend, $t$-Test). 


\section{Diskussion}

\subsection{Vermehrte T-Lymphozytendichte und Mikrogliaaktivierung in der NAWM}

In allen drei Studiengruppen wurde eine geringe Infiltration der NAWM mit T-Lymphozyten nachgewiesen. In der NAWM von MS- und NMO-Fällen war die Zahl der vereinzelt infiltrierenden T-Lymphozyten leicht erhöht, verglichen mit der WM von Kontrollen sowohl im Gehirn als auch im Rückenmark. Unsere Ergebnisse stimmen mit bisher veröffentlichten Daten überein, welche von einer diffusen $\mathrm{T}$ Lymphozyteninfiltration der NAWM bei MS im Gehirn (Kutzelnigg et al. 2005) und Rückenmark (Androdias et al. 2010) berichten. Diese Studie deutet auf ähnliche geringgradige Entzündungsprozesse in der NAWM von MS und NMO in Gehirn und Rückenmark hin.

Im Gegensatz zum Parenchym konnten wir keinen Unterschied in der TLymphozyteninfiltration im Virchow-Robin-Raum zwischen MS-, NMO- und Kontrollfällen feststellen. Auch dies stimmt mit den Beobachtungen von Androidias et al. überein (Androdias et al. 2010).

Es wird diskutiert, dass diese geringe, jedoch konstante Entzündung des ZNSParenchyms eine Rolle bei der diffusen Schädigung der WM spielt, welche typischerweise bei den progressiven Formen der MS zu finden ist (Kutzelnigg et al. 2005). Angesichts der sehr geringen Anzahl an T-Lymphozyten, welche in dieser Studie und auch in der vorliegenden Arbeit in der NAWM detektiert werden konnte, erscheint eine bedeutende T-Lymphozyten Beteiligung an der axonalen Schädigung allerdings eher unwahrscheinlich. Dennoch können wir einen Einfluss der T-Lymphozyten auf die diffuse Schädigung der WM generell nicht ausschließen.

Im Parenchym der Mäuse mit chronischer EAE wurde - im Gegensatz zum humanen Parenchym - eine deutlich höhere Anzahl an T-Lymphozyten in der NAWM detektiert. Ihre Dichte war mit dem Grad der Demyelinisierung assoziiert. Im spinalen Gewebe der Kontrollmäuse waren T-Lymphozyten nahezu nicht vorhanden. Auch Herrero-Herranz et al. konnten in der NAWM eine vermehrte T-Lymphozyteninfiltration beobachten, wenngleich sie am Tag 60 p. i. im Krankheitsverlauf bereits gesunken war (HerreroHerranz et al. 2008). Die in der vorliegenden Arbeit nachgewiesene deutlich höhere 
Anzahl an T-Lymphozyten bei EAE als bei MS oder NMO ist sicher auf die noch frischere Erkrankungen bei den Tieren (Untersuchungszeitpunkt 60 Tagen nach Immunisierung) zurückzuführen.

Mikrogliazellen sind als residente Immunzellen des Gehirns und Rückenmarks verantwortlich für die immunologische Überwachung des ZNS (Aguzzi et al. 2013). Bei der MS ist die Mikrogliaaktivierung in und um Läsionen herum mit irreversiblen Gewebeschäden und der Eliminierung zerstörten Gewebes assoziiert, was sowohl zu günstigen als auch nachteiligen Effekten führen kann. Darüber hinaus wird über die Rolle der Mikroglia bei der Initiierung der Autoimmunität im ZNS diskutiert (Jack et al. 2005). Bislang gibt es keine publizierten Untersuchungen zur Mikroglia in der NAWM bei NMO.

In der vorliegenden Arbeit war eine erhöhte Mikrogliaaktivierung in der NAWM bei MS und NMO im Vergleich zu den Kontrollen nachweisbar, wobei sich insbesondere bei der MS eine deutlich vermehrte Mikrogliaaktivierung im Rückenmark zeigte. In Übereinstimmung mit den Beobachtungen im humanen Gewebe, war die Mikrogliadichte in der NAWM von Mäusen mit chronischer EAE verglichen mit Kontrollen ebenfalls erhöht. Die Dichte korrelierte bei den Tieren mit dem steigenden Grad der Demyelinisierung. Howell et al. postulieren 2010, dass das Ausmaß mikroglialer Entzündung in der NAWM mit der Störung paranodaler axoglialer Zellkontakte korreliert und infolgedessen $\mathrm{zu}$ nachweisbarer Axonverletzung führt (Howell et al. 2010), nachdem sie die NAWM im zerebralen Parenchym bei MS und im spinalen Parenchym von Mäusen mit chronischer EAE untersucht hatten. Ihre Ergebnisse unterstützen die Hypothese, dass die mikrogliale Aktivität in der Tat zur Induktion von diffusen pathologischen Veränderungen in der NAWM bei MS und NMO beiträgt.

Neben der Mikrogliaaktivierung wurde in der vorliegenden Arbeit auch das Vorhandensein von Mikrogliaknötchen untersucht. In der NAWM des Rückenmarks von MS-Patienten wiesen über $80 \%$ der Patienten Mikrogliaknötchen auf, verglichen mit lediglich 33\% im Gewebe der Kontrollen. In der NAWM der Mäuse mit chronischer EAE traten Mikrogliaknötchen bei nahezu allen Tieren auf, bei den Kontrollen waren sie dagegen vollständig abwesend. 
Es wird diskutiert, ob das Auftreten von Mikrogliaknötchen in der zerebralen NAWM bei MS ein Merkmal für eine sehr frühe Formen einer MS-Läsion, auch ,,präaktive Läsion“ ((p)reactive lesion) genannt, sein könnte (De Groot et al. 2001; Van Horssen et al. 2012). Erst kürzlich wurden Mikrogliaknötchen in der NAWM unmittelbar mit der Schädigung und Degeneration von Axonen in Zusammenhang gebracht (Singh et al. 2013), wobei hier allerdings Patienten mit früher Erkrankung untersucht wurden.

Die gesteigerte Häufung der Mikroglia in der spinalen NAWM bei MS (und auch bei den EAE-Mäusen) könnte zur axonalen Schädigung des Gewebes beitragen. Passend hierzu deuten Arbeiten von Howell et al. darauf hin, dass spinale Mikroglia bei MS iNOS (induzierbare Stickstoffmonoxid-Synthase) exprimierten und mit $\mathrm{SMI}_{2}{ }^{+}$ geschwollenen Axonen assoziiert erschienen (Howell et al. 2010).

\subsection{Vermehrte akute axonale Schädigung sowie axonaler Verlust in der NAWM}

Die axonale Dichte war in der NAWM sowohl bei MS als auch bei NMO im Vergleich zu gesunden Kontrollen reduziert. Bei MS war der axonale Verlust im Gehirn sehr gering (5\%), während er im Rückenmark auf beachtliche ca. 40\% anstieg. Bei NMO ähnelte die axonale Dichte im Gehirn der Dichte gesunder Kontrollfälle. Im Rückenmark zeigten allerdings beide humanen Erkrankungen einen ähnlichen stark ausgeprägten axonalen Verlust von etwa 40\% im Vergleich zu den Kontrollfällen.

Die verminderte axonale Dichte in der NAWM ist ein bereits beschriebenes Phänomen bei MS. Evangelou et al. berichteten einen Verlust der axonalen Dichte von 34\% (im Bereich von 15-56\%) in der NAWM des Corpus callosum von MS-Patienten (Evangelou et al. 2000a; Evangelou et al. 2000b). In der spinalen NAWM von MSPatienten war in Vorarbeiten ein zu der vorliegenden Arbeit vergleichbarer axonaler Verlust von 15-33\% gezeigt worden (Ganter et al. 1999; DeLuca et al. 2004; DeLuca et al. 2006). DeLuca et al. berichtet des Weiteren, dass die reduzierte axonale Dichte anscheinend nicht mit der Läsionslast bei MS im Rückenmark korreliert (DeLuca et al. 2006). Es konnte nachgewiesen werden, dass der axonale Verlust von einer Atrophie der weißen Substanz im Rückenmark (Ganter et al. 1999) bzw. des Corpus callosum begleitet wird (Evangelou et al. 2000a). 
Der in der vorliegenden Arbeit beobachtete massive axonale Verlust im Rückenmark von MS- und NMO-Patienten könnte auf verschiedenen Mechanismen beruhen. Es wird zum einen angenommen, dass der diffuse axonale Verlust in der NAWM durch die distale Degeneration der in Läsionen durchtrennten Axone verursacht werden könnte (Evangelou et al. 2000b), ein Phänomen, dass Wallersche Degeneration genannt wird. Da Nervenfaserbahnen im Rückenmark sehr lang sind, kann ein Einfluss weit entfernter Läsionen auf die axonale Dichte in der untersuchten NAWM nicht ausgeschlossen werden.

Ein anderer Ansatz, den axonalen Verlust in der NAWM zu erklären, ist die zunehmende Anfälligkeit vorgeschädigter Axone. In diesem Zusammenhang wurde auch berichtet, dass Demyelinisierung zur abnormalen Expression von Natriumkanälen auf Axonen führen könnte, was wiederum die Anfälligkeit zur Degeneration fördert (Waxman 2001; Bjartmar et al. 2003). Vermutlich tragen beide Mechanismen Wallersche Degeneration und Vulnerabilität vorgeschädigter Axone - zum ausgeprägten axonalen Verlust in der NAWM bei NMO und MS im Rückenmark bei.

Die diffuse Schädigung der weißen Substanz ist bei MS gut beschrieben, es gibt jedoch nur wenige Daten darüber wie es sich bei NMO verhält. In der vorliegenden Arbeit zeigt die quantitative Analyse der axonalen Dichte eindeutig, dass Veränderungen in der spinalen NAWM bei NMO auftreten.

In der NAWM von Mäusen mit EAE konnten wir im Rückenmark ebenfalls eine Reduktion der axonalen Dichte feststellen, wobei die Veränderungen mit steigender Läsionslast zunahmen. Die Reduktion der axonalen Dichte bei Mäusen mit EAE lag zwischen $13 \%$ bei Tieren mit geringer Läsionslast und $21 \%$ bei Tieren mit hoher Läsionslast. Das heißt, insgesamt waren die Reduktion der axonalen Dichte bei den EAE-Tieren weniger stark ausgeprägt als in der spinalen NAWM bei MS und NMO (ca. 40\%). Diese experimentellen Ergebnisse (60 Tage p. i.) an Mäusen mit EAE mit hohem Ausmaß spinaler Läsionen ähneln denen von Herrero-Herranz et al. (40 Tage p. i.), auch wenn die eigene Untersuchung hier an einem späteren Erkrankungszeitpunkt ansetzt und in der Studie von Herrero-Herranz et al. kein Bezug auf die Läsionslast genommen wird (Herrero-Herranz et al. 2008). Des Weiteren konnten Herrero-Herranz et al. zeigen, dass die motorische Beeinträchtigung der chronisch erkrankten Tiere mehr vom Grad des axonalen Verlustes in der NAWM als vom axonalen Verlust in Läsionen abhing (Herrero-Herranz et al. 2008). 
Die akute axonale Schädigung lässt sich durch die Akkumulation axonaler Transportproteine nachweisen. In der vorliegenden Arbeit wurden hierzu Axone mit Akkumulation des axonalen Amyloid-Vorläufer-Proteins (APP) quantifiziert. APP ist ein physiologischer Bestandteil der Neurone (Kornek et al. 2000) und unterliegt einem schnellen anterograden axonalen Transport (Koo et al. 1990). Eine axonale Schädigung führt hingegen zur Unterbrechung des Transportes, es kommt zur Akkumulation von APP im proximalen Abschnitt des Axons und schließlich zur spezifischen Sphäroidbildung (Sherriff et al. 1994a; Ferguson et al. 1997; Bitsch et al. 2000). Diese $\mathrm{APP}^{+}$-Sphäroide können bereits drei Stunden nach Verletzung detektiert werden (Sherriff et al. 1994a; Graham et al. 2004) und sind bis zu 30 Tage sichtbar (Sherriff et al. 1994a; Sherriff et al. 1994b; Li et al. 1995; Pierce et al. 1996; Bramlett et al. 1997; Yam et al. 1997; Graham et al. 2004). Aufgrund dieses kurzen Intervalls der Nachweisbarkeit dient APP als sensitiver Standard-Marker für den akuten axonalen Schaden.

In der vorliegenden Arbeit war die Zahl $\mathrm{APP}^{+}$-Axone in der zerebralen NAWM bei MS(um das 2,6fache) und NMO-Patienten (um das 1,9fache) im Vergleich zu gesunden Kontrollen erhöht. Die Präsenz und Menge von akut geschädigter Axone in zerebraler NAWM von MS-Patienten entspricht der Literatur (Kutzelnigg et al., 2005b).

Kuhlmann et al. postulierten, dass der akute axonale Schaden in vorwiegend zerebralen Läsionen eine wesentliche Rolle in der frühen Phase der MS spielt, wobei die Dichte der $\mathrm{APP}^{+}$-Axone mit der Dichte der T-Lymphozyten in Läsionen korrelierte und beide Parameter mit dem Alter der Läsionen abnahmen (Kuhlmann et al. 2002).

In der vorliegenden Arbeit zeigte sich insbesondere eine deutliche Erhöhung $\mathrm{APP}^{+}$Axone in der spinalen NAWM (4,7fache Erhöhung im Vergleich zu den Kontrollen). Diese akute axonale Schädigung in der spinalen NAWM war hier bei progredienter MS auch in späteren Krankheitsstadien nachweisbar (durchschnittliche Erkrankungsdauer 15.0 Jahre \pm 10.0 ). Hier gab es allerdings keine Korrelation zwischen akuter axonaler Schädigung und der T-Lymphozytenzahl in der NAWM.

In der NAWM von Mäusen mit EAE waren nur bei Tieren mit einer hohen Läsionslast signifikant vermehrte $\mathrm{APP}^{+}$-Axone nachweisbar. Auch bei Kontrolltieren waren einige $\mathrm{APP}^{+}$-Axone $\mathrm{zu}$ beobachten. Bei Herrero-Herranz et al. wiesen die Tiere im chronischen Erkrankungsstadium ebenfalls $\mathrm{APP}^{+}$-Axone auf, auch wenn dort lediglich relative Werte angegeben werden (Herrero-Herranz et al. 2008). 
Dephosphorylierte Neurofilamente können in Axonen aufgrund von Demyelinisierung, axonalen Schäden, Störungen des axonalen Transportes oder axonaler Durchtrennung auftreten (Sherriff et al. 1994b; Trapp et al. 1998; Schirmer et al. 2013) und mit Hilfe vom SMI32-Antikörpern untersucht werden (Trapp et al. 1998). Zahlreiche SMI32+Axone waren in zerebralen (Trapp et al. 1998; Schirmer et al. 2013) und spinalen MSLäsionen nachweisbar (Schirmer et al. 2013). In der vorliegenden Arbeit zeigte sich eine etwa 10 fache Steigerung SMI32 ${ }^{+}$-Axone in der zerebralen NAWM bei MS im Vergleich zu Kontrollen. Im Gegensatz dazu war die Zahl SMI32 ${ }^{+}$-Axone bei NMO lediglich leicht erhöht (1,7fach).

Trotz ähnlich reduzierter axonaler Dichte bei beiden Erkrankungen war der akut ablaufende axonale Schaden in der NAWM insbesondere im Rückenmark bei MS deutlich stärker ausgeprägt als bei NMO. Dies könnte eine mögliche Erklärung für die Progredienz des Krankheitsverlaufes bei MS sein.

\subsection{Veränderte astrozytäre und gliale Parameter in der NAWM}

Das saure Gliafaserprotein (glial fibrillary acidic protein, GFAP) wird als sensitiver und zuverlässiger immunhistochemischer Marker angesehen, der die meisten reaktiven, auf ZNS-Schädigung reagierenden Astrozyten markiert (Sofroniew und Vinters 2010). Reaktive Astrozyten traten in der NAWM beider Erkrankungen im Vergleich zu den Kontrollen vermehrt auf. Besonders in der NAWM von NMO-Patienten war die Anzahl der GFAP $^{+}$-Astrozyten mit sternförmigen Ausläufern erhöht. Sowohl im Gehirn, als auch im Rückenmark. In der NAWM bei MS zeigte sich im Vergleich zur NMO ein geringerer Anstieg, der nur im Rückenmark signifikant war.

Die NMO ist durch das Auftreten des hochspezifischen NMO-IgG im Serum gekennzeichnet. Diese Antikörper richten sich direkt gegen den Wasserkanal AQP4. Hohe Konzentrationen von AQP4 finden sich auf den Endfüsschen von Astrozyten, welche einen wesentlichen Bestandteil der Blut-Hirn-Schranke bilden. Bindet das NMO-IgG an AQP4, führt das zur Komplementaktivierung und letztendlich zur Zerstörung der Astrozyten (Wingerchuk et al. 2007). Dadurch dass Astrozyten bei der NMO spezifisch durch NMO-IgG in Läsionen depletiert werden, kommt es in der Folge $\mathrm{zu}$ einer deutlichen astroglialen Regeneration im umliegenden Gewebe (und teilweise auch in den Läsionen) bei der NMO. Diese ausgeprägte astrogliale Regeneration trägt 
vermutlich zu der in der vorliegenden Arbeit beobachteten höheren Dichte reaktiver Astrozyten in der NAWM bei NMO - im Vergleich zur MS und zu den Kontrollen - bei.

In der vorliegenden Arbeit zeigte sich auch bei Mäusen mit chronischer EAE eine erhöhte Astrozyten-Reaktivität in der NAWM, wobei diese Veränderungen mit dem Grad der Demyelinisierung zunahmen.

Die Rolle von Astrozyten ist bei Entzündungen des ZNS komplex. Den reaktiven Astrozyten kommen verschiedenste relevante Funktionen zu, wie die Sekretion von Zytokinen (Dong und Benveniste 2001; Carpentier et al. 2005; Burkert et al. 2012), etwaige Antigen-Präsentation (Nikcevich et al. 1997; Tan et al. 1998) und die unmittelbare Erfassung von Gefahren und Infektionen durch die Expression von Toll-like-Rezeptoren (Carpentier et al. 2005). Die Fähigkeit von Astrozyten auf pathogene Reize des ZNS Gewebes reagieren zu können, ist sicher ein wesentlicher Grund für die gesteigerte Reaktivität dieser Zellen in der NAWM bei den beiden humanen Erkrankungen sein.

Die Zahl reifer $\mathrm{p} 25^{+}$-Oligodendrozyten war in der NAWM von erkrankten Patienten im Vergleich zu gesunden Kontrollen verändert. P25 ist ein Tubulin polymerization promoting protein (TPPP), welches spezifisch mit Mikrotubuli interagiert. Im ZNS wird es selektiv von reifen Oligodendrozyten (Skjoerringe et al. 2006) exprimiert, daher ist es ein geeigneter Marker für diese Zellpopulation (Takahashi et al. 1993; Höftberger et al. 2010).

In der vorliegenden Arbeit war die Zahl reifer Oligodendrozyten in der zerebralen NAWM von MS-Patienten erhöht, bei NMO blieb sie dagegen vergleichbar zu den Kontrollfällen. Vergleichbare Ergebnisse für die zerebrale NAWM bei MS brachte auch eine Studie von Höftberger et al. hervor. Deren Studie zeigte zudem eine negative Korrelation zwischen der Oligodendrozytenzahl in der NAWM und dem Alter (Höftberger et al. 2010). Die vorliegende Arbeit konnte jedoch keine Korrelation zwischen $\mathrm{p} 25^{+}$-Oligodendrozyten in der zerebralen NAWM und dem Alter der MSPatienten nachweisen.

Im Rückenmark war in der vorliegenden Arbeit die absolute Zahl reifer Oligodendrozyten sowohl in der NAWM bei MS als auch bei NMO herabgesetzt, verglichen mit den Kontrollen. Diese Reduktion könnte durch den ausgeprägten 
Axonverlust (ca. 40\% in MS und NMO im Vergleich zu den Kontrollen) erklärt werden, welchen mit Hilfe der Bielschowsky-Silberimprägnierung untersucht wurden. In Relation zur axonalen Dichte im Rückenmark, zeigte sich jedoch ein ähnliches Bild wie im Hirn. Der Quotient reifer Oligodendrozyten in Relation zur axonalen Dichte war bei MS auch in der spinalen NAWM erhöht. Bei NMO blieb der Quotient sowohl im Gehirn als auch im Rückenmark vergleichbar zu den Kontrollfällen.

Auch bei Mäusen mit EAE war die Zahl p25+-Oligodendrozyten in der NAWM im Vergleich zu den Kontrollen erhöht.

Die relativ erhöhte oligodendrogliale Dichte in der NAWM bei MS und auch bei Mäusen mit EAE ist möglicherweise auf die oligodendrogliale Regeneration in der NAWM zurückzuführen. Hierzu könnten auch astrozytäre Faktoren beitragen, wie beispielsweise das das von Astrozyten sezernierte Zytokin IL-11, welches in der PPWM (periplaque white matter) bei MS festgestellt worden ist und zum Überleben und Ausreifen von Oligodendrozyten beitragen kann (Zhang et al. 2006). 


\subsection{Unterschiede zwischen MS, NMO und EAE}

Ein Vergleich der untersuchten Parameter in der NAWM beider chronischdemyelinisierender humaner Erkrankungen zeigte eine weitgehend ähnliche Entzündungsaktivität. Hinsichtlich der axonalen und glialen Parameter unterschieden sich MS und NMO in der NAWM jedoch teils deutlich voneinander.

Die T-Lymphozytendichte war in der NAWM bei beiden Erkrankungen ähnlich erhöht im Vergleich zu den Kontrollfällen. Hinsichtlich der Mikrogliaaktivierung zeigte sich spinal nur bei MS eine signifikant erhöhte Mikrogliaaktivierung. Auch Mikrogliaknötchen traten nur in der spinalen NAWM bei MS vermehrt auf. Erst kürzlich wurde das Auftreten von Mikrogliaknötchen in der NAWM unmittelbar mit der Schädigung und Degeneration von Axonen in Zusammenhang gebracht (Singh et al. 2013).

Die vermehrte Mikrogliaaktivierung und Bildung von Mikrogliaknötchen in der spinalen NAWM bei MS könnten zu den deutlich ausgeprägteren akuten axonalen Veränderungen im Rückenmark bei MS beitragen.

Der Verlust der axonalen Dichte war in der spinalen NAWM bei MS und NMO ähnlich stark ausgeprägt (beide um ca. 40\%) im Vergleich zu gesunden Kontrollen. Während bei der MS auch zerebral ein sehr geringer axonaler Verlust nachweisbar war (ca. 5\%), konnte bei der NMO keine veränderte axonale Dichte im Gehirn beobachtet werden. Der akute axonale Schaden ( $\mathrm{APP}^{+}$-Axone) war zerebral bei beiden Erkrankungen ähnlich ausgeprägt, wobei er quantitativ bei NMO geringer ausgeprägt war. Allerdings wiesen Patienten mit MS einen höheren Anteil dephosphorylierter Axone in der zerebralen NAWM auf als Patienten mit NMO. Die deutlichste akute axonale Schädigung fand sich allerdings spinal und war nur bei der MS nachweisbar. Dort fand sich eine erhöhte Zahl akut geschädigter Axone auf das 4,7fache im Vergleich zu den Kontrollen, während die NMO-Fälle diesbezüglich den Kontrollfällen ähnelten. Die signifikant erhöhte akute axonale Schädigung in der spinalen NAWM könnte eine mögliche Erklärung für die Progredienz des Krankheitsverlaufes bei MS sein.

Vergleicht man die Zahl reaktiver Astrozyten in der NAWM beider Erkrankungen, wird deutlich, dass zerebral und auch spinal mehr reaktive Astrozyten bei NMO als bei MS nachweisbar waren. Vermutlich kommt es bei der NMO in der NAWM zu einer deutlicheren astroglialen Regeneration als bei der MS, da bei der NMO Astrozyten in 
Läsionen spezifisch durch NMO-IgG depletiert werden. In der vorliegenden Arbeit war die relative Zahl p $25^{+}$-Oligodendrozyten bezogen auf die axonale Dichte sowohl in der zerebralen, als auch spinalen NAWM von MS-Patienten erhöht. Bei NMO war die Dichte hingegen vergleichbar $\mathrm{zu}$ den Kontrollfällen. Diese relativ erhöhte oligodendrogliale Dichte in der NAWM bei MS deutet möglicherweise auf eine verstärkte oligodendrogliale Regeneration in der NAWM hin. Die Zahl p25 Oligodendrozyten erscheint bei NMO proportional zur axonalen Dichte und vergleichbar zu den Kontrollfällen zu sein.

Im Parenchym der Mäuse mit chronischer EAE wurde, im Gegensatz zu den humanen Erkrankungen, eine größere Menge an T-Lymphozyten in der NAWM detektiert. Ihre absolute Anzahl war mit dem Grad der Demyelinisierung assoziiert. Im spinalen Gewebe der Kontrollmäuse waren T-Lymphozyten nahezu nicht vorhanden. Die gesteigerte T-Lymphozyteninfiltration dürfte u. a. auf den deutlich kürzeren Krankheitsverlauf der Tiere im Vergleich zu den humanen Erkrankungen zurückzuführen sein. In Übereinstimmung mit den Beobachtungen im humanen Gewebe war die Mikrogliadichte in der NAWM von Mäusen mit chronischer EAE verglichen mit Kontrollen - ebenfalls erhöht. Neben der Mikrogliaaktivierung wurde auch das Vorhandensein von Mikrogliaknötchen untersucht. In der NAWM des Rückenmarks von MS-Patienten wiesen über $80 \%$ Mikrogliaknötchen auf, verglichen mit lediglich 33\% im Gewebe der Kontrollen. In der NAWM der Mäuse mit chronischer EAE traten Mikrogliaknötchen bei den meisten Tieren auf, bei den Kontrollen waren sie dagegen vollständig abwesend. Die gesteigerte Häufung der Mikroglia in der spinalen NAWM bei MS und den Mäusen mit chronischer EAE könnte zur akuten axonalen Schädigung des Gewebes beitragen.

In Übereinstimmung mit den Beobachtungen im humanen Gewebe war die axonale Dichte in der NAWM von Mäusen mit chronischer EAE im Vergleich zu den Kontrolltieren ebenfalls reduziert. Der Verlust der axonalen Dichte stieg mit dem Grad der Demyelinisierung. Jedoch erreichte der axonale Verlust selbst bei Mäusen mit einem hohen Ausmaß spinaler Läsionen (ca. 21\%) nur etwa die Hälfte der spinalen Werte beim Menschen (ca. 40\%). Ebenso war der akute axonale Schaden bei Mäusen mit EAE, welche ein hohes Ausmaß spinaler Läsionen aufwiesen, wie auch im spinalen Parenchym von MS-Patienten deutlich erhöht. 
Wie auch im humanen Rückenmark wurde eine erhöhte Dichte reaktiver Astrozyten in der NAWM von Mäusen mit chronischer EAE beobachtet, wobei diese Veränderungen mit dem Grad der Demyelinisierung zunahmen. Auch die Zahl p25 -Oligodendrozyten war im Vergleich zu den Kontrollen erhöht. Die Astrozyten beeinflussen die Ausreifung der oligodendroglialen Zellen, was zu Neuroprotektion und Remyelinisierung beitragen könnte. 


\subsection{Ausblick}

Bisherige pathologische Untersuchungen haben sich hauptsächlich auf die fokalen Läsionen der weißen Substanz von demyelinisierenden Erkrankungen konzentriert. Neuere bildgebende Studien weisen jedoch immer deutlicher auf die Beteiligung der NAWM bei MS hin. In der vorliegenden Arbeit konnten deutliche Veränderungen in der NAWM nicht nur bei MS, sondern auch bei NMO, nachgewiesen werden. Die vorliegenden Ergebnisse liefern die ersten Hinweise darauf, dass sich die Veränderungen in der NAWM beider Erkrankungen teilweise deutlich unterschieden. Für ein besseres Verständnis dafür, wie Veränderungen in der NAWM zur klinischen Symptomatik der Erkrankungen beitragen, sind allerdings weitere Untersuchungen erforderlich. Zudem werden weitere Studien auch zeigen müssen, ob die Veränderungen in der NAWM bei NMO ähnlichen Mechanismen wie bei MS unterliegen und welche anderen pathophysiologischen Mechanismen den unterschiedlichen Erkrankungsverlauf erklären und letztendlich Hinweise auf optimale Therapieansätze liefern könnten.

Der Vergleich zwischen Mensch und Tier zeigt, dass auch das Tiermodell der experimentell induzierten chronischen EAE bei Mäusen Hinweise zur Pathogenese der Veränderungen in der NAWM liefern kann. Der Vergleich macht jedoch auch deutlich, dass aus Tiermodellen gewonnene Forschungsergebnisse immer einer kritischen Prüfung unterzogen werden und nicht zwingend direkt übertragbar sein müssen. 


\section{$5 \quad$ Zusammenfassung}

Die häufigste entzündlich-demyelinisierende Erkrankung des ZNS ist die Multiple Sklerose (MS). In der chronischen Phase der MS kommt es meist zur Progression der klinischen Defizite, wobei davon ausgegangen wird, dass neben den fokalen Läsionen in der weißen Substanz auch Veränderungen der normal erscheinenden weißen Substanz (normal appearing white matter, NAWM) eine wichtige Rolle für den heterogenen und progredienten Krankheitsverlauf spielen. Die seltenere entzündlichdemyelinisierende Erkrankung Neuromyelitis optica (NMO), bei der meist Antikörper gegen Aquaporin-4 (AQP4) nachgewiesen werden können, zeichnet sich im Gegensatz zur MS durch eine relative klinische Stabilität zwischen den Schüben aus.

Das Hauptziel dieser Arbeit bestand darin, die Veränderungen in der NAWM bei den beiden Erkrankungen im Vergleich zu gesunden Kontrollfällen zu untersuchen. Dabei sollte die Hypothese getestet werden, dass sich bei der MS deutlichere axondegenerative Veränderungen - als Korrelat der schleichenden klinischen Verschlechterung - finden. Ergänzend wurden zudem auch die Veränderungen der NAWM an Mäusen mit experimenteller autoimmuner Enzephalomyelitis (EAE), dem häufigsten Tiermodell der MS, untersucht.

Methodisch wurden die zerebralen und spinalen Veränderungen in der NAWM an Autopsiegewebe von 24 Patienten mit MS und fünf Patienten mit NMO histopathologisch hinsichtlich entzündlicher, axonaler und glialer Parameter analysiert. Des Weiteren wurden ähnliche Untersuchungen in der NAWM im Rückenmark von Mäusen mit EAE mit unterschiedlicher Läsionslast und gesunden Kontrolltieren durchgeführt.

Die Untersuchungen in der NAWM beider humaner chronisch-demyelinisierender Erkrankungen zeigte eine weitgehend ähnliche Dichte an T-Lymphozyten und aktivierter Mikroglia, während Mikrogliaknötchen nur in der spinalen NAWM bei MS vermehrt nachweisbar waren. Bei der MS und der NMO zeigte sich ein ähnlicher axonaler Verlust von ca. $40 \%$ in der spinalen NAWM im Vergleich zu gesunden Kontrollfällen. Während bei der MS auch zerebral ein sehr geringer axonaler Verlust nachweisbar war (ca. 5\%), konnte bei der NMO keine veränderte axonale Dichte im Gehirn nachgewiesen werden. Der deutlichste Unterschied zwischen den beiden Erkrankungen war eine signifikante 4,7fache Erhöhung $\mathrm{APP}^{+}$akut geschädigter Axone 
im Rückenmark bei MS, NMO-Fälle zeigten hingegen in der spinalen NAWM ebenso wenig akut geschädigte Axone wie die Kontrollfälle. Zerebral zeigte sich bei beiden Erkrankungen eine geringgradig erhöhte Dichte akut geschädigter Axone im Vergleich $\mathrm{zu}$ den Kontrollen. Beide Erkrankungen zeigten mehr reaktive Astrozyten in der NAWM als Kontrollfälle, wobei die reaktive Gliose bei den NMO-Fällen sowohl zerebral als auch spinal ausgeprägter als bei MS war. Nur bei der MS zeigte sich sowohl zerebral als auch spinal ein signifikanter Anstieg des Quotienten der p25 Oligodendrozyten relativ zur axonalen Dichte.

Im Vergleich zu gesunden Tieren zeigten Mäuse mit EAE in der spinalen NAWM eine Zunahme der T-Zellen, der aktivierten Mikrogliazellen, der akuten axonalen Schädigung, des axonalen Verlusts (bis zu 21\%) sowie einen Anstieg der oligodendroglialen und astrozytären Dichte. Die meisten dieser untersuchten quantitativen Veränderungen nahmen mit der Läsionslast der Tiere zu, was darauf hindeutet, dass bei den Mäusen die Veränderungen in der spinalen NAWM mit dem Ausmaß der spinalen Demyelinisierung im Zusammenhang stehen.

Zusammenfassend kann gesagt werden, dass beide humane Erkrankungen deutliche entzündliche und gliale Veränderungen in der NAWM zeigten. Hinsichtlich der glialen Parameter fand sich nur in der NAWM bei MS eine signifikante Erhöhung der oligodendroglialen Zellen relativ zur axonalen Dichte als möglicher Hinweis auf oligodendrogliale Regeneration. Hingegen zeigte sich bei der NMO der deutlichste Anstieg reaktiver Astrozyten sowohl in der zerebralen als auch in der spinalen NAWM, was am ehesten auf die ausgeprägtere astrogliale Regeneration bei dieser Antikörpervermittelten Erkrankung mit primärer astrozytärer Schädigung hindeutet. Bei beiden Erkrankungen fand sich ein signifikanter spinaler axonaler Verlust in der NAWM, aber nur bei der MS war eine deutliche akut ablaufende axonale Schädigung in der NAWM im Rückenmark nachweisbar. Dies könnte ein mögliches pathologisches Korrelat für die klinische Progredienz bei chronischer MS sein. Weitere Analysen sind erforderlich, um zu ermitteln, wie es zur vermehrten akuten axonalen Schädigung im Rückenmark bei MS kommt und welche Faktoren - wie beispielsweise spinale Mikrogliaknötchen hierbei eine Rolle spielen. Die vorliegenden Erkenntnisse können zu einem besseren Verständnis der beiden humanen Erkrankungen und potentieller künftiger Therapien beitragen. 


\section{Literaturverzeichnis}

Aboul-Enein F, Krssak M, Hoftberger R, Prayer D, Kristoferitsch W (2010): Diffuse white matter damage is absent in neuromyelitis optica. Am J Neuroradiol 31(1), 76-79

Aguzzi A, Barres B A, Bennett M L (2013): Microglia: scapegoat, saboteur, or something else? Science 339(6116), 156-161

Aktas O, Hartung H P (2009): Neuromyelitis and more: the unfolding spectrum of aquaporin 4-related neurological diseases. J Neurol 256(11), 1906-1908

Allen I V, McKeown S R (1979): A histological, histochemical and biochemical study of the macroscopically normal white matter in multiple sclerosis. J Neurol Sci $\underline{41}(1), 81-91$

Alonso A, Hernan M A (2008): Temporal trends in the incidence of multiple sclerosis: a systematic review. Neurology $\underline{71}(2), 129-135$

Amiry-Moghaddam M, Ottersen O P (2003): The molecular basis of water transport in the brain. Nat Rev Neurosci 4 (12), 991-1001

Andreasen A K, Spliid P E, Andersen H, Jakobsen J (2010): Fatigue and processing speed are related in multiple sclerosis. Eur J Neurol 17(2), 212-218

Androdias G, Reynolds R, Chanal M, Ritleng C, Confavreux C, Nataf S (2010): Meningeal $\mathrm{T}$ cells associate with diffuse axonal loss in multiple sclerosis spinal cords. Ann Neurol 68(4), 465-476

Bannerman P, Hahn A, Soulika A, Gallo V, Pleasure D (2007): Astrogliosis in EAE spinal cord: derivation from radial glia, and relationships to oligodendroglia. Glia 55(1), 57-64

Banwell B, Ghezzi A, Bar-Or A, Mikaeloff Y, Tardieu M (2007): Multiple sclerosis in children: clinical diagnosis, therapeutic strategies, and future directions. Lancet Neurol $\underline{6}(10), 887-902$

Barkhof F, Bruck W, De Groot C J, Bergers E, Hulshof S, Geurts J, Polman C H, van d, V (2003): Remyelinated lesions in multiple sclerosis: magnetic resonance image appearance. Arch Neurol 60(8), 1073-1081

Beecham A H, Patsopoulos N A, Xifara D K, Davis M F, Kemppinen A, Cotsapas C, Shah T S, Spencer C, Booth D, Goris A et al. (2013): Analysis of immunerelated loci identifies 48 new susceptibility variants for multiple sclerosis. Nat Genet $\underline{45}(11), 1353-1360$

Bichuetti D B, Rivero R L, de Oliveira E M, Oliveira D M, de Souza N A, Nogueira R G, Abdala N, Gabbai A (2008): White matter spectroscopy in neuromyelitis optica: a case control study. J Neurol 255(12), 1895-1899 
Bischof A, Sprenger T (2014): Interferon beta-associated recurrence of painful trigeminal neuropathy attributed to a multiple sclerosis plaque. J Headache Pain $\underline{15}(1), 21$

Bitsch A, da Costa C, Bunkowski S, Weber F, Rieckmann P, Bruck W (1998): Identification of macrophage populations expressing tumor necrosis factor-alpha mRNA in acute multiple sclerosis. Acta Neuropathol 95(4), 373-377

Bitsch A, Schuchardt J, Bunkowski S, Kuhlmann T, Bruck W (2000): Acute axonal injury in multiple sclerosis. Correlation with demyelination and inflammation. Brain 123(Pt 6), 1174-1183

Bjartmar C, Trapp B D (2001): Axonal and neuronal degeneration in multiple sclerosis: mechanisms and functional consequences. Curr Opin Neurol 14(3), 271-278

Bjartmar C, Wujek J R, Trapp B D (2003): Axonal loss in the pathology of MS: consequences for understanding the progressive phase of the disease. $\mathrm{J}$ Neurol Sci 206(2), 165-171

Bo L, Vedeler C A, Nyland H I, Trapp B D, Mork S J (2003): Subpial demyelination in the cerebral cortex of multiple sclerosis patients. J Neuropathol Exp Neurol $\underline{62}(7), 723-732$

Bradl M, Misu T, Takahashi T, Watanabe M, Mader S, Reindl M, Adzemovic M, Bauer J, Berger T, Fujihara K et al. (2009): Neuromyelitis optica: pathogenicity of patient immunoglobulin in vivo. Ann Neurol 66(5), 630-643

Bramlett H M, Kraydieh S, Green E J, Dietrich W D (1997): Temporal and regional patterns of axonal damage following traumatic brain injury: a beta-amyloid precursor protein immunocytochemical study in rats. J Neuropathol Exp Neurol $\underline{56}(10), 1132-1141$

Brück W (2005): The pathology of multiple sclerosis is the result of focal inflammatory demyelination with axonal damage. J Neurol 252 Suppl 5, v3-v9

Burkert K, Moodley K, Angel C E, Brooks A, Graham E S (2012): Detailed analysis of inflammatory and neuromodulatory cytokine secretion from human NT2 astrocytes using multiplex bead array. Neurochem Int 60(6), 573-580

Carpentier P A, Begolka W S, Olson J K, Elhofy A, Karpus W J, Miller S D (2005): Differential activation of astrocytes by innate and adaptive immune stimuli. Glia $\underline{49}(3), 360-374$

Carton H, Vlietinck R, Debruyne J, De K J, D'Hooghe M B, Loos R, Medaer R, Truyen L, Yee I M, Sadovnick A D (1997): Risks of multiple sclerosis in relatives of patients in Flanders, Belgium. J Neurol Neurosurg Psychiatry 62(4), 329-333

Cruccu G, Biasiotta A, Di R S, Fiorelli M, Galeotti F, Innocenti P, Mameli S, Millefiorini E, Truini A (2009): Trigeminal neuralgia and pain related to multiple sclerosis. Pain $\underline{143}(3), 186-191$

De Groot C J, Bergers E, Kamphorst W, Ravid R, Polman C H, Barkhof F, van d, V (2001): Post-mortem MRI-guided sampling of multiple sclerosis brain lesions: 
increased yield of active demyelinating and (p)reactive lesions. Brain 124(Pt 8), $1635-1645$

DeLuca G C, Ebers G C, Esiri M M (2004): Axonal loss in multiple sclerosis: a pathological survey of the corticospinal and sensory tracts. Brain $\underline{127}(\mathrm{Pt} \mathrm{5})$, 1009-1018

DeLuca G C, Williams K, Evangelou N, Ebers G C, Esiri M M (2006): The contribution of demyelination to axonal loss in multiple sclerosis. Brain 129(Pt 6), 1507-1516

Denic A, Johnson A J, Bieber A J, Warrington A E, Rodriguez M, Pirko I (2011): The relevance of animal models in multiple sclerosis research. Pathophysiology $\underline{18}(1), 21-29$

Dong Y, Benveniste E N (2001): Immune function of astrocytes. Glia $\underline{36}(2), 180-190$

Dziedzic T, Metz I, Dallenga T, Konig F B, Muller S, Stadelmann C, Bruck W (2010): Wallerian degeneration: a major component of early axonal pathology in multiple sclerosis. Brain Pathol 20(5), 976-985

Eng L F, Ghirnikar R S, Lee Y L (2000): Glial fibrillary acidic protein: GFAP-thirtyone years (1969-2000). Neurochem Res 25(9-10), 1439-1451

Evangelou N, Esiri M M, Smith S, Palace J, Matthews P M (2000a): Quantitative pathological evidence for axonal loss in normal appearing white matter in multiple sclerosis. Ann Neurol 47(3), 391-395

Evangelou N, Konz D, Esiri M M, Smith S, Palace J, Matthews P M (2000b): Regional axonal loss in the corpus callosum correlates with cerebral white matter lesion

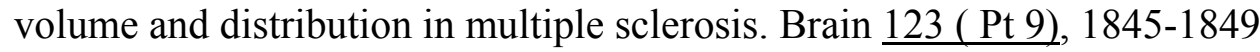

Fazekas F, Barkhof F, Filippi M, Grossman R I, Li D K, McDonald W I, McFarland H F, Paty D W, Simon J H, Wolinsky J S et al. (1999): The contribution of magnetic resonance imaging to the diagnosis of multiple sclerosis. Neurology $\underline{53}(3), 448-456$

Ferguson B, Matyszak M K, Esiri M M, Perry V H (1997): Axonal damage in acute multiple sclerosis lesions. Brain 120 ( Pt 3), 393-399

Filippi M, Rocca M A, Barkhof F, Bruck W, Chen J T, Comi G, DeLuca G, De S N, Erickson B J, Evangelou N et al. (2012): Association between pathological and MRI findings in multiple sclerosis. Lancet Neurol 11(4), 349-360

Freitas E, Guimarães J (2015): Neuromyelitis optica spectrum disorders associated with other autoimmune diseases. Rheumatol Int 35(2), 243-253

Ganter P, Prince C, Esiri M M (1999): Spinal cord axonal loss in multiple sclerosis: a post-mortem study. Neuropathol Appl Neurobiol 25(6), 459-467

Gilmore C P, Donaldson I, Bo L, Owens T, Lowe J, Evangelou N (2009): Regional variations in the extent and pattern of grey matter demyelination in multiple sclerosis: a comparison between the cerebral cortex, cerebellar cortex, deep grey matter nuclei and the spinal cord. J Neurol Neurosurg Psychiatry $\underline{\text { 80}}(2), 182-187$ 
Gold R, Linington C, Lassmann H (2006): Understanding pathogenesis and therapy of multiple sclerosis via animal models: 70 years of merits and culprits in experimental autoimmune encephalomyelitis research. Brain $\underline{129}(\mathrm{Pt} \mathrm{8}), 1953-$ 1971

Graham D I, Smith C, Reichard R, Leclercq P D, Gentleman S M (2004): Trials and tribulations of using beta-amyloid precursor protein immunohistochemistry to evaluate traumatic brain injury in adults. Forensic Sci Int 146(2-3), 89-96

Hauser S L, Bhan A K, Gilles F, Kemp M, Kerr C, Weiner H L (1986): Immunohistochemical analysis of the cellular infiltrate in multiple sclerosis lesions. Ann Neurol 19(6), 578-587

Hein T, Hopfenmuller W (2000): Hochrechnung der Zahl an Multiple Sklerose erkrankten Patienten in Deutschland [Projection of the number of multiple sclerosis patients in Germany]. Nervenarzt 71(4), 288-294

Herrero-Herranz E, Pardo L A, Gold R, Linker R A (2008): Pattern of axonal injury in murine myelin oligodendrocyte glycoprotein induced experimental autoimmune encephalomyelitis: implications for multiple sclerosis. Neurobiol Dis $\underline{30}(2), 162-$ 173

Hlavanda E, Kovacs J, Olah J, Orosz F, Medzihradszky K F, Ovadi J (2002): Brainspecific p25 protein binds to tubulin and microtubules and induces aberrant microtubule assemblies at substoichiometric concentrations. Biochemistry $\underline{41}(27), 8657-8664$

Höftberger R, Fink S, Aboul-Enein F, Botond G, Olah J, Berki T, Ovadi J, Lassmann H, Budka H, Kovacs G G (2010): Tubulin polymerization promoting protein (TPPP/p25) as a marker for oligodendroglial changes in multiple sclerosis. Glia $\underline{58}(15), 1847-1857$

Howell O W, Rundle J L, Garg A, Komada M, Brophy P J, Reynolds R (2010): Activated microglia mediate axoglial disruption that contributes to axonal injury in multiple sclerosis. J Neuropathol Exp Neurol $\underline{69}(10), 1017-1033$

Jack C, Ruffini F, Bar-Or A, Antel J P (2005): Microglia and multiple sclerosis.

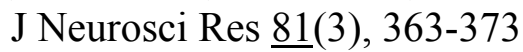

Jarius S, Paul F, Franciotta D, Waters P, Zipp F, Hohlfeld R, Vincent A, Wildemann B (2008): Mechanisms of disease: aquaporin-4 antibodies in neuromyelitis optica. Nat Clin Pract Neurol 4(4), 202-214

Jarius S, Wildemann B (2010): AQP4 antibodies in neuromyelitis optica: diagnostic and pathogenetic relevance. Nat Rev Neurol $\underline{6}(7), 383-392$

Jarius S, Frederikson J, Waters P, Paul F, Akman-Demir G, Marignier R, Franciotta D, Ruprecht K, Kuenz B, Rommer P et al. (2010): Frequency and prognostic impact of antibodies to aquaporin-4 in patients with optic neuritis. J Neurol Sci $\underline{298}(1-2), 158-162$

Jarius S, Jacobi C, de S J, Zephir H, Paul F, Franciotta D, Rommer P, Mader S, Kleiter I, Reindl M et al. (2011): Frequency and syndrome specificity of antibodies to 
aquaporin-4 in neurological patients with rheumatic disorders. Mult Scler 17(9), $1067-1073$

Jeantroux J, Kremer S, Lin X Z, Collongues N, Chanson J B, Bourre B, Fleury M, Blanc F, Dietemann J L, de S J (2012): Diffusion tensor imaging of normalappearing white matter in neuromyelitis optica. J Neuroradiol 39(5), 295-300

Jones M V, Nguyen T T, Deboy C A, Griffin J W, Whartenby K A, Kerr D A, Calabresi P A (2008): Behavioral and pathological outcomes in MOG 35-55 experimental autoimmune encephalomyelitis. J Neuroimmunol 199(1-2), 83-93

Jose S M (2008): Psychological aspects of multiple sclerosis. Clin Neurol Neurosurg $\underline{110}(9), 868-877$

Jurynczyk M, Craner M, Palace J (2015): Overlapping CNS inflammatory diseases: differentiating features of NMO and MS. J Neurol Neurosurg Psychiatry $\underline{86}(1)$, 20-25

Kim S H, Kim W, Li X F, Jung I J, Kim H J (2012): Clinical spectrum of CNS aquaporin-4 autoimmunity. Neurology $\underline{78}(15), 1179-1185$

Koo E H, Sisodia S S, Archer D R, Martin L J, Weidemann A, Beyreuther K, Fischer P, Masters C L, Price D L (1990): Precursor of amyloid protein in Alzheimer disease undergoes fast anterograde axonal transport. Proc Natl Acad Sci U S A $\underline{87}(4), 1561-1565$

Kornek B, Storch M K, Weissert R, Wallstroem E, Stefferl A, Olsson T, Linington C, Schmidbauer M, Lassmann H (2000): Multiple sclerosis and chronic autoimmune encephalomyelitis: a comparative quantitative study of axonal injury in active, inactive, and remyelinated lesions. Am J Pathol 157(1), 267-276

Kuhlmann T, Lingfeld G, Bitsch A, Schuchardt J, Bruck W (2002): Acute axonal damage in multiple sclerosis is most extensive in early disease stages and decreases over time. Brain 125(Pt 10), 2202-2212

Kutzelnigg A, Lassmann H (2005): Cortical lesions and brain atrophy in MS. J Neurol Sci 233(1-2), 55-59

Kutzelnigg A, Lucchinetti C F, Stadelmann C, Bruck W, Rauschka H, Bergmann M, Schmidbauer M, Parisi J E, Lassmann H (2005): Cortical demyelination and diffuse white matter injury in multiple sclerosis. Brain 128 (Pt 11), 2705-2712

Lennon V A, Wingerchuk D M, Kryzer T J, Pittock S J, Lucchinetti C F, Fujihara K, Nakashima I, Weinshenker B G (2004): A serum autoantibody marker of

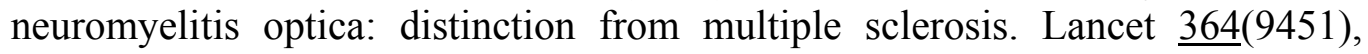
2106-2112

Lennon V A, Kryzer T J, Pittock S J, Verkman A S, Hinson S R (2005): IgG marker of optic-spinal multiple sclerosis binds to the aquaporin-4 water channel. J Exp Med 202(4), 473-477 
Li G L, Farooque M, Holtz A, Olsson Y (1995): Changes of beta-amyloid precursor protein after compression trauma to the spinal cord: an experimental study in the rat using immunohistochemistry. J Neurotrauma 12(3), 269-277

Lovas G, Szilagyi N, Majtenyi K, Palkovits M, Komoly S (2000): Axonal changes in chronic demyelinated cervical spinal cord plaques. Brain 123(Pt 2), 308-317

Lublin F D, Reingold S C (1996): Defining the clinical course of multiple sclerosis: results of an international survey. National Multiple Sclerosis Society (USA) Advisory Committee on Clinical Trials of New Agents in Multiple Sclerosis. Neurology $\underline{46}(4), 907-911$

Lucchinetti C F, Mandler R N, McGavern D, Bruck W, Gleich G, Ransohoff R M, Trebst C, Weinshenker B, Wingerchuk D, Parisi J E et al. (2002): A role for humoral mechanisms in the pathogenesis of Devic's neuromyelitis optica. Brain $\underline{125}(\mathrm{Pt} 7), 1450-1461$

Ludwin S K (2006): The pathogenesis of multiple sclerosis: relating human pathology to experimental studies. J Neuropathol Exp Neurol 65(4), 305-318

Mandler R N, Davis L E, Jeffery D R, Kornfeld M (1993): Devic's neuromyelitis optica: a clinicopathological study of 8 patients. Ann Neurol 34(2), 162-168

Markoullis K, Sargiannidou I, Schiza N, Hadjisavvas A, Roncaroli F, Reynolds R, Kleopa K A (2012): Gap junction pathology in multiple sclerosis lesions and normal-appearing white matter. Acta Neuropathol 123(6), 873-886

McDonald W I, Compston A, Edan G, Goodkin D, Hartung H P, Lublin F D, McFarland H F, Paty D W, Polman C H, Reingold S C et al. (2001): Recommended diagnostic criteria for multiple sclerosis: guidelines from the International Panel on the diagnosis of multiple sclerosis. Ann Neurol 50(1), $121-127$

Mendel I, Kerlero de R N, Ben-Nun A (1995): A myelin oligodendrocyte glycoprotein peptide induces typical chronic experimental autoimmune encephalomyelitis in $\mathrm{H}-2 \mathrm{~b}$ mice: fine specificity and $\mathrm{T}$ cell receptor $\mathrm{V}$ beta expression of encephalitogenic T cells. Eur J Immunol 25(7), 1951-1959

Misu T, Fujihara K, Nakashima I, Sato S, Itoyama Y (2005): Intractable hiccup and nausea with periaqueductal lesions in neuromyelitis optica. Neurology 65(9), $1479-1482$

Misu T, Fujihara K, Kakita A, Konno H, Nakamura M, Watanabe S, Takahashi T, Nakashima I, Takahashi H, Itoyama Y (2007): Loss of aquaporin 4 in lesions of neuromyelitis optica: distinction from multiple sclerosis. Brain $\underline{130}(\mathrm{Pt} 5), 1224-$ 1234

Misu T, Hoftberger R, Fujihara K, Wimmer I, Takai Y, Nishiyama S, Nakashima I, Konno H, Bradl M, Garzuly F et al. (2013): Presence of six different lesion types suggests diverse mechanisms of tissue injury in neuromyelitis optica. Acta Neuropathol 125(6), 815-827 
Moll N M, Rietsch A M, Thomas S, Ransohoff A J, Lee J C, Fox R, Chang A, Ransohoff R M, Fisher E (2011): Multiple sclerosis normal-appearing white matter: pathology-imaging correlations. Ann Neurol 70(5), 764-773

Nikcevich K M, Gordon K B, Tan L, Hurst S D, Kroepfl J F, Gardinier M, Barrett T A, Miller S D (1997): IFN-gamma-activated primary murine astrocytes express B7 costimulatory molecules and prime naive antigen-specific $\mathrm{T}$ cells. $\mathrm{J}$ Immunol $\underline{158}(2), 614-621$

Noseworthy J H, Lucchinetti C, Rodriguez M, Weinshenker B G (2000): Multiple sclerosis. N Engl J Med 343(13), 938-952

O'Riordan J I, Gallagher H L, Thompson A J, Howard R S, Kingsley D P, Thompson E J, McDonald W I, Miller D H (1996): Clinical, CSF, and MRI findings in Devic's neuromyelitis optica. J Neurol Neurosurg Psychiatry 60(4), 382-387

Ozawa K, Suchanek G, Breitschopf H, Bruck W, Budka H, Jellinger K, Lassmann H (1994): Patterns of oligodendroglia pathology in multiple sclerosis. Brain $\underline{117}$ (Pt 6), 1311-1322

Paulus W, Roggendorf W, Kirchner T (1992): Ki-M1P as a marker for microglia and brain macrophages in routinely processed human tissues. Acta Neuropathol $\underline{84}(5), 538-544$

Pierce J E, Trojanowski J Q, Graham D I, Smith D H, McIntosh T K (1996): Immunohistochemical characterization of alterations in the distribution of amyloid precursor proteins and beta-amyloid peptide after experimental brain injury in the rat. J Neurosci 16(3), 1083-1090

Pittock S J, Lennon V A, Krecke K, Wingerchuk D M, Lucchinetti C F, Weinshenker B G (2006a): Brain abnormalities in neuromyelitis optica. Arch Neurol 63(3), 390396

Pittock S J, Weinshenker B G, Lucchinetti C F, Wingerchuk D M, Corboy J R, Lennon V A (2006b): Neuromyelitis optica brain lesions localized at sites of high aquaporin 4 expression. Arch Neurol $\underline{63}(7), 964-968$

Pittock S J, Lennon V A, de S J, Vermersch P, Homburger H A, Wingerchuk D M, Lucchinetti C F, Zephir H, Moder K, Weinshenker B G (2008): Neuromyelitis optica and non organ-specific autoimmunity. Arch Neurol 65(1), 78-83

Polman C H, Reingold S C, Edan G, Filippi M, Hartung H P, Kappos L, Lublin F D, Metz L M, McFarland H F, O'Connor P W et al. (2005): Diagnostic criteria for multiple sclerosis: 2005 revisions to the "McDonald Criteria". Ann Neurol $\underline{58}(6), 840-846$

Polman C H, Reingold S C, Banwell B, Clanet M, Cohen J A, Filippi M, Fujihara K, Havrdova E, Hutchinson M, Kappos L et al. (2011): Diagnostic criteria for multiple sclerosis: 2010 revisions to the McDonald criteria. Ann Neurol 69(2), 292-302 
Popescu B F, Parisi J E, Cabrera-Gomez J A, Newell K, Mandler R N, Pittock S J, Lennon V A, Weinshenker B G, Lucchinetti C F (2010): Absence of cortical demyelination in neuromyelitis optica. Neurology $\underline{75}(23), 2103-2109$

Radzun H J, Hansmann M L, Heidebrecht H J, Bodewadt-Radzun S, Wacker H H, Kreipe H, Lumbeck H, Hernandez C, Kuhn C, Parwaresch M R (1991): Detection of a monocyte/macrophage differentiation antigen in routinely processed paraffin-embedded tissues by monoclonal antibody Ki-M1P. Lab Invest $\underline{65}(3), 306-315$

Reeves S A, Helman L J, Allison A, Israel M A (1989): Molecular cloning and primary structure of human glial fibrillary acidic protein. Proc Natl Acad Sci U S A $\underline{86}(13), 5178-5182$

Riphagen J, Modderman P, Verrips A (2010): Hiccups, nausea, and vomiting: water channels under attack! Lancet $\underline{375}(9718), 954$

Roemer S F, Parisi J E, Lennon V A, Benarroch E E, Lassmann H, Bruck W, Mandler R N, Weinshenker B G, Pittock S J, Wingerchuk D M et al. (2007): Patternspecific loss of aquaporin-4 immunoreactivity distinguishes neuromyelitis optica from multiple sclerosis. Brain 130(Pt 5), 1194-1205

Rueda Lopes F C, Doring T, Martins C, Cabral F C, Malfetano F R, Pereira V C, AlvesLeon S, Gasparetto E L (2012): The role of demyelination in neuromyelitis optica damage: diffusion-tensor MR imaging study. Radiology 263(1), 235-242

Saadoun S, Waters P, Bell B A, Vincent A, Verkman A S, Papadopoulos M C (2010): Intra-cerebral injection of neuromyelitis optica immunoglobulin $\mathrm{G}$ and human complement produces neuromyelitis optica lesions in mice. Brain $\underline{133}(\mathrm{Pt} 2)$, 349-361

Schirmer L, Merkler D, Konig F B, Bruck W, Stadelmann C (2013): Neuroaxonal Regeneration is More Pronounced in Early Multiple Sclerosis than in Traumatic Brain Injury Lesions. Brain Pathol 23(1), 2-12

Schmidt R, Schmidt H, Haybaeck J, Loitfelder M, Weis S, Cavalieri M, Seiler S, Enzinger C, Ropele S, Erkinjuntti T et al. (2011): Heterogeneity in age-related white matter changes. Acta Neuropathol 122(2), 171-185

Seewann A, Vrenken H, van d, V, Blezer E L, Knol D L, Castelijns J A, Polman C H, Pouwels P J, Barkhof F, Geurts J J (2009): Diffusely abnormal white matter in chronic multiple sclerosis: imaging and histopathologic analysis. Arch Neurol $\underline{66}(5), 601-609$

Sherriff F E, Bridges L R, Sivaloganathan S (1994a): Early detection of axonal injury after human head trauma using immunocytochemistry for beta-amyloid precursor protein. Acta Neuropathol $\underline{87}(1), 55-62$

Sherriff F E, Bridges L R, Gentleman S M, Sivaloganathan S, Wilson S (1994b): Markers of axonal injury in post mortem human brain. Acta Neuropathol $\underline{88}(5)$, 433-439 
Simpson J E, Fernando M S, Clark L, Ince P G, Matthews F, Forster G, O'Brien J T, Barber R, Kalaria R N, Brayne C et al. (2007): White matter lesions in an unselected cohort of the elderly: astrocytic, microglial and oligodendrocyte precursor cell responses. Neuropathol Appl Neurobiol 33(4), 410-419

Singh S, Metz I, Amor S, van d, V, Stadelmann C, Bruck W (2013): Microglial nodules in early multiple sclerosis white matter are associated with degenerating axons. Acta Neuropathol 125(4), 595-608

Skjoerringe T, Lundvig D M, Jensen P H, Moos T (2006): P25alpha/Tubulin polymerization promoting protein expression by myelinating oligodendrocytes of the developing rat brain. J Neurochem $\underline{99}$ (1), 333-342

Smestad C, Sandvik L, Landro N I, Celius E G (2010): Cognitive impairment after three decades of multiple sclerosis. Eur J Neurol 17(3), 499-505

Sofroniew M V, Vinters H V (2010): Astrocytes: biology and pathology. Acta Neuropathol $\underline{119}(1), 7-35$

Stadelmann C, Wegner C, Bruck W (2011): Inflammation, demyelination, and degeneration - recent insights from MS pathology. Biochim Biophys Acta $\underline{1812}(2), 275-282$

Sternberger L A, Sternberger N H (1983): Monoclonal antibodies distinguish phosphorylated and nonphosphorylated forms of neurofilaments in situ. Proc

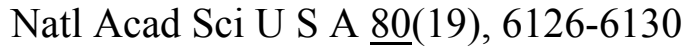

Takahashi M, Tomizawa K, Fujita S C, Sato K, Uchida T, Imahori K (1993): A brainspecific protein p25 is localized and associated with oligodendrocytes, neuropil, and fiber-like structures of the CA3 hippocampal region in the rat brain. $\mathrm{J}$ Neurochem $\underline{60}(1), 228-235$

Takahashi T, Miyazawa I, Misu T, Takano R, Nakashima I, Fujihara K, Tobita M, Itoyama Y (2008): Intractable hiccup and nausea in neuromyelitis optica with anti-aquaporin-4 antibody: a herald of acute exacerbations. J Neurol Neurosurg Psychiatry $\underline{79}(9), 1075-1078$

Tan L, Gordon K B, Mueller J P, Matis L A, Miller S D (1998): Presentation of proteolipid protein epitopes and B7-1-dependent activation of encephalitogenic T cells by IFN-gamma-activated SJL/J astrocytes. J Immunol 160(9), 4271-4279

Trapp B D, Peterson J, Ransohoff R M, Rudick R, Mork S, Bo L (1998): Axonal transection in the lesions of multiple sclerosis. N Engl J Med 338(5), 278-285

Trebst C, Jarius S, Berthele A, Paul F, Schippling S, Wildemann B, Borisow N, Kleiter I, Aktas O, Kumpfel T (2014): Update on the diagnosis and treatment of neuromyelitis optica: recommendations of the Neuromyelitis Optica Study Group (NEMOS). J Neurol 261(1), 1-16

Trip S A, Miller D H (2005): Imaging in multiple sclerosis. J Neurol Neurosurg Psychiatry 76 Suppl 3, iii11-iii18 
Van Horssen J, Singh S, van der Pol S, Kipp M, Lim J L, Peferoen L, Gerritsen W, Kooi E J, Witte M E, Geurts J J et al. (2012): Clusters of activated microglia in normal-appearing white matter show signs of innate immune activation. J Neuroinflammation $\underline{9}, 156$

Waxman S G (2001): Acquired channelopathies in nerve injury and MS. Neurology $\underline{56}(12), 1621-1627$

Weinshenker B G, Wingerchuk D M, Vukusic S, Linbo L, Pittock S J, Lucchinetti C F, Lennon V A (2006): Neuromyelitis optica IgG predicts relapse after longitudinally extensive transverse myelitis. Ann Neurol 59(3), 566-569

Wingerchuk D M, Hogancamp W F, O'Brien P C, Weinshenker B G (1999): The clinical course of neuromyelitis optica (Devic's syndrome). Neurology $\underline{53}(5)$, $1107-1114$

Wingerchuk D M, Lennon V A, Pittock S J, Lucchinetti C F, Weinshenker B G (2006): Revised diagnostic criteria for neuromyelitis optica. Neurology 66(10), 14851489

Wingerchuk D M, Lennon V A, Lucchinetti C F, Pittock S J, Weinshenker B G (2007): The spectrum of neuromyelitis optica. Lancet Neurol $\underline{6}(9), 805-815$

Wrzos C, Winkler A, Metz I, Kayser D M, Thal D R, Wegner C, Bruck W, Nessler S, Bennett J L, Stadelmann C (2014): Early loss of oligodendrocytes in human and experimental neuromyelitis optica lesions. Acta Neuropathol 127(4), 523-538

Yam P S, Takasago T, Dewar D, Graham D I, McCulloch J (1997): Amyloid precursor protein accumulates in white matter at the margin of a focal ischaemic lesion. Brain Res 760(1-2), 150-157

Yu C, Lin F, Li K, Jiang T, Qin W, Sun H, Chan P (2008): Pathogenesis of normalappearing white matter damage in neuromyelitis optica: diffusion-tensor MR imaging. Radiology 246(1), 222-228

Yu C S, Lin F C, Li K C, Jiang T Z, Zhu C Z, Qin W, Sun H, Chan P (2006): Diffusion tensor imaging in the assessment of normal-appearing brain tissue damage in relapsing neuromyelitis optica. AJNR Am J Neuroradiol 27(5), 1009-1015

Zhang R, Xue Y Y, Lu S D, Wang Y, Zhang L M, Huang Y L, Signore A P, Chen J, Sun F Y (2006): Bcl-2 enhances neurogenesis and inhibits apoptosis of newborn neurons in adult rat brain following a transient middle cerebral artery occlusion. Neurobiol Dis 24(2), 345-356 


\section{Anhang}

Tabelle 9: Verwendete Substanzen

\begin{tabular}{|c|c|}
\hline Substanz & Bezugsquelle \\
\hline Ammoniaklösung (32\%) & Merck KGaA, Darmstadt, Deutschland \\
\hline Chloralhydrat (14\%) in Aqua bidest. & Fagron GmbH \& Co. KG, Barsbüttel, Deutschland \\
\hline $\begin{array}{l}\text { DAB (3-3'-Diaminobenzidin- } \\
\text { Tetrahydrochlorid) }\end{array}$ & Sigma-Aldrich Chemie GmbH, Steinheim, Deutschland \\
\hline DePeX Mounting medium & SERVA Electrophoresis GmbH, Heidelberg, Deutschland \\
\hline EDTA $0.5 \mathrm{M}$ & Carl Roth GmbH + Co. KG, Karlsruhe, Deutschland \\
\hline EDTA $1 \mathrm{M}$ & Calbiochem ${ }^{\circledast} /$ Merck KGaA, Darmstadt, Deutschland \\
\hline Eosin-G Certistain $^{\circledR}$ & Merck KGaA, Darmstadt, Deutschland \\
\hline Essigsäure 100\% (Eisessig) & Merck KGaA, Darmstadt, Deutschland \\
\hline Ethanol absolut (Isopropanol) & Merck KGaA, Darmstadt, Deutschland \\
\hline ExtrAvidin $^{\circledR}$ & Sigma-Aldrich Chemie GmbH, Steinheim, Deutschland \\
\hline fetal calf serum (FCS) & Biochrom AG, Berlin, Deutschland \\
\hline Formalin & Merck KGaA, Darmstadt, Deutschland \\
\hline goat serum & PAA Laboratories $\mathrm{GmbH}$, Austria \\
\hline Ketamin (10\%) & Medistar Arzneimittelvertrieb GmbH, Ascheberg, Deutschland \\
\hline Lithiumcarbonat $(0.05 \%)$ & Merck KGaA, Darmstadt, Deutschland \\
\hline Luxol-Fast-Blue (LFB) & BDH Laboratory supplies, VWR Int. Ltd., UK \\
\hline Mannide monooleate & Sigma-Aldrich Chemie GmbH, Steinheim, Deutschland \\
\hline Mayers Hämalaunlösung & Merck KGaA, Darmstadt, Deutschland \\
\hline $\mathrm{MOG}_{35-55}(4 \mathrm{mg} / \mathrm{ml}$ in PBS$)$ & $\begin{array}{l}\text { Institut für Medizinische Immunologie, Universitätsklinikum } \\
\text { Charité, Berlin, Deutschland }\end{array}$ \\
\hline Mycobacterium tuberculosis H37RA & Difco Laboratories, Augsburg, Deutschland \\
\hline Natriumhydroxid $\mathrm{NaOH}, 1 \mathrm{M}$ & Merck KGaA, Darmstadt, Deutschland \\
\hline Natriumthiosulfat-Pentahydrat & Merck KGaA, Darmstadt, Deutschland \\
\hline Paraffin Paraplast Plus & Tyco Healthcare GmbH, Deutschland \\
\hline Paraffinöl & Carl Roth GmbH \& Co. KG, Karlsruhe, Deutschland \\
\hline Paraformaldehyd (PFA) & Merck KGaA, Darmstadt, Deutschland \\
\hline PBS (phosphate-buffered saline) & Biochrom AG, Berlin, Deutschland \\
\hline Perjodsäure & Merck KGaA, Darmstadt, Deutschland \\
\hline Pertussis-Toxin (PTx $100 \mathrm{ng} / \mu \mathrm{l}$ in PBS) & List Biological Laboratories, London, UK \\
\hline Salpetersäure (65\%) & Merck KGaA, Darmstadt, Deutschland \\
\hline Salzsäure $\mathrm{HCl}, 1 \mathrm{M}$ & Merck KGaA, Darmstadt, Deutschland \\
\hline Schiff'sches Reagenz & Sigma-Aldrich Chemie GmbH, Steinheim, Deutschland \\
\hline Silbernitrat AgNO3 & Carl Roth GmbH + Co. KG, Karlsruhe, Deutschland \\
\hline Tris: Trizma ${ }^{\circledR}$ base & Sigma-Aldrich Chemie GmbH, Steinheim, Deutschland \\
\hline Wasserstoffperoxid $\mathrm{H}_{2} \mathrm{O}_{2}(30 \%)$ & Merck KGaA, Darmstadt, Deutschland \\
\hline Xylazin (2\%) & Riemser Pharma GmbH, Greifswald- Insel Riems, Deutschland \\
\hline Xylol & J.T.Baker, Deventer, Niederlande \\
\hline Zitronensäure-Monohydrat & Merck KGaA, Darmstadt, Deutschland \\
\hline
\end{tabular}


Tabelle 10: Verwendete Lösungen und Reagenzien

\begin{tabular}{|c|c|c|}
\hline Lösung & \multicolumn{2}{|l|}{ Zusammensetzung } \\
\hline Bielschowsky-Entwickler & Formalin (37\%) & $20 \mathrm{ml}$ \\
\hline \multirow[t]{3}{*}{ (Bielschowsky-Silberimprägnation) } & Aqua bidest. & $100 \mathrm{ml}$ \\
\hline & Zitronensäure-Monohydrat & $0,5 \mathrm{~g}$ \\
\hline & konzentrierte Salpetersäure (65\%) & 1 Tropfen \\
\hline CFA & IFA & $15 \mathrm{ml}$ \\
\hline \multirow[t]{2}{*}{ (complete Freund's adjuvant) } & Mycobacterium tuberculosis H37RA & 100 mg \\
\hline & $\rightarrow$ Mykobakterien-Konzentration & $6,66 \mathrm{mg} / \mathrm{ml}$ \\
\hline Citrat-Puffer (10 mM) & Zitronensäure-Monohydrat & $2,1014 \mathrm{~g}$ \\
\hline \multirow[t]{2}{*}{ (Immunhistochemie) } & Aqua bidest. & 11 \\
\hline & $\rightarrow \mathrm{pH}$ auf 6,0 einstellen & \\
\hline DAB & PBS & $49 \mathrm{ml}$ \\
\hline \multirow[t]{2}{*}{ (Immunhistochemie) } & $\mathrm{DAB}$ & $1 \mathrm{ml}$ \\
\hline & $30 \% \mathrm{H}_{2} \mathrm{O}_{2}$ & $20 \mu \mathrm{l}$ \\
\hline \multirow[t]{2}{*}{ FCS/PBS-Lösung, 10\%ig } & PBS & $9 \mathrm{ml}$ \\
\hline & FCS (fetal calf serum) & $1 \mathrm{ml}$ \\
\hline HCl-Alkohol-Lösung, 1\%ig & Isopropanol & $1750 \mathrm{ml}$ \\
\hline \multirow[t]{2}{*}{ (auch: HCl-Alkohol) } & Aqua dest. & $750 \mathrm{ml}$ \\
\hline & Salzsäure (25\%) & $25 \mathrm{ml}$ \\
\hline IFA & Paraffinöl & $85 \%$ \\
\hline (incomplete Freund's adjuvant) & Emulgator Mannide monooleat & $15 \%$ \\
\hline Isopropanol & \multirow{2}{*}{\multicolumn{2}{|c|}{$\begin{array}{l}\text { Ethanol absolut bis zur gewünschten Konzentration } \\
\text { mit Aqua dest. verdünnt }\end{array}$}} \\
\hline in verschiedenen Konzentrationen & & \\
\hline Isoxylol & \multicolumn{2}{|l|}{ Xylol und Isopropanol zu gleichen Teilen } \\
\hline LFB-Lösung & LFB in & $1 \mathrm{~g}$ \\
\hline \multirow[t]{3}{*}{ (LFB/PAS-Färbung) } & 96\%igem Ethanol lösen & $5 \mathrm{ml}$ \\
\hline & 10\%ige Essigsäure zusetzen & 11 \\
\hline & filtrieren & \\
\hline MOG $_{35-55} /$ CFA-Emulsion & $\mathrm{MOG}_{35-55}(4 \mathrm{mg} / \mathrm{ml}$ in PBS$)$ & $500 \mu l$ \\
\hline \multirow[t]{2}{*}{$\left(\mathrm{MOG}_{35-55} 1 \mathrm{mg} / \mathrm{ml}\right.$ in CFA) } & PBS & $500 \mu l$ \\
\hline & CFA & $1 \mathrm{ml}$ \\
\hline Natrium-Thiosulfat-Lösung, 2\%ig & Natriumthiosulfat-Pentahydrat & $10 \mathrm{~g}$ \\
\hline (Bielschowsky-Silberimprägnation) & Aqua dest. & $500 \mathrm{ml}$ \\
\hline Perjodsäure, 1\%ig & Perjodsäure & $1 \mathrm{~g}$ \\
\hline (LFB/PAS-Färbung) & Aqua bidest. & $99 \mathrm{ml}$ \\
\hline \multirow[t]{5}{*}{ PFA-Lösung, 4\%ig } & PFA & $40 \mathrm{~g}$ \\
\hline & $\begin{array}{l}\text { in Aqua bidest. lösen und unter } \\
\text { Rühren auf } 60-65^{\circ} \mathrm{C} \text { erhitzen }\end{array}$ & $500 \mathrm{ml}$ \\
\hline & $\begin{array}{l}1 \mathrm{M} \mathrm{NaOH} \text { zugeben, bis die Lösung } \\
\text { klar wird }\end{array}$ & Einige Tropfen \\
\hline & $1 \times$ PBS & $500 \mathrm{ml}$ \\
\hline & $\rightarrow \mathrm{pH}$ auf 7,4 einstellen & $=11$ \\
\hline
\end{tabular}




\begin{tabular}{lll}
\hline Silbernitrat-Lösung, 20\%ig & $\mathrm{AgNO}_{3}$ & $15 \mathrm{~g}$ \\
(Bielschowsky-Silberimprägnation) & Aqua dest. & $75 \mathrm{ml}$ \\
\hline Tris/EDTA & Trizma base $(10 \mathrm{mM})$ & $1,21 \mathrm{~g}$ \\
(Immunhistochemie) & EDTA 1mM & $1 \mathrm{ml}$ von 1M EDTA \\
& Aqua bidest. & $1 \mathrm{I}$ \\
& $\rightarrow$ pH auf 9,0 einstellen & \\
\hline wässrige Eosin-Lösung, 1\%ig & Eosin G Certistain ${ }^{\circledR}$ & $2 \mathrm{~g}$ \\
(HE-Färbung) & $70 \%$ Isopropanol & $198 \mathrm{ml}$ \\
& Eisessig & 2 Tropfen \\
\hline
\end{tabular}

$\mathrm{M}=$ Mol; $\mathrm{mM}=$ Millimol

Tabelle 11: Geräte und relevante Verbrauchsmaterialien

\begin{tabular}{ll}
\hline Geräte/Verbrauchsmaterialien & Hersteller \\
\hline Deckgläser 24 x 36 mm & Gerhard Menzel GmbH, Braunschweig, Deutschland \\
\hline Digital-Mikroskopkamera DP 71 & Olympus, Hamburg, Deutschland \\
\hline Einbettautomat TP 1020 & Leica, Deutschland \\
\hline Okular WH10X-H/22 mit Zählgitter & Olympus Corporation, Tokyo, Japan \\
\hline Okular WH10X-H/22 mit Axonzählgitter & Olympus Corporation, Tokyo, Japan \\
\hline Lichtmikroskop BX-41 & Olympus Corporation, Tokyo, Japan \\
\hline Mikrotom Leica SM 2000R & Leica Microsystems GmbH, Nussloch, Deutschland \\
\hline Objektträger SuperFrost ${ }^{\circledR}$ Plus & Gerhard Menzel GmbH, Braunschweig, Deutschland \\
\hline Paraffinausgießstation Histocentre 2A & Shandon, Frankfurt, Deutschland \\
\hline pH-Meter & WTW, Hamburg, Deutschland \\
\hline Pipetten, Research & Eppendorf, Hamburg, Deutschland \\
\hline Vortexer Heidolph Reax top & Heidolph Insruments, Schwabach, Deutschland \\
\hline
\end{tabular}


Tabelle 12, Teil 1: Klinische Daten humaner Autopsiefälle - altersentsprechende gesunde Kontrollen

\begin{tabular}{|c|c|c|c|c|c|c|}
\hline Diagnose & Fall & Alter* & Geschl. & Vorerkrankungen/klinische Angaben & Todesursache & $\begin{array}{l}\text { PMI } \\
\text { (Tage) }\end{array}$ \\
\hline \multirow[t]{13}{*}{ Kontrollen } & K1 & 63 & $\mathrm{~m}$ & $\begin{array}{l}\text { Meningeosis carcinomatosa bei unbekanntem Primärtumor; Hypertonus; Diabetes } \\
\text { mellitus; Niereninsuffizienz }\end{array}$ & k. A. & 1 \\
\hline & K2 & 70 & $\mathrm{~m}$ & $\begin{array}{l}\text { Z. n. Rectumcarcinom; infrarenales Bauchaortenaneurysma; Cholecystolithiasis; Adiposi- } \\
\text { tas; Steatosis hepatis; mediale Bachwandhernie; dauerhafte Double-J-Schienung links bei } \\
\text { Harnleiterenge; aktuell Radiotherapie bei Iymphogen metastasiertem Bronchialcarcinom } \\
\text { und mediastinaler Infiltration; Ileussymptomatik }\end{array}$ & Asystolie & 1 \\
\hline & K3 & 80 & w & $\begin{array}{l}\text { V. a. akute Leukämie; arterielle Hypertonie; kompensierte Herzinsuffizienz; nicht insulin- } \\
\text { abhängige Diabetes mellitus Typ } 2\end{array}$ & $\begin{array}{l}\text { Exitus letalis bei fulminanter Bradykardie } \\
\text { und Asystolie }\end{array}$ & 3 \\
\hline & K4 & 42 & $\mathrm{~m}$ & $\begin{array}{l}\text { vorbestehende 3-Gefäß-KHK; } 8 \text { Tage vor dem Versterben kardiogen und SIRS bedingter } \\
\text { Schock, Kammerflimmern mit CPR; Stentimplantation }\end{array}$ & $\begin{array}{l}\text { Exitus letalis bei Lungenödem und } \\
\text { Asystolie, V. a. Reinfarkt }\end{array}$ & 1 \\
\hline & K5 & 54 & w & $\begin{array}{l}\text { unbekannte KHK; Hypotonie mit Schockzeichen, intermittierende Asystolie, Stentimplanta- } \\
\text { tion; Raumforderung rechter Hilus Lymphknoten, DD Bronchialcarcinom }\end{array}$ & $\begin{array}{l}\text { Exitus letalis bei kardiogenem Schock und } \\
\text { elektromechanischer Entkopplung }\end{array}$ & 1 \\
\hline & K6 & 45 & $\mathrm{~m}$ & k. A. & $\begin{array}{l}\text { Äußeres + inneres Verbluten nach } \\
\text { Durchtrennung des Vorderhalsen und } \\
\text { Stichverletzungen von Herz, Lunge, Leber }\end{array}$ & k. A. \\
\hline & K7 & 81 & $\mathrm{~m}$ & $\begin{array}{l}\text { Sepsis bei V. a. Bronchopneumonie; Aufnahme aufgrund eines akuten Koronarsyndroms; } \\
\text { Niereninsuffizienz }\end{array}$ & Sepsis & 1 \\
\hline & K8 & 64 & w & V. a. Leberversagen oder toxische Veränderung & Asystolie & 2 \\
\hline & к9 & 67 & $\mathrm{~m}$ & $\begin{array}{l}\text { Aufnahme bei V.a. septischer Schub bei Endokarditis der Mitral- und Aortenklappe; } \\
\text { Pneumonie, Pleuraergüsse, Nierenversage }\end{array}$ & septisches Multiorganversagen & 1 \\
\hline & K10 & 65 & w & $\begin{array}{l}\text { bekannte Tachyarrhythmia absoluta bei Vorhofflimmern, Marcumartherapie; med. Th. bei } \\
\text { chronischer Polyarthritis; bekannte Eisenmangelanämie; Adipositas; bei Aufnahme } \\
\text { Induzierte Lungenfibrose und atypische Pneumonie }\end{array}$ & V. a. Lungenembolie & k. A. \\
\hline & K11 & 73 & $\mathrm{~m}$ & Prostatacarcinom, Z. n. R1- Resektion; Blasencarcinom, Z. n. R0- Resektion; Neoblase & Sepsis/Urosepsis & 1 \\
\hline & K12 & 56 & $\mathrm{~m}$ & Rezidiv eines Nichtkleinzelliges Bronchialkarzinom (NSCLC) & kardiogener Schock & 2 \\
\hline & K13 & 54 & $\mathrm{~m}$ & 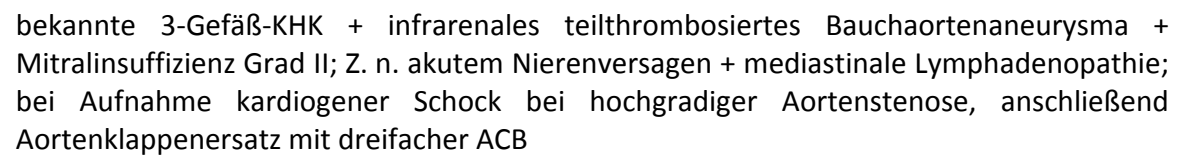 & Ruptur des Bauchaortenaneurysmas & 3 \\
\hline
\end{tabular}


Tabelle 12, Teil 2: Klinische Daten humaner Autopsiefälle - Patienten mit Multipler Sklerose (MS)

\begin{tabular}{|c|c|c|c|c|c|c|c|c|}
\hline Diagnose & Fall & Alter* & Geschl. & $\begin{array}{c}\text { KD } \\
\text { (Jahre) }\end{array}$ & Verlauf & Symptome & Todesursache & $\begin{array}{l}\text { PMI } \\
\text { (Tage) }\end{array}$ \\
\hline \multirow[t]{13}{*}{ MS } & MS1 & 61 & $\mathrm{~m}$ & 6 & k. A. & k. A. & k. A. & k. A. \\
\hline & MS2 & 67 & $\mathrm{~m}$ & k. A. & k. A. & $\begin{array}{l}\text { k. A. zur MS-Symptomatik; Nebenbefunde: Chron. Polyarthritis, Hyper- } \\
\text { tonus, KHK, rezidivierende Myokardinfarkte, Arteriosklerose }\end{array}$ & Biventrikuläres Herzversagen & 1 \\
\hline & MS3 & 56 & $\mathrm{~m}$ & k. A. & PMS & k. A. zur MS-Symptomatik; Nebenbefunde: Morbus Crohn & fulminante Lungenembolie & 1 \\
\hline & MS4 & 36 & w & k. A. & PPMS & $\begin{array}{l}\text { Degeneration der linken Pyramidenbahn bis ins Sakralmark; Befall des N. } \\
\text { opticus }\end{array}$ & Lungenembolie & k. A. \\
\hline & MS5 & 56 & w & 9 & PMS & k. A. & k. A. & 1 \\
\hline & MS6 & 61 & $\mathrm{~m}$ & k. A. & k. A. & $\begin{array}{l}\text { k. A. zur MS-Symptomatik; Nebenbefund: Pneumonie, KHK, Z. n. Herzin- } \\
\text { farkt, Z. n. Unterschenkelamputation wegen PAVK, Dekubitalulzera }\end{array}$ & Myokardinfarkt & k. A. \\
\hline & MS7 & 42 & $\mathrm{~m}$ & k. A. & k. A. & k. A. & k. A. & k. A. \\
\hline & MS8 & 39 & w & $>10$ & PMS & $\begin{array}{l}\text { k. A. zur MS-Symptomatik, wegen MS im Pflegeheim; Nebenbefund: } \\
\text { Pneumonie, Milztumor }\end{array}$ & V. a. lleus & k. A. \\
\hline & MS9 & 77 & w & $>3$ & k. A. & k. A. & $\begin{array}{l}\text { respiratorische und rechtskardiale } \\
\text { Insuffizienz bei beidseitig aktiver azinös- } \\
\text { nodöser reaktivierter Lungentuberkulose }\end{array}$ & k. A. \\
\hline & MS10 & 59 & $\mathrm{~m}$ & 36 & SPMS & $\begin{array}{l}\text { SPMS seit } 12 \text { Jahren; spastische Paraparese, hochgradige Stand- und } \\
\text { Gangataxie }\end{array}$ & k. A. & k. A. \\
\hline & MS11 & 66 & $\mathrm{~m}$ & 12 & PPMS & $\begin{array}{l}\text { spastische Paraparese, ataktische Gangstörung, Harninkontinenz, } \\
\text { Aufnahme bei deutlicher Verwirtheit, Verschlechterung des Gangbildes } \\
\text { und Ernährungszustands; Medikamentenintoxikation bei Einnahme von } \\
\text { Baclofen }\end{array}$ & Ileus & k. A. \\
\hline & MS12 & 41 & $\mathrm{~m}$ & $>10$ & k. A. & $\begin{array}{l}\text { seit Jahren bettlägerig, Arme nur noch schwach hebend, schizoaffektive } \\
\text { Störung; Nebenbefund: Atherosklerose, Z. n. Vorderwandinfarkt; chron. } \\
\text { karnifizierte Pneumonie }\end{array}$ & $\begin{array}{l}\text { akutes Rechtsherzversagen aufgrund } \\
\text { einer Lungenarterienembolie }\end{array}$ & k. A. \\
\hline & MS13 & 47 & w & 25 & SPMS & $\begin{array}{l}\text { Optikusneuritis; Visus beidseitig vermindert, höhergradige Paraplastik } \\
\text { und Blasenentleerungsstörung, skandierende Sprache, progrediente } \\
\text { Gangstörung }\end{array}$ & k. A. & 6 \\
\hline
\end{tabular}




\begin{tabular}{|c|c|c|c|c|c|c|c|}
\hline MS14 & 74 & w & $>10$ & PMS & $\begin{array}{l}\text { MS-Diagnose erst durch neuropathologische Untersuchung im Rahmen } \\
\text { einer Autopsie. Gehen nur mit Gehilfe, Bewegungsstörung des rechten } \\
\text { Beines (damals einer Arthritis zugeschrieben); Muskelatrophie des } \\
\text { rechten Armes; fraglich positives Babinskizeichen bilateral; paranoide } \\
\text { Persönlichkeitsstörung; Glaukom linkes Auge }\end{array}$ & Bronchopneumonie & k. A. \\
\hline MS15 & 54 & $\mathrm{~m}$ & 11 & SPMS & $\begin{array}{l}\text { Optikusatrophie bilateral, links stärker; Asymmetrie der Pupillen, links } \\
\text { größer und ohne Reaktion auf Licht; Hemiparese rechts; M. trapezius } \\
\text { Schwäche links und abstehendes Schulterblatt; Babinskizeichen bilateral }\end{array}$ & metastasierendes Tonsillenkarzinom & k. A. \\
\hline MS16 & 66 & $\mathrm{~m}$ & $>10$ & PMS & k. A. & akuter Myokardinfarkt & k. A. \\
\hline MS17 & 60 & w & 14 & PPMS & $\begin{array}{l}\text { Verschlechterung des Gangbildes, progrediente Taubheit beider Füße; } \\
\text { ataktische Gangstörung; spastische Paraparese; Harninkontinenz; } \\
\text { Hypoalgesie unterhalb Th10; bilateral positives Babinskizeichen; } \\
\text { Symptome eines Morbus Meniere; Migräne; Hyperreflexie und deutliche } \\
\text { Schwäche aller Extremitäten; fehlende Bauchreflexe }\end{array}$ & Aneurysma-Ruptur A. carotis interna & k. A. \\
\hline MS18 & 76 & $\mathrm{~m}$ & 34 & SPMS & $\begin{array}{l}\text { Taubheit rechte Hand; Schwäche zunächst im rechten Bein, dann } \\
\text { bilateral, bis zur Paraparese, auf Rollstuhl angewiesen über } 25 \text { Jahre; } \\
\text { Diplopie; homonyme Hemianopsie, nach links; ischämische Infarkt, dann } \\
\text { Paralyse rechter Arm und rechte Gesichtshälfte, Deviation des Palatum } \\
\text { nach links und der Zunge nach rechts; Dysarthrie; geistig wach; Verlust } \\
\text { Würgreflex; bilateral positives Babinskizeichen; Reflexe in den Beinen } \\
\text { abwesend, in den Armen je 3/4; Blaseninkontinenz; "burned out" MS } \\
\text { (keine Verschlechterung des Krankheitsbildes in den letzten } 15 \text { Jahren } \\
\text { bis zum Infarkt) }\end{array}$ & akute Aspiration und Hypoxie & k. A. \\
\hline MS19 & 59 & w & 16 & SPMS & $\begin{array}{l}\text { verminderter Kornealreflex; nur schwache Reaktion der Pupillen auf } \\
\text { Licht; internukleäre Parese von Hirnnerven; Lähmung des VI Hirnnerves; } \\
\text { Lähmung rechter Gesichtshälfte; spastische Flexor-Kontraktionen der } \\
\text { Arme und Erschlaffung der Beine, an Rollstuhl gebunden; Hyporeflexie; } \\
\text { Hypoästhesie unterhalb des Nabels; Vergrößerte Ventrikel bei zerebraler } \\
\text { Atrophie; zudem metastasierender Brustkrebs; Bischoff's Myelotomie; } \\
\text { erschwerte Atmung, Rasselgeräusche, Kurzatmigkeit; Sepsis aufgrund } \\
\text { rezidivierender Harnwegsinfektion }\end{array}$ & Sepsis & k. A. \\
\hline MS20 & 66 & $\mathrm{~m}$ & 34 & SPMS & $\begin{array}{l}\text { Beinschwäche, Kribbeln in den Beinen; dann milde Optikusatrophie, } \\
\text { Tetraparese; Harninkontinenz; Schwund der Handmuskulatur; rege } \\
\text { Reflexe mit positiven Babinskizeichen; geistig wacher Zustand; } \\
\text { Aorteninsuffizienz; links Ventrikelhypertrophie; Fieber und erhöhte } \\
\text { Leukozytenzahl ( } 21000 / \mu l) \text {; Fieber zentralen Ursprungs; desorientiert } \\
\text { vor Todeseintritt; Morbus Paget des Schädels }\end{array}$ & bakterielle Endokarditis & k. A. \\
\hline
\end{tabular}




\begin{tabular}{|c|c|c|c|c|c|c|c|}
\hline MS21 & 59 & w & 5 & k. A. & $\begin{array}{l}\text { Epilepsie; retrobulbäre Neuritis; bilaterale Optikusatrophie; } \\
\text { Sensibilitätsstörungen Füße, Knöchel, Dermatome T9 und T10; } \\
\text { Carcinoma medullare der Brust mit Metastasenbildung }\end{array}$ & metastasierender Brustkrebs & k. A. \\
\hline MS22 & 57 & $\mathrm{~m}$ & 15 & PPMS & $\begin{array}{l}\text { graduell progressive Beinschwäche und Gangstörungen; Nystagmus zur } \\
\text { linken Seite; Gleichgewichtsstörungen; keine Pyramidenbahnzeichen; } \\
\text { graduell progressive spastische Gangstörung, später ataktisch, } \\
\text { Unsicherheit, taumelnd und in jede Richtung abweichend, Fuß } \\
\text { nachziehend; Darmmotilitäts- und Blasenentleerungsstörung; Tremor } \\
\text { und Dyskoordination aller Extremitäten; generalisierte Hyperreflexie; } \\
\text { bilateral positives Babinskizeichen; leicht beeinträchtigte } \\
\text { Vibrationsempfindung in den Beinen; Laborwerte und Lumbalpunktion } \\
\text { o.p. B.; Veränderung der mentalen Leistungsfähigkeit; Reizbarkeit, } \\
\text { unangemessenes Verhalten; spastische Schwäche der Beine; } \\
\text { Rumpfataxie; zerebrale Atrophie }\end{array}$ & k. A. & k. A. \\
\hline MS23 & 51 & $\mathrm{~m}$ & 8 & PPMS & $\begin{array}{l}\text { Schmerzen und Taubheit der Hüfte und des Beines links; } \\
\text { Spondylolisthesis L5-S1 mit anschließender Spondylodese; graduell } \\
\text { steigende Taubheit der linken Hand; Veränderte Reflexe; sinkende } \\
\text { Libido; Darm- und Blasenentleerungsstörung, dann Harninkontinenz; } \\
\text { Prostatahypertrophie, nach Prostataektomie Rückbildung der } \\
\text { Harninkontinenz; bitemporal Blässe der Papilla nervi optici; verstrichene } \\
\text { Nasolabialfalte links und stärkerer M. masseter rechts; nach Sturz } \\
\text { Einengung des intervertebralen Raumes Höhe C5-6 und in dessen Folge } \\
\text { viele weitere Symptome, Parästhesien aller Extremitäten, Schwäche in } \\
\text { den Beinen, Spastik im rechten Bein }\end{array}$ & Lungenembolie & k. A. \\
\hline MS24 & k. A. & w & 17 & SPMS & $\begin{array}{l}\text { Beginn mit Visustrübung, Schwäche im linken Bein und Arm; Taubheit in } \\
\text { den Beinen; schwankende Gangart; zunächst milde geistige Verwirrung } \\
\text { mit einer milden Demenz; bilateral positiven Babinskizeichen; später } \\
\text { massive mentale Beeinträchtigung; Paralyse der unteren Extremitäten } \\
\text { mit erhöhtem Tonus; bilateral Internukleäre Ophthalmoplegie; } \\
\text { Harninkontinenz; Trigeminusneuralgie }\end{array}$ & Bronchopneumonie & k. A. \\
\hline
\end{tabular}

* Alter zum Zeitpunkt des Todes; KD (Jahre) = Krankheitsdauer in Jahren; Geschlecht: $\mathbf{m}=$ männlich, $\mathbf{w}=$ weiblich; PMI = Postmortemintervall: Zeitraum zwischen Eintritt des Todes und Fixierung des Gehirns in Formalin; k. A. = keine Angabe hierzu im Befund vermerkt; V. a. = Verdacht auf; Z. $\mathbf{n} . \quad$ Zustand nach; $\mathbf{o} . \mathbf{p}$. B. = ohne pathologischen Befund; $\mathrm{CPR}=$ cardiopulmonale Reanimation; $\mathrm{KHK}=$ Koronare Herzkrankheit; med. Th. = medikamentöse Therapie; PAVK = peripheren arteriellen Verschlusskrankheit; SIRS = Systemic Inflammatory Response Syndrome 
Tabelle 12, Teil 3: Klinische Daten humaner Autopsiefälle - Patienten mit Neuromyelitis optica (NMO)

\begin{tabular}{|c|c|c|c|c|c|}
\hline Diagnose Fall & Alter* Geschl. & $\begin{array}{c}\text { KD } \\
\text { (Jahre) }\end{array}$ & Symptome & Todesursache & $\begin{array}{c}\text { PMI } \\
\text { (Tage) }\end{array}$ \\
\hline
\end{tabular}

NMO NMO1 69 w 18 rezidivierende Diplopie; folgende klinischen Angaben traten innerhalb der letzten protrahierter schwerer NMO-Schub mit $\quad$ k. A.

nachlassend, nachfolgend Empfindungs-Störung; Schmerzen im Rücken Höhe

T6-T8, verstärkt durch Bücken/Husten; progressive Beinschwäche, Tremor linkes

Bein, besonders beim Gehen; Taubheit/fehlendes Schmerz- und

Temperaturempfinden linke Seite vom Bauchnabel bis Fuß; Darmmotilitäts- und Blasenentleerungsstörung; Reflexe normal; weitere Empfindungsstörungen

Dermatome T6-8 und unterhalb von T10; Alle Labortests unauffällig; schließlich hypotone Paralyse beider Beine, fehlender tiefer Sehnenreflex und erhöhter Proteingehalt im Liquor; Symptome teilweise abklingend; folgend Armschwäche, Beinzucken; Harninkontinenz, leichte Muskelschwäche facial rechts; reduzierte bis fehlende Reflexe in den Beinen, positives Babinskizeichen; schließlich Tetraparese, Zungenparese und Palatum-Paralyse, bewegungslose Gesichtsmuskeln, schwache Augen- und Lidbewegungen, geistig wach, kommunizierte über Augen-/ Augenlidbewegungen und Nicken; bald darauf traten Benommenheit und komatöser Zustand bis zum Tod ein; es wurde keine NMO-IgG/AQP4-Ak Serum-Diagnostik durchgeführt

\begin{tabular}{|c|c|c|c|c|c|c|}
\hline NMO2 & 49 & $w$ & 0,3 & $\begin{array}{l}\text { Visustrübung; spastische Paralyse rechte obere und beide untere Extremitäten, } \\
\text { spastische Parese linke obere Extremität; Vertigo; Blasenentleerungsstörung; } \\
\text { es wurde keine NMO-IgG/AQP4-Ak Serum-Diagnostik durchgeführt }\end{array}$ & k. A. & 1 \\
\hline NMO3 & 44 & $w$ & 1,25 & $\begin{array}{l}\text { spastische Tetraparese; sensibles Querschnittssyndrom; Z. n. Neuritis nervi optici, } \\
\text { rezidivierend; lymphozytäre Pleozytose; Blasen- und Mastdarmstörung; } \\
\text { positiver NMO-IgG/AQP4-Ak Serumtest }\end{array}$ & $\begin{array}{l}\text { ausgedehnte, destruierende } \\
\text { Kleinhirnblutung }\end{array}$ & k. A. \\
\hline NMO4 & 77 & $w$ & 24 & $\begin{array}{l}\text { Tetraparese, sensomotorische Querschnittssymptomatik; Erblindung; granulo- } \\
\text { lymphozytäre Pleozytose; histologischer AQP4-Verlust; } \\
\text { es wurde keine NMO-IgG/AQP4-Ak Serum-Diagnostik durchgeführt }\end{array}$ & $\begin{array}{l}\text { akute Koronarinsuffizienz mit links } \\
\text { prävalierender kardialer } \\
\text { Dekompensation }\end{array}$ & k. A. \\
\hline NMO5 & 72 & $\mathrm{~m}$ & 0,75 & $\begin{array}{l}\text { Querschnittssyndrom in Höhe Th4 bis C9; Nebenbefund: Paragangliom in } \\
\text { Assoziation zur Rückenmarksläsion; positiver NMO-IgG/AQP4-Ak Serumtest }\end{array}$ & Hirnstammläsion & k. A. \\
\hline
\end{tabular}

* Alter zum Zeitpunkt des Todes; KD (Jahre) = Krankheitsdauer in Jahren; Geschlecht: $\mathbf{m}=$ männlich, $\mathbf{w}=$ weiblich; PMI = Postmortemintervall: Zeitraum zwischen Eintritt des Todes und Fixierung des Gehirns

in Formalin; k. A. = keine Angabe hierzu im Befund vermerkt; V. a. = Verdacht auf; Z. $\mathbf{n} .=$ Zustand nach; o. p. $\mathbf{B} .=$ ohne pathologischen Befund 
Tabelle 13, Teil 1: Alle Ergebnisse in der Übersicht - Auswertung: Hirn humaner Autopsiefälle

\begin{tabular}{|c|c|c|c|c|c|c|c|c|c|c|c|c|c|c|}
\hline \multicolumn{6}{|c|}{ allgemeine Daten } & \multicolumn{9}{|c|}{ Ergebnisse Hirn } \\
\hline Diagnose & Fall & Alter* & $\begin{array}{c}\text { KD } \\
\text { (Jahre) }\end{array}$ & Geschl. & $\begin{array}{l}\text { NAWM Hirn, } \\
\text { subkortikale Region** }\end{array}$ & $\overline{\mathrm{x}} \mathrm{CD}^{+} / \mathrm{mm}^{2}$ & $\begin{array}{c}\text { Score } \text { CD3 }^{+} \\
\text {VRR }\end{array}$ & $\begin{array}{c}\text { Score KiM1P } \\
{[0-2]}\end{array}$ & $\begin{array}{c}\text { Score KiM1P } \\
\text { MGK }[0 / 1]\end{array}$ & $\bar{x}$ Biel. ${ }^{+}[\%]$ & $\overline{\mathrm{x}} \mathrm{APP}^{+} / \mathrm{mm}^{2}$ & $\overline{\mathrm{x}} \mathrm{SMI} 32^{+} / \mathrm{mm}^{2}$ & $\overline{\mathrm{X}} \mathrm{p} 25^{+} / \mathrm{mm}^{2}$ & $\overline{\mathrm{x}} \mathrm{GFAP}^{+} / \mathrm{mm}^{2}$ \\
\hline \multirow[t]{13}{*}{ Kontrollen } & K1 & 63 & -- & $\mathrm{m}$ & frontal & 0,00 & 1 & 0,5 & 1 & 94,46 & 5,87 & 2,40 & 475,20 & 69,82 \\
\hline & $\mathrm{K2}$ & 70 & -- & $\mathrm{m}$ & frontal & 0,13 & 2 & 0,5 & 0 & 100,72 & 3,73 & 3,20 & 638,40 & 70,55 \\
\hline & K3 & 80 & -- & $\mathrm{w}$ & parietal & 0,13 & 2 & 1 & 0 & 102,07 & 3,73 & 7,20 & 345,60 & 77,82 \\
\hline & K4 & 42 & -- & $\mathrm{m}$ & frontal, parietal & 0,27 & 1,5 & 0,25 & 0 & 108,11 & 7,73 & 5,60 & 567,20 & 89,09 \\
\hline & K5 & 54 & -- & w & frontal, parietal & 0,40 & 1,5 & 0 & 0 & 102,96 & 3,73 & 2,80 & 400,80 & 82,91 \\
\hline & K6 & 45 & -- & $\mathrm{m}$ & frontal $2 x$ & 0,20 & 1,75 & 0,25 & 0 & 97,37 & 9,33 & 2,40 & 636,00 & 72,00 \\
\hline & K7 & 81 & -- & $\mathrm{m}$ & frontal $2 x$ & 0,07 & 1,5 & 1 & 0 & 96,69 & 2,13 & 3,60 & 608,00 & 75,27 \\
\hline & K8 & 64 & -- & $\mathrm{w}$ & frontal, parietal & 0,20 & 1,5 & 0,5 & 0 & 88,64 & 6,67 & 3,20 & 406,40 & 90,91 \\
\hline & K9 & 67 & -- & $\mathrm{m}$ & frontal $2 x$ & 0,07 & 1 & 1 & 1 & 115,27 & 2,13 & 5,60 & 550,40 & 87,64 \\
\hline & K10 & 65 & -- & $w$ & frontal, parietal & 0,33 & 1,5 & 0 & 0 & 102,07 & 4,80 & 1,60 & 392,00 & 78,18 \\
\hline & K11 & 73 & -- & $\mathrm{m}$ & frontal, parietal & 0,40 & 1,75 & 0,75 & 0 & 97,14 & 5,07 & 5,20 & 511,20 & 89,45 \\
\hline & K12 & 56 & -- & $\mathrm{m}$ & frontal, parietal & 0,25 & 0,5 & 0,25 & 0 & 99,60 & 4,00 & 6,80 & 444,00 & 94,55 \\
\hline & K13 & 54 & -- & $\mathrm{m}$ & frontal & 0,00 & 0,5 & 0,5 & 0 & 94,90 & 2,13 & 8,00 & 528,00 & 69,09 \\
\hline \multirow[t]{16}{*}{ MS } & MS2 & 67 & k. A. & $\mathrm{m}$ & k. A. zerebral & 0,67 & 1 & 1 & 0 & 91,32 & 9,60 & $-{ }^{*}$ & $--^{*}$ & $--^{*}$ \\
\hline & MS5 & 56 & 9 & $w$ & k. A. zerebral & 0,93 & 1 & 0 & 1 & 89,98 & 18,67 & 86,40 & 419,20 & 92,37 \\
\hline & MS7 & 42 & k. A. & $\mathrm{m}$ & parietal & $--^{*}$ & $--^{*}$ & 1 & 1 & 92,67 & 10,67 & 43,20 & 724,80 & 56,72 \\
\hline & MS8 & 39 & $>10$ & w & frontal & 1,47 & 2 & 0,5 & 0 & 100,72 & 9,60 & 29,60 & 771,20 & 61,82 \\
\hline & MS9 & 77 & $>3$ & $w$ & frontal & $--^{*}$ & $--^{*}$ & 0 & 0 & 90,43 & 3,73 & 11,20 & 568,00 & 74,18 \\
\hline & MS10 & 59 & 36 & $\mathrm{~m}$ & frontal & 0,53 & 1,5 & 0,5 & 0 & 87,29 & 9,07 & 92,00 & 505,60 & 77,82 \\
\hline & MS11 & 66 & 12 & $\mathrm{~m}$ & parietal & 0,27 & 2 & 0 & 0 & 109,68 & 14,40 & 53,60 & 465,60 & 74,18 \\
\hline & MS12 & 41 & $>10$ & $\mathrm{~m}$ & frontal & 0,27 & 1 & 0,5 & 0 & 108,33 & 6,40 & 16,00 & 459,20 & 64,00 \\
\hline & MS13 & 47 & 25 & $w$ & frontal, parietal & 0,20 & 0,75 & 0,5 & 1 & 108,33 & 13,07 & 29,20 & 643,20 & 75,27 \\
\hline & MS14 & 74 & $>10$ & w & parietal & 0,40 & 1,5 & 0 & 0 & 90,87 & 9,07 & 15,20 & 848,00 & 103,28 \\
\hline & MS16 & 66 & $>10$ & $\mathrm{~m}$ & frontal $2 x$ & 0,53 & 1,5 & 0,25 & 1 & 96,02 & 10,40 & 32,00 & 604,80 & 82,90 \\
\hline & MS17 & 60 & 14 & $w$ & frontal $2 x$ & 0,47 & 1,5 & 0,75 & 1 & 91,99 & 16,00 & 56,80 & 680,80 & 93,46 \\
\hline & MS19 & 59 & 16 & $w$ & parietal & 0,80 & 1,5 & 1 & 1 & 90,43 & 18,13 & 42,40 & 883,20 & 88,72 \\
\hline & MS20 & 66 & 34 & $\mathrm{~m}$ & frontal & 0,40 & 2 & 1 & 1 & 93,56 & 25,60 & 78,40 & 432,00 & 90,91 \\
\hline & MS21 & 59 & 5 & $w$ & frontal & 0,27 & 1 & 0,5 & 0 & 84,61 & 4,80 & 9,60 & 598,40 & 64,00 \\
\hline & MS22 & 57 & 15 & $m$ & frontal $2 x$ & 0,13 & 1,5 & 0,5 & 0 & 90,43 & 14,93 & 33,60 & 512,00 & 69,82 \\
\hline \multirow[t]{3}{*}{ NMO } & NMO2 & 49 & 0,3 & w & temporal, frontal & 0,67 & 1,75 & 1 & 0 & 98,04 & 10,67 & 0,80 & 457,60 & 97,45 \\
\hline & NMO4 & 77 & 24 & $w$ & frontal, parietal & $--^{*}$ & $--^{*}$ & 1 & 0 & 100,95 & 8,00 & 3,60 & 563,20 & 94,18 \\
\hline & NMO5 & 72 & 0,75 & $\mathrm{~m}$ & k. A. zerebral $2 x$ & 0,60 & 2 & 0,5 & 0 & 105,87 & 7,47 & 18,40 & 405,60 & 106,91 \\
\hline
\end{tabular}

* Alter zum Zeitpunkt des Todes; ** Anzahl ausgewerteter Blöcke: bei Angaben von mehr als einem Block pro Fall und Hirn wurden alle Blöcke einzeln ausgewertet. Anschließend wurde zur besseren Verarbeitung der Daten der Mittelwert gezogen, sodass pro Fall und Hirn nur jeweils ein Datenwert angegeben wird. $K$ D (Jahre) = Krankheitsdauer in Jahren; Geschlecht: $m=$ männlich, w = weiblich;

$\overline{\mathbf{X}}=$ Mittelwert; VRR = Virchow-Robin-Raum; k. A. = keine Angaben hierzu im Befund vorhanden; MGK = Mikrogliaknötchen; -- * Die entsprechenden histologischen/immunhistochemischen Färbungen konnten am vorliegenden Paraffinmaterial nicht etabliert werden 
Tabelle 13, Teil 2: Alle Ergebnisse in der Übersicht - Auswertung: Rückenmark humaner Autopsiefälle

\begin{tabular}{|c|c|c|c|c|c|c|c|c|c|c|c|c|c|c|}
\hline \multicolumn{6}{|c|}{ allgemeine Daten } & \multicolumn{9}{|c|}{ Ergebnisse Rückenmark } \\
\hline Diagnose & Fall & Alter* & $\begin{array}{c}\text { KD } \\
\text { (Jahre) }\end{array}$ & Geschl. & NAWM spinale Region** & $\bar{x} \mathrm{CD}^{+} / \mathrm{mm}^{2}$ & $\begin{array}{c}{\text { Score } \text { CD3 }^{+}} \\
\text {VRR }\end{array}$ & $\begin{array}{c}\text { Score KiM1P } \\
{[0-2]}\end{array}$ & $\begin{array}{c}\text { Score KiM1P } \\
\text { MGK }[0 / 1]\end{array}$ & $\overline{\mathbf{X}}$ Biel. ${ }^{+}[\%]$ & $\overline{\mathrm{x}} \mathrm{APP}^{+} / \mathrm{mm}^{2}$ & $\overline{\mathrm{X}} \mathrm{SMI} 32^{+} / \mathrm{mm}^{2}$ & $\overline{\mathrm{X}} \mathrm{p} 25^{+} / \mathrm{mm}^{2}$ & $\overline{\mathrm{x}} \mathrm{GFAP}^{+} / \mathrm{mm}^{2}$ \\
\hline \multirow[t]{12}{*}{ Kontrollen } & K1 & 63 & -- & $\mathrm{m}$ & zervikal, thorakal, lumbal & 2,04 & 1,83 & 0,33 & 1 & 76,92 & 14,76 & $--^{* *}$ & 213,87 & 110,55 \\
\hline & K2 & 70 & -- & $\mathrm{m}$ & thorakal & 0,00 & 1 & 0 & 0 & 104,35 & 6,40 & $--* *$ & 283,20 & 112,00 \\
\hline & K3 & 80 & -- & w & zervikal & 0,53 & 1 & 1 & 0 & 92,09 & 8,00 & - -** $^{*}$ & 284,80 & 104,00 \\
\hline & K4 & 42 & -- & $\mathrm{m}$ & zervikal & 1,07 & 1,5 & 0 & 0 & 109,95 & 5,87 & $--^{* *}$ & 280,00 & 111,27 \\
\hline & K6 & 45 & -- & $\mathrm{m}$ & zervikal & 1,20 & 1 & 0,5 & 1 & 101,55 & 5,33 & $--* *$ & 363,20 & 99,64 \\
\hline & K7 & 81 & -- & $\mathrm{m}$ & zervikal, thorakal, lumbal & 0,49 & 0,67 & 1,33 & 1 & 104,81 & 6,22 & $--* *$ & 271,47 & 120,97 \\
\hline & K8 & 64 & -- & $w$ & zervikal & 0,80 & 1 & 1 & 0 & 94,19 & 9,07 & $--* *$ & 246,40 & 127,27 \\
\hline & K9 & 67 & -- & $\mathrm{m}$ & zervikal, thorakal & 0,67 & 1 & 1,5 & 1 & 108,55 & 6,67 & $--^{* * *}$ & 244,00 & 122,55 \\
\hline & K10 & 65 & -- & w & zervikal & 1,07 & 0,5 & 0 & 0 & 104,00 & 5,33 & $--^{* *}$ & 256,00 & 104,73 \\
\hline & K11 & 73 & -- & $\mathrm{m}$ & zervikal & 1,33 & 1,5 & 1 & 0 & 114,15 & 7,47 & $--^{* * *}$ & 272,00 & 109,09 \\
\hline & K12 & 56 & -- & $\mathrm{m}$ & zervikal & 0,80 & 1 & 0,5 & 0 & 87,19 & 4,80 & $--^{* *}$ & 240,00 & 100,36 \\
\hline & K13 & 54 & -- & $\mathrm{m}$ & zervikal, thorakal & 0,47 & 0,75 & 0,50 & 0 & 102,25 & 5,07 & $--* *$ & 219,20 & 108,73 \\
\hline \multirow[t]{12}{*}{ MS } & MS1 & 61 & 6 & $\mathrm{~m}$ & k. A. spinal & 1,33 & 1,5 & 0,5 & 1 & 65,13 & 22,93 & --.** & 190,40 & 130,91 \\
\hline & MS3 & 56 & k. A. & $\mathrm{m}$ & k. A. spinal & 4,27 & 2 & 1 & 1 & 56,73 & 29,87 & $--^{* *}$ & 246,40 & 131,63 \\
\hline & MS4 & 36 & k. A. & $w$ & k. A. spinal & 2,13 & 1,5 & 2 & 0 & 58,48 & 29,87 & $--^{* *}$ & 152,00 & 197,09 \\
\hline & MS6 & 61 & k. A. & $\mathrm{m}$ & lumbal & 1,60 & 1,5 & 1 & 1 & 54,63 & 27,73 & $--^{* * *}$ & 190,40 & 175,28 \\
\hline & MS10 & 59 & 36 & $\mathrm{~m}$ & zervikal & 2,13 & 1,5 & 2 & 1 & 75,28 & 25,07 & $--^{* *}$ & 345,60 & 134,54 \\
\hline & MS15 & 54 & 11 & $\mathrm{~m}$ & thorakal, lumbal & 1,60 & 1,25 & 1 & 1 & 68,28 & 18,40 & $--^{* *}$ & 205,60 & 150,18 \\
\hline & MS16 & 66 & $>10$ & $\mathrm{~m}$ & C5-6, Th2, Th4-5 & 0,80 & 1 & 0,67 & 1 & 58,94 & 35,91 & $--^{* *}$ & 161,60 & 128,73 \\
\hline & MS17 & 60 & 14 & $w$ & lumbal & 0,80 & 1 & 2 & 1 & 53,92 & 44,27 & $--^{* *}$ & 254,40 & 121,46 \\
\hline & MS18 & 76 & 34 & $\mathrm{~m}$ & zervikal & 0,53 & 1 & 1 & 1 & 53,57 & 43,73 & $--* *$ & 185,60 & 141,82 \\
\hline & MS21 & 59 & 5 & $w$ & zervikal & 0,80 & 1 & 1 & 0 & 68,28 & 30,93 & - -** $^{*}$ & 260,80 & 119,28 \\
\hline & MS23 & 51 & 8 & $\mathrm{~m}$ & C2 & 1,07 & 2 & 2 & 1 & 51,82 & 65,60 & $--^{* *}$ & 200,00 & 160,72 \\
\hline & MS24 & k. A. & 17 & $\mathrm{w}$ & $\mathrm{C} 4+\mathrm{C} 8$ & 1,40 & 1 & 1 & 1 & 53,22 & 24,00 & $--* *$ & 196,00 & 136,73 \\
\hline \multirow[t]{5}{*}{ NMO } & NMO1 & 69 & 18 & w & C6 & 1,07 & 1 & 1 & 0 & 58,13 & 8,53 & ---** & 169,60 & 136,00 \\
\hline & NMO2 & 49 & 0,3 & $\mathrm{w}$ & Th3 2x & 1,20 & 1 & 1,25 & 0 & 51,12 & $--^{*}$ & $--* *$ & 176,80 & 172,36 \\
\hline & NMO3 & 44 & 1,25 & $\mathrm{w}$ & zervikal-thorakal & 0,67 & 1 & 1 & 1 & 54,27 & 10,13 & $--* *$ & 155,20 & 190,55 \\
\hline & NMO4 & 77 & 24 & $w$ & C1 & $--^{*}$ & 2 & 1 & 0 & 61,98 & 4,80 & $--{ }^{* * *}$ & 171,20 & 144,00 \\
\hline & NMO5 & 72 & 0,75 & $\mathrm{~m}$ & zervikal & 2,13 & 2 & 1,5 & 0 & 60,58 & 10,13 & $--{ }^{-* *}$ & 152,00 & 192,00 \\
\hline
\end{tabular}

* Alter zum Zeitpunkt des Todes; ** Anzahl ausgewerteter Blöcke: bei Angaben von mehr als einem Block pro Fall und Rückenmark wurden alle Blöcke einzeln ausgewertet. Anschließend wurde zur besseren Verarbeitung der Daten der Mittelwert gezogen, sodass pro Fall und Rückenmark nur jeweils ein Datenwert angegeben wird. $\mathbf{K D}$ (Jahre) = Krankheitsdauer in Jahren; Geschlecht: $\mathbf{m}=$ männlich, $\mathbf{w}=$ weiblich; $\overline{\mathbf{X}}=$ Mittelwert; $\mathbf{V R R}=$ Virchow-Robin-Raum; $\mathbf{k} \cdot \mathbf{A}$. = keine Angaben hierzu im Befund vorhanden; $\mathbf{M G K}=$ Mikrogliaknötchen; $\mathbf{C}=$ zervikales Rückenmark; Th $=$ thorakales Rückenmark; $\mathbf{L}=$ lumbales Rückenmark; -- * Die entsprechenden histologischen/immunhistochemischen Färbungen konnten am vorliegenden Paraffinmaterial nicht etabliert werden; --** SMI32-Färbungen konnten zwar am vorliegenden Paraffinmaterial etabliert werden, jedoch war im Rückenmark keine eindeutige Auswertung möglich (siehe Kapitel 2.3.1.5 SMI32+-geschädigte Axone) 
Tabelle 13, Teil 3: Alle Ergebnisse in der Übersicht - Auswertung: Rückenmark der Mäuse

\begin{tabular}{|c|c|c|c|c|c|c|c|c|c|}
\hline Gruppe & Fall & DM [\%] & $\overline{\mathrm{x}} \mathrm{CD}^{+} / \mathrm{mm}^{2}$ & $\begin{array}{c}\text { Score } \mathrm{MAC3}^{+} \\
{[0-2]}\end{array}$ & $\begin{array}{c}\text { Score MAC3+ }^{+} \\
\text {MGK }[0 / 1]\end{array}$ & $\overline{\mathbf{x}}$ Biel. [\%] & $\overline{\mathrm{x}} \mathrm{APP}^{+} / \mathrm{mm}^{2}$ & $\overline{\mathrm{x}} \mathrm{p} 25^{+} / \mathrm{mm}^{2}$ & $\overline{\mathrm{x}} \mathrm{GFAP}^{+} / \mathrm{mm}^{2}$ \\
\hline \multirow[t]{5}{*}{ gesunde Mäuse } & KM1 & 0,0 & 1,6 & 0 & 0 & 110 & 36,8 & 537,6 & 161,6 \\
\hline & KM2 & 0,0 & 0 & 0 & 0 & 98 & 43,2 & 596,8 & 161,6 \\
\hline & KM3 & 0,0 & 0 & 0 & 0 & 96 & 41,6 & 542,4 & 176,0 \\
\hline & KM4 & 0,0 & 0 & 0 & 0 & 96 & 35,2 & 539,2 & 169,6 \\
\hline & KM5 & 0,0 & 0 & 0 & 0 & 100 & 16,0 & 620,8 & 150,4 \\
\hline \multirow{7}{*}{$\begin{array}{l}\text { geringe Läsionslast } \\
\text { (<5\% DM; EAE gering) }\end{array}$} & EAE01 & 1,73 & 24,0 & 0,5 & 1 & 87 & 40,0 & 678,4 & 241,6 \\
\hline & EAE02 & 2,47 & 25,6 & 0,5 & 1 & 86 & 46,4 & 691,2 & 182,4 \\
\hline & EAE03 & 1,77 & 20,8 & 0,5 & 0 & 82 & 38,4 & 836,8 & 174,4 \\
\hline & EAE04 & 2,86 & 24,0 & 0,5 & 1 & 99 & 27,2 & 753,6 & 219,2 \\
\hline & EAE05 & 4,44 & 30,4 & 1 & 1 & 82 & 22,4 & 772,8 & 214,4 \\
\hline & EAE06 & 0,45 & 16,0 & 0,5 & 1 & 96 & 40,0 & 756,8 & 163,2 \\
\hline & EAE07 & 3,08 & 27,2 & 0,5 & 1 & 81 & 38,4 & 691,2 & 172,8 \\
\hline \multirow{7}{*}{$\begin{array}{l}\text { hohe Läsionslast } \\
(10-15 \% \text { DM; EAE }\end{array}$} & EAE08 & 14,46 & 49,6 & 1,5 & 1 & 75 & 72,0 & 865,6 & 302,4 \\
\hline & EAE09 & 11,32 & 41,6 & 1 & 1 & 86 & 56,0 & 728,0 & 195,2 \\
\hline & EAE10 & 10,45 & 44,8 & 0,5 & 1 & 82 & 68,8 & 817,6 & 228,8 \\
\hline & EAE11 & 13,60 & 43,2 & 1 & 1 & 77 & 80,0 & 772,8 & 240,0 \\
\hline & EAE12 & 11,91 & 41,6 & 1 & 1 & 76 & 57,6 & 948,8 & 236,8 \\
\hline & EAE13 & 10,80 & 44,8 & 0,5 & 1 & 80 & 49,6 & 830,4 & 171,2 \\
\hline & EAE14 & 10,26 & 38,4 & 0,5 & 1 & 78 & 56,0 & 881,6 & 230,4 \\
\hline
\end{tabular}

DM = Demyelinisierung; $\overline{\mathbf{X}}=$ Mittelwert; MGK = Mikrogliaknötchen 


\section{Danksagung}

Zunächst möchte ich Herrn Prof. Dr. med. Wolfgang Brück sowie Frau PD Dr. Dr. med. Christiane Theodossiou-Wegner dafür danken, meine Dissertation in der Abteilung für Neuropathologie des Universitätsklinikums Göttingen ermöglicht zu haben.

Mein herzlichster Dank gilt dabei Frau PD Dr. Dr. med. Christiane TheodossiouWegner für ihre Anregung zu dieser Arbeit, die hervorragende und engagierte Betreuung, für stete fachliche Unterstützung, Motivation und konstruktive Kritik in allen Phasen des Projektes.

Außerdem danke ich Dr. Martina Ott für ihre fortwährende Unterstützung bei meinem Dissertationsvorhaben, insbesondere für die Hilfestellung und Einführung in die Methodik der tierexperimentellen Forschung. Auch für die mühevolle Arbeit des Korrekturlesens möchte ich mich herzlich bedanken.

Des Weiteren möchte ich mich bei allen Mitarbeiterinnen des Instituts, insbesondere bei Brigitte Maruschak, Jasmin Reichl, Heidi Brodmerkel, Frau Uta Scheidt sowie Katja Schulz für die freundliche Arbeitsatmosphäre und ihre tatkräftige Unterstützung im Labor bedanken, die wesentlich zum Gelingen dieser Arbeit beigetragen haben. 